University of South Florida

DIGITAL COMMONS Digital Commons @ University of @ UNIVERSITY OF SOUTH FLORIDA South Florida

\title{
The Impacts of Emerging Mobility Options and Vehicle Technologies on Travel Behavior
}

CUTR

Follow this and additional works at: https://digitalcommons.usf.edu/cutr_nctr

\section{Recommended Citation}

"The Impacts of Emerging Mobility Options and Vehicle Technologies on Travel Behavior," National Center for Transit Research (NCTR) Report No. CUTR-NCTR-RR-2020-20, Center for Urban Transportation Research, University of South Florida, 2020.

DOI: https://doi.org/10.5038/CUTR-NCTR-RR-2020-20

Available at: https://scholarcommons.usf.edu/cutr_nctr/253

This Technical Report is brought to you for free and open access by the National Center for Transit Research (NCTR) Archive (2000-2020) at Digital Commons @ University of South Florida. It has been accepted for inclusion in Research Reports by an authorized administrator of Digital Commons @ University of South Florida. For more information, please contact digitalcommons@usf.edu. 


\title{
The Impacts of Emerging Mobility Options and Vehicle Technologies on Travel Behavior
}

\author{
Project Number \\ CUTR-NCTR-RR-2020-20
}

Xia Jin, Alireza Rahimi, and Ghazaleh Azimi

Florida International University

\author{
Prepared For \\ National Center for Transit Research
}

Forecasting and Trends Office

Florida Department of Transportation

July 2020

\section{CUTR. CUSF.EDU SOUTH FLORIDA}


Technical Memorandum

FDOT Master University Agreement BDV29-977-47

\title{
The Impacts of Emerging Mobility Options and Vehicle Technologies on Travel Behavior
}

\author{
Deliverable 6 -Final Report
}

Prepared For

Forecasting and Trends Office

Florida Department of Transportation

Prepared By

Xia Jin, Alireza Rahimi, and Ghazaleh Azimi

Florida International University

10555 W Flagler St., EC 3603

Miami, FL 33174

Date

July 2020 


\section{DISCLAIMER}

The opinions, findings, and conclusions expressed in this publication are those of the authors and not necessarily those of the State of Florida Department of Transportation or the U.S. Department of Transportation.

Prepared in cooperation with the State of Florida Department of Transportation and the U.S. Department of Transportation. 
METRIC CONVERSION CHART

\section{APPROXIMATE CONVERSIONS TO SI UNITS}

\begin{tabular}{|c|c|c|c|c|}
\hline SYMBOL & WHEN YOU KNOW & MULTIPLY BY & TO FIND & SYMBOL \\
\hline \multicolumn{5}{|c|}{ LENGTH } \\
\hline in & inches & 25.4 & millimeters & $\mathrm{mm}$ \\
\hline $\mathbf{f t}$ & feet & 0.305 & meters & $\mathrm{m}$ \\
\hline yd & yards & 0.914 & meters & $\mathrm{m}$ \\
\hline mi & miles & 1.61 & kilometers & $\mathrm{km}$ \\
\hline \multicolumn{5}{|c|}{ AREA } \\
\hline in $^{2}$ & square inches & 645.2 & square millimeters & $\mathrm{mm}^{2}$ \\
\hline $\mathbf{f t}^{2}$ & square feet & 0.093 & square meters & $\mathrm{m}^{2}$ \\
\hline $\mathrm{yd}^{2}$ & square yards & 0.836 & square meters & $\mathrm{m}^{2}$ \\
\hline ac & acres & 0.405 & hectares & ha \\
\hline $\mathbf{m i}^{2}$ & square miles & 2.59 & square kilometers & $\mathrm{km}^{2}$ \\
\hline \multicolumn{5}{|c|}{ VOLUME } \\
\hline fl oz & fluid ounces & 29.57 & milliliters & $\mathrm{mL}$ \\
\hline gal & gallons & 3.785 & liters & $\mathrm{L}$ \\
\hline $\mathbf{f t}^{3}$ & cubic feet & 0.028 & cubic meters & $\mathrm{m}^{3}$ \\
\hline $\mathrm{yd}^{3}$ & cubic yards & 0.765 & cubic meters & $\mathrm{m}^{3}$ \\
\hline \multicolumn{5}{|c|}{ NOTE: Volumes greater than $1,000 \mathrm{~L}$ shall be shown in $\mathrm{m}^{3}$} \\
\hline \multicolumn{5}{|c|}{ MASS } \\
\hline $\mathbf{o z}$ & ounces & 28.35 & grams & $g$ \\
\hline $1 b$ & pounds & 0.454 & kilograms & $\mathrm{kg}$ \\
\hline $\mathbf{T}$ & short tons $(2,000 \mathrm{lb})$ & 0.907 & $\begin{array}{l}\text { megagrams } \\
\text { (or metric ton) }\end{array}$ & $\operatorname{Mg}($ or $\mathrm{t})$ \\
\hline \multicolumn{5}{|c|}{ TEMPERATURE (exact degrees) } \\
\hline${ }^{\circ} \mathbf{F}$ & Fahrenheit & $\begin{array}{l}5 r(F-32) / 9 \\
\text { or }(F-32) / 1.8\end{array}$ & Celsius & ${ }^{\circ} \mathrm{C}$ \\
\hline \multicolumn{5}{|c|}{ ILLUMINATION } \\
\hline fc & foot-candles & 10.76 & $\operatorname{lux}$ & lx \\
\hline fl & foot-Lamberts & 3.426 & candela $/ \mathrm{m}^{2}$ & $\mathrm{~cd} / \mathrm{m}^{2}$ \\
\hline \multicolumn{5}{|c|}{ FORCE and PRESSURE or STRESS } \\
\hline lbf & pound force & 4.45 & newton & $\mathrm{N}$ \\
\hline lbf/in ${ }^{2}$ & pound force per square inch & 6.89 & kilopascals & $\mathrm{kPa}$ \\
\hline
\end{tabular}


APPROXIMATE CONVERSIONS TO SI UNITS

\begin{tabular}{|c|c|c|c|c|}
\hline SYMBOL & WHEN YOU KNOW & MULTIPLY BY & TO FIND & SYMBOL \\
\hline \multicolumn{5}{|c|}{ LENGTH } \\
\hline $\mathrm{mm}$ & millimeters & 0.039 & inches & in \\
\hline m & meters & 3.28 & feet & $\mathrm{ft}$ \\
\hline $\mathbf{m}$ & meters & 1.09 & yards & $\mathrm{yd}$ \\
\hline km & kilometers & 0.621 & miles & $\mathrm{mi}$ \\
\hline \multicolumn{5}{|c|}{ AREA } \\
\hline $\mathrm{mm}^{2}$ & square millimeters & 0.0016 & square inches & in $^{2}$ \\
\hline $\mathbf{m}^{2}$ & square meters & 10.764 & square feet & $\mathrm{ft}^{2}$ \\
\hline $\mathrm{m}^{2}$ & square meters & 1.195 & square yards & $\mathrm{yd}^{2}$ \\
\hline ha & hectares & 2.47 & acres & ac \\
\hline $\mathrm{km}^{2}$ & square kilometers & 0.386 & square miles & $\mathrm{mi}^{2}$ \\
\hline \multicolumn{5}{|c|}{ VOLUME } \\
\hline $\mathrm{mL}$ & milliliters & 0.034 & fluid ounces & $\mathrm{fl} \mathrm{oz}$ \\
\hline $\mathbf{L}$ & liters & 0.264 & gallons & gal \\
\hline $\mathrm{m}^{3}$ & cubic meters & 35.314 & cubic feet & $\mathrm{ft}^{3}$ \\
\hline $\mathbf{m}^{3}$ & cubic meters & 1.307 & cubic yards & $\mathrm{yd}^{3}$ \\
\hline \multicolumn{5}{|c|}{ MASS } \\
\hline g & grams & 0.035 & ounces & $\mathrm{oz}$ \\
\hline kg & kilograms & 2.202 & pounds & $\mathrm{lb}$ \\
\hline $\operatorname{Mg}($ or $t)$ & $\begin{array}{l}\text { mega } \\
\text { (or metric ton) }\end{array}$ & 1.103 & \begin{tabular}{|lr} 
short & tons \\
$(2,000 \mathrm{lb})$ &
\end{tabular} & $\mathrm{T}$ \\
\hline \multicolumn{5}{|c|}{ TEMPERATURE (exact degrees) } \\
\hline${ }^{\circ} \mathrm{C}$ & Celsius & $1.8 \mathrm{C}+32$ & Fahrenheit & ${ }^{\circ} \mathrm{F}$ \\
\hline \multicolumn{5}{|c|}{ ILLUMINATION } \\
\hline $1 x$ & $\operatorname{lux}$ & 0.0929 & foot-candles & fc \\
\hline $\mathrm{cd} / \mathrm{m}^{2}$ & candela/m² & 0.2919 & foot-Lamberts & $\mathrm{fl}$ \\
\hline \multicolumn{5}{|c|}{ FORCE and PRESSURE or STRESS } \\
\hline $\mathbf{N}$ & newton & 0.225 & pound force & lbf \\
\hline $\mathbf{k P a}$ & kilopascals & 0.145 & $\begin{array}{l}\text { pound force per } \\
\text { square inch }\end{array}$ & lbf/in ${ }^{2}$ \\
\hline
\end{tabular}

*SI is the symbol for the International System of Units. Appropriate rounding should be made to comply with Section 4 of ASTM E380. (Revised March 2003) 


\section{TECHNICAL REPORT DOCUMENTATION PAGE}

\begin{tabular}{|c|c|c|c|c|}
\hline \multirow{3}{*}{\multicolumn{3}{|c|}{\begin{tabular}{l|l} 
1. Report No. & 2. Government Accession No. \\
4. Title and Subtitle \\
The Impacts of Emerging Mobility Options and Vehicle \\
Technologies on Travel Behavior
\end{tabular}}} & \multicolumn{2}{|c|}{ 3. Recipient's Catalog No. } \\
\hline & & & \multicolumn{2}{|l|}{$\begin{array}{l}\text { 5. Report Date } \\
\text { July } 2020\end{array}$} \\
\hline & & & \multicolumn{2}{|c|}{ 6. Performing Organization Code } \\
\hline \multicolumn{3}{|c|}{$\begin{array}{l}\text { 7. Author(s) } \\
\text { Xia Jin, Alireza Rahimi, and Ghazaleh Azimi }\end{array}$} & \multicolumn{2}{|c|}{ 8. Performing Organization Report No. } \\
\hline \multirow{2}{*}{\multicolumn{3}{|c|}{$\begin{array}{l}\text { 9. Performing Organization Name and Address } \\
\text { Florida International University } \\
10555 \text { W. Flagler Street Miami, Florida } 33174\end{array}$}} & \multicolumn{2}{|c|}{ 10. Work Unit No. (TRAIS) } \\
\hline & & & \multicolumn{2}{|c|}{$\begin{array}{l}\text { 11. Contract or Grant No. } \\
\text { BDV29-977-47 }\end{array}$} \\
\hline \multicolumn{3}{|c|}{$\begin{array}{l}\text { 12. Sponsoring Agency Name and Address } \\
\text { Florida Department of Transportation } \\
605 \text { Suwannee St., } \\
\text { Tallahassee, FL } 32301\end{array}$} & \multicolumn{2}{|c|}{$\begin{array}{l}\text { 13. Type of Report and Period Covered } \\
\text { Final Report } \\
\text { January } 2019 \text { - July } 2020\end{array}$} \\
\hline \multicolumn{5}{|c|}{ 15. Supplementary Notes } \\
\hline \multicolumn{5}{|l|}{ 16. Abstract } \\
\hline \multicolumn{5}{|c|}{$\begin{array}{l}\text { This report presents a study that investigated potential travel behavior changes in light of automated, } \\
\text { connected, electric, and shared-use vehicle (ACES) technologies. Three main aspects of choice } \\
\text { behavior were investigated: AV adoption and willingness to pay (WTP), shared mobility adoption, and } \\
\text { mode choice. Particularly, this study focuses on exploring the roles of attitudes in individuals' travel } \\
\text { choice behavior. Data collected through a stated preference (SP) survey were used for this study. } \\
\text { The survey included a series of attitude-related questions that cover various aspects of user attitudes, } \\
\text { which include general mobility preferences, perceived benefits and concerns of shared mobility, } \\
\text { reasons against or for private ownership, and motivations for and desired features of AVs. Various } \\
\text { modeling techniques were employed to identify influential factors and examine the impacts of } \\
\text { attitudes, including error component models, structural equations model, and support vector machine } \\
\text { method. The models identified various attitudes that played significant roles in individuals' choice } \\
\text { behavior. These include joy of driving, technology-savviness, choice reasoning, trust issues, data } \\
\text { privacy concerns, favor for private-vehicle utility, on-demand services, green travel preferences, and } \\
\text { desire for efficiency and technology, etc. Model results showed that attitudes played important roles } \\
\text { in shaping travelers' choice behavior. Incorporating these factors improved the model performance } \\
\text { and prediction accuracy of travel behavior models, which will lead to a more reliable assessment of } \\
\text { the likelihood and magnitude of behavioral shifts toward future mobility options. }\end{array}$} \\
\hline \multicolumn{5}{|c|}{$\begin{array}{l}\text { This study provides useful and meaningful insights into users' attitudes and perceptions toward ACES } \\
\text { technologies and how these attitudes and other contributing factors may influence travelers' choice } \\
\text { behavior. Recognizing that the market will not react homogeneously toward new technologies, the } \\
\text { study results contribute to a better understanding of user acceptance and adoption of emerging } \\
\text { mobility options and better assessment of their potential impacts. The findings could be helpful for } \\
\text { planners and service providers to better plan for and address the needs and concerns of travelers. }\end{array}$} \\
\hline $\begin{array}{l}\text { 17. Key Words } \\
\text { ACES, shared mobility, aut } \\
\text { stated preference survey }\end{array}$ & omous vehicle, attitudes, & & ution Statement & \\
\hline $\begin{array}{l}\text { 19. Security Classif. (of this report) } \\
\text { Unclassified } \\
\end{array}$ & $\begin{array}{c}\text { 20. Security Classif. (of this } p \\
\text { Unclassified }\end{array}$ & & \begin{tabular}{|c|} 
21. No. of Pages \\
106
\end{tabular} & 22. Price \\
\hline
\end{tabular}

Form DOT F 1700.7 (8-72) $\quad$ Reproduction of completed page authorized 


\section{EXECUTIVE SUMMARY}

Today's world is deeply influenced by the way new technology evolves. Rapidly emerging mobile apps have contributed to the quick expansion of car sharing, ridesourcing, and various other on-demand services around the world. Similarly, connected and autonomous vehicle technologies are expected to bring a paradigm shift in how we define mobility. It is essential to incorporate ridesourcing and automated vehicle (AV) considerations into current long-range transportation planning efforts, which usually extend to the next 20 to 30 years. On the other hand, there are a lot of uncertainties with respect to technology development, regulations, and user acceptance that make it challenging to draw a clear picture of how shared mobility and AVs may affect our daily travel and the potential effects on the society as a whole.

To address these challenges, this report presents a study investigating potential travel behavior changes in light of automated, connected, electric, and shared-use vehicle (ACES) technologies. Particularly, this study focuses on exploring the roles of attitudes in individuals' travel choice behavior. Data collected through a stated preference (SP) survey were used for this study. The survey targeted 10 metropolitan areas in the nation and the state of Florida. The survey included a series of attitude-related questions that cover various aspects of user attitudes, which include:

- general mobility preferences,

- perceived benefits and concerns of shared mobility,

- reasons against or for private ownership, and

- motivations for and desired features of AVs.

Three main aspects of choice behavior were investigated: AV adoption and willingness to pay (WTP), shared mobility adoption, and mode choice. Various modeling techniques were employed to identify influential factors and examine the impacts of attitudes, including error component models, structural equations model, and support vector machine method. The models identified various attitudes that played significant roles in individuals' choice behavior.

\section{AV Adoption and WTP}

The survey results revealed that the plurality of the respondents were either willing to maintain basic vehicle utilization $(36 \%)$ or at most add some advanced features $(37 \%)$ such as adaptive cruise control. Only $12 \%$ of the respondents expected themselves to be riding in a fully autonomous vehicle in the next ten years. The average WTP increased along with the level of adoption, ranging from $\$ 652$ for basic vehicles to $\$ 1,192$ for advanced features, $\$ 1,542$ for partial automation, and $\$ 1,769$ for fully automated

People see themselves driving in ten years (WTP shown in parentheses):

- $36 \%$ - basic vehicles (\$600)

- $37 \%$ - advanced features $(\$ 1,100)$

- $15 \%$ - partial automation $(\$ 1,500)$

- $12 \%$ - fully automated $(\$ 1,800)$ alternatives. 
In terms of the role of attitudes, those who enjoy driving would be the hardest to persuade toward AV adoption or to pay for automated features. Technology-savvy people revealed a higher tendency toward AV adoption. The results also showed that people might be willing to pay more for automated features if they believe that these features provide them better utility, in terms of time and cost saving, convenience, etc. Individuals with trust issues also showed higher WTP, which might indicate that strategies or services that address privacy issues may be worthwhile even at a higher cost for some groups of users.

In terms of demographic variables, individuals 55-59 years old, high school graduates, lowincome groups $(<\$ 50 \mathrm{k})$, and those with driver's licenses were less likely to adopt partial or full AVs, compared to other groups. Full-time students, self-employed individuals, Black Americans, frequent online shoppers, and those who already experienced ride-sharing options were willing to pay more for AV technologies.

\section{Ridesourcing vs. Private Vehicle - Mobility Option}

This analysis focused on what it takes or what will convince travelers to adopt ridesourcing instead of private mobility. Survey results indicated that a monthly transportation cost increase of $\$ 100$ would persuade $60 \%$ of the drivers to switch to ridesourcing services. The average cost of driving was about $\$ 9,300$

Average cost/fare per mile / passenger mile by mode:

- $\$ 0.62$ auto (AAA 2019)

- $\$ 0.27$ transit (APTA 2017)

- $\$ 1-2$ Uber/Lift annually, or about $\$ 773$ per month according to AAA 2019 driving cost study. This shows promising potential for ridesourcing options.

On the other hand, a 25-minute time saving was needed to achieve the same magnitude of effect, which would be unrealistic considering that the average trip length was about 24 minutes. About $39 \%$ of the drivers indicated that they needed at least 30 minutes of time savings for regular trips

Sixty percent of drivers may switch to ridesourcing with:

- $\$ 100$ cost saving per month, or

- 25-minute reduction in travel time to switch to on-demand service as a mobility option. To some degree, this might indicate that cost plays a stronger role in mobility decisions than time savings or that people mostly view cost saving as the main advantage of ridesourcing compared to driving private vehicles.

For transit users, the time and cost saving required to switch to ridesourcing were much lower compared to drivers, at about $\$ 50$ per month and 15 minutes per trip to persuade $60 \%$ of the users.

Model results showed that young people (25 years old or younger), low-income individuals, and people with previous ridesourcing experience tend to expect less in view of both travel time and travel cost saving and, therefore, will be persuaded more easily to use ridesourcing compared to other groups. On the contrary, middle-aged people, highly car-dependent individuals, and selfemployed were likely to demand higher savings from ridesourcing options. 
In view of latent attitudinal factors, it is evident that those with trust issues and private ownership advantages (such as comfort, convenience, and reliability) act as barriers against regular ridesourcing usage, therefore requiring higher cost saving to convince them to switch to ridesourcing. On the other hand, those concerned with both financial (including capital and maintenance costs) and non-financial (such as parking issues) issues of private ownership required less time savings for them to choose ridesourcing. As expected, mode choice reasoning users (as opposed to habitual actions) are more likely to switch to ridesourcing with less cost saving. Interestingly, even those who favor multitasking still expect to see some amount of time saving compared to the conventional modes.

\section{Ridesourcing vs. Private Vehicle - Mode choice}

This analysis focused on daily mode choice between private vehicles and ridesourcing (including exclusive rides and shared rides) for a regular trip.

In general, the models showed positive influences of high income and full employment toward exclusive rides, mid-income toward shared rides, and a negative association between lower education and retirees and ridesourcing options. It also showed that social and school trips had a higher propensity of being made with exclusive ride services than other trips. In terms of age, it seems that college students or young graduates (age between 1824) or those aged between 50 and 54 were more likely to take shared rides, and people between 30-34 were more likely to use ondemand services (both exclusive and shared), compared to other
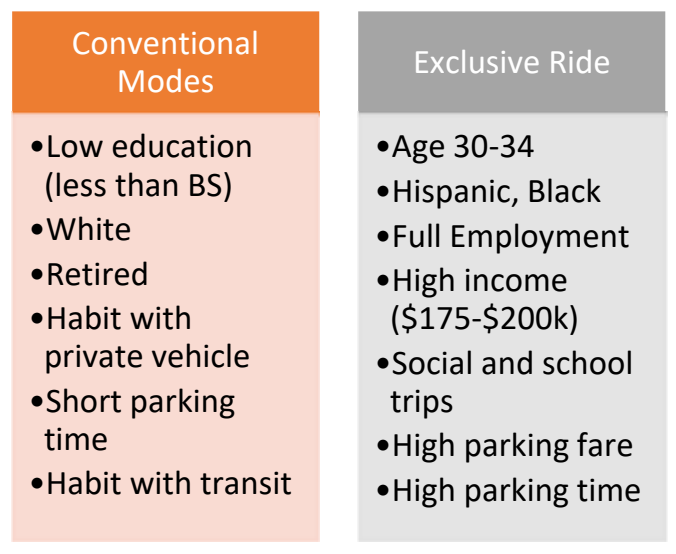

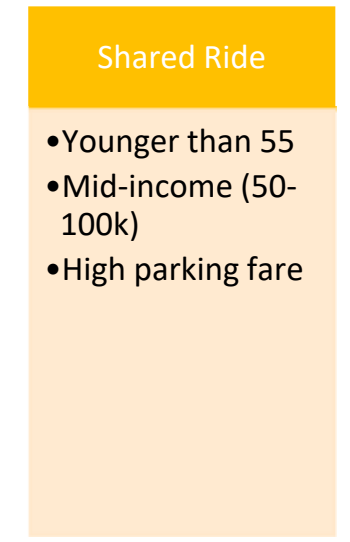
age groups.

Habit associated with private vehicles, either as a driver or passenger, had strong negative impacts on the probability of using ridesourcing services, either as an exclusive ride or shared ride. This indicates that if a person frequently drives for regular trips, the probability of shifting to alternative options significantly decreases, despite the desirable level of service of the alternative modes. The habitual linkage with public transit was not significant. This may indicate that transit users are more willing to use ridesourcing services. On the other hand, the habitual linkage with ridesourcing showed strong positive impacts on the probability of choosing ridesourcing. Interestingly, this effect only affects the choice for an exclusive ride. It does not present significant impacts on the choice of a shared ride. This may imply a barrier to arranging shared rides for regular daily purposes. High parking costs and time also showed a positive influence on the usage of ridesourcing alternatives. 
This analysis focused on daily mode choice between transit and ridesourcing (including exclusive rides and shared rides) in two different contexts: daily travel for regular transit users and occasional trip (such as visiting a new place, to or from airports, etc.) for regular auto users. Regular auto users are those who use a private vehicle on a regular basis, transit users are those who use transit for a regular or frequent trip.

For regular transit users, females showed a positive tendency to use ridesourcing services and were more inclined to use exclusive rides, compared with transit. Full-time employees were more likely to use exclusive rides. This positive correlation may indicate the impact of work-schedule restrictions associated with full-time employees and that they may prefer exclusive services for lower travel times and probably higher reliability. Students and lower education groups (high school of less) showed a strong inclination to use shared rides compared to transit. As expected, low-income groups (less than $\$ 50 \mathrm{k}$ annually) were more likely to use transit than ridesourcing. Very high-income groups ( $\$ 200 \mathrm{~K}$ or above) were less likely to use shared services. Those in between generally showed a higher tendency to use exclusive rides compared with transit as income levels increased.

In view of attitudes, technology savviness, on-demand service and travel time advantage are positive factors toward the choice of ridesourcing (both exclusive and shared forms) instead of transit. Interestingly, those who desire the utility of private vehicles or prefer alternative modes are more likely to stay with transit. Positive associations were observed between the tendency to use shared rides and the interest in full automation, technology and efficiency. Individuals who seek efficiency and technology were interested in using shared ride services, presumably because shared travel modes are cost-efficient. Moreover, those who cared about mobility for non-drivers were inclined to use exclusive services. This may indicate the preference for those who are not able to drive

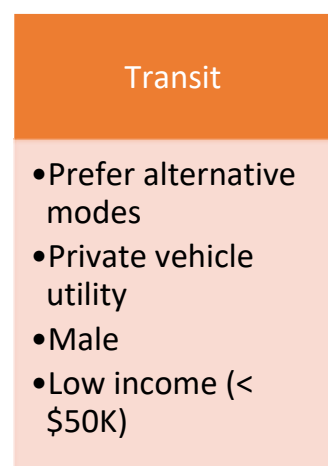

themselves but prefer a private and exclusive travel experience.
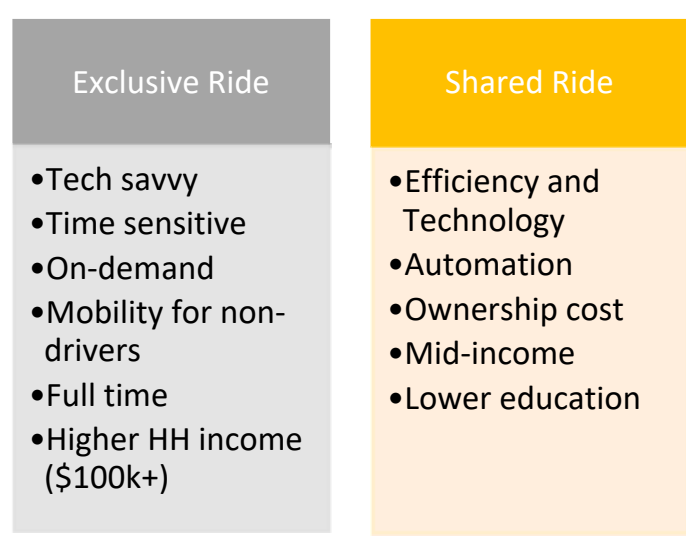

For auto users, students showed a positive tendency to use on-demand services, both exclusive and shared ride service, probably because students are usually more open and eager to experience new technologies. Income showed mixed results. In general, low-income individuals were less likely to use exclusive rides, and high-income individuals were less likely to use shared rides.

In view of attitudes, tech-savvy individuals, choice reasoning users, and those who desire ondemand services would choose ridesourcing over transit services. Interestingly, those who enjoy 
driving or have issues with traveling with strangers preferred transit over ridesourcing options. On the other hand, those who desire stress relief or enjoy the utility of private vehicles would be more likely to use exclusive rides than transit.

In summary, model results showed that attitudes played important roles in shaping travelers' choice behavior. Incorporating these factors improved the model performance and prediction accuracy of travel behavior models, which will lead to a more reliable assessment of the likelihood and magnitude of behavioral shifts toward future mobility options.

This study provides useful and meaningful insights into users' attitudes and perceptions toward ACES technologies and how these attitudes and other contributing factors may influence travelers' choice behavior. Recognizing that the market will not react homogeneously toward new technologies, the study results contribute to a better understanding of user acceptance and adoption of emerging mobility options and better assessment of their potential impacts. The findings could be helpful for planners and service providers to better plan for and address the needs and concerns of travelers. This may also provide important inputs for the development of strategies in promoting alternative mobility options.

Future research can adopt the behavioral insights derived from this study and develop assumptions on model parameter changes to reflect potential behavioral shifts under different scenarios. This scenario analysis will help explore a wide range of possibilities and evaluate the combined effects or outcomes of new technologies and trends. 


\section{TABLE OF CONTENTS}

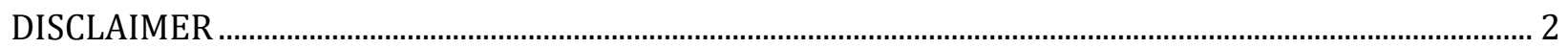

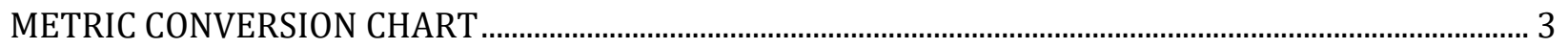

TECHNICAL REPORT DOCUMENTATION PAGE ……………………………………………….................... 5

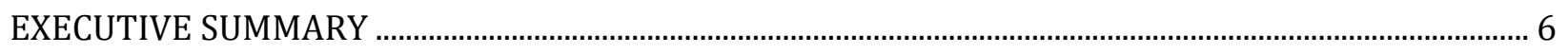

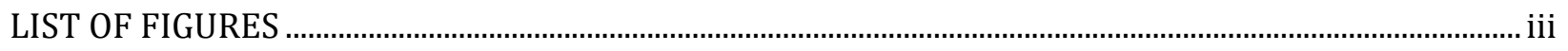

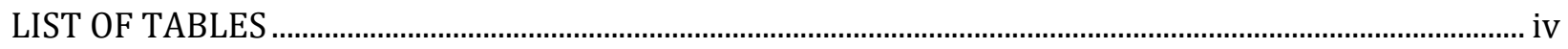

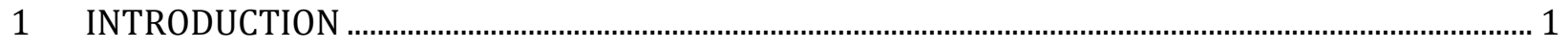

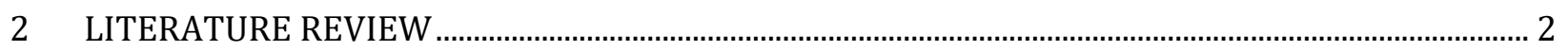

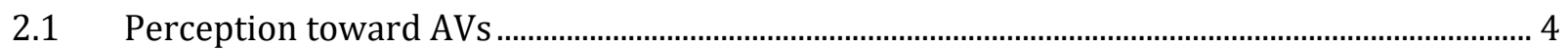

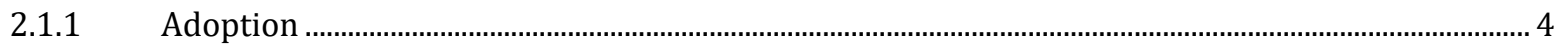

2.1.2 Willingness to Pay .......................................................................................................................................................

2.1.3 Mode Choice ....................................................................................................................................................... 8

2.1.4 Benefits and Concerns ................................................................................................................................. 9

2.1.5 Perception of Technology and Operations ...........................................................................................11

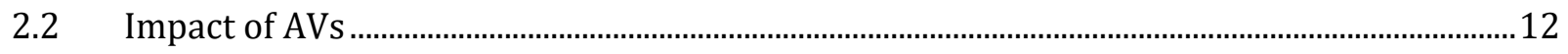

2.2.1 Travel Demand.......................................................................................................................................................12

2.2.2 Traffic Operation .................................................................................................................................................15

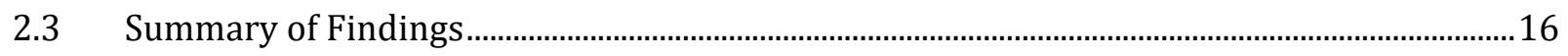

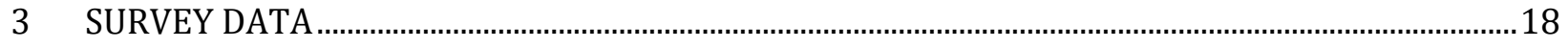

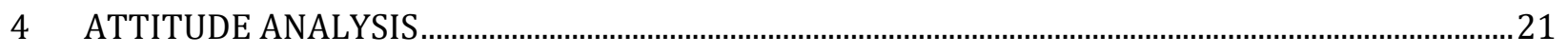

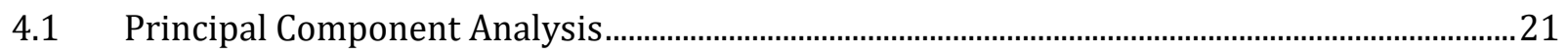

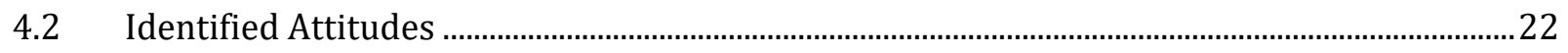

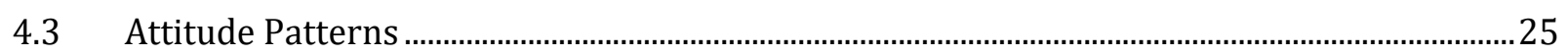

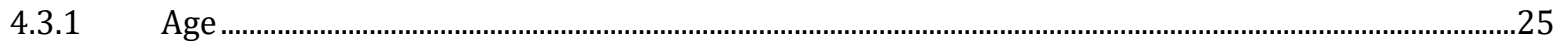

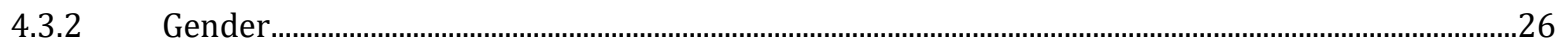

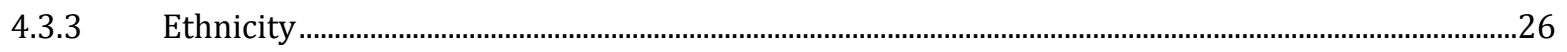

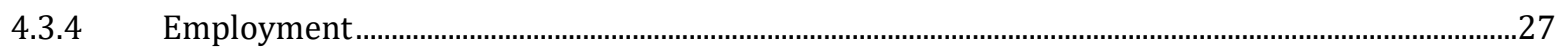

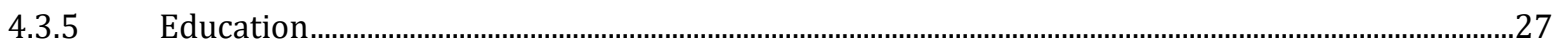

4.3.6 Household Income .................................................................................................................................29

4.3.7 Household Size ...............................................................................................................................................30

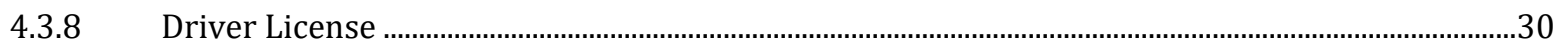

4.3.9 Number of Household Drivers .................................................................................................................30

4.3.10 Mode Usage ..............................................................................................................................................................32

4.3.11 Regular Trip Distance ....................................................................................................................35

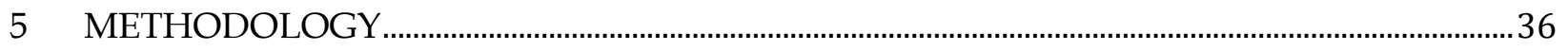

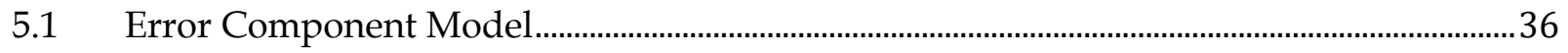

5.1.1 Error Component Model with Multinomial Logit Structure .......................................................................36

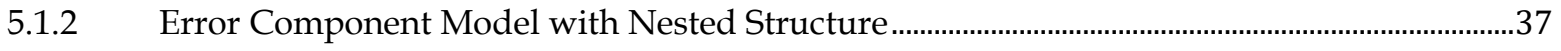

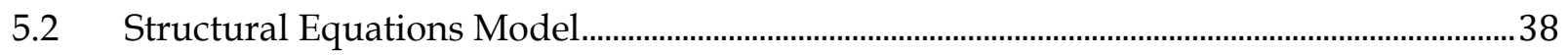

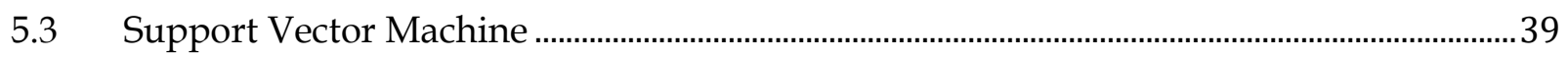

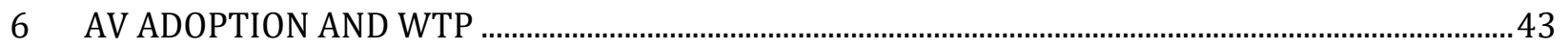

$6.1 \quad$ Model Results.................................................................................................................................... 43

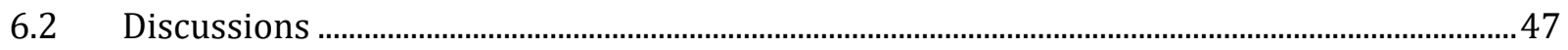


7 RIDESOURCING ADOPTION ............................................................................................................48

7.1 Expected Travel Time and Cost saving to Switch from Private Mobility to Ridesourcing...48

7.1.1 Model Results ................................................................................................................................................4

7.1.2 Discussions ......................................................................................................................................................54

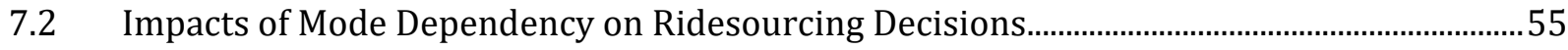

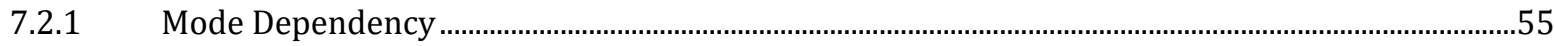

7.2.2 Model Results ....................................................................................................................................................5

7.2.3 Discussions ...........................................................................................................................................................60

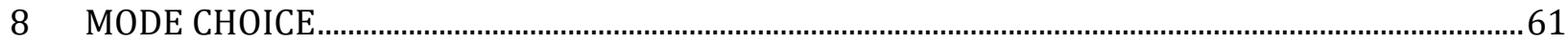

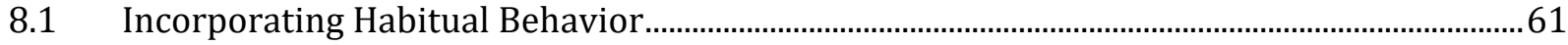

8.1.1 Habitual Strength Index........................................................................................................................................62

8.1.2 Mobility Auxiliary Expenses.................................................................................................................................66

8.1.3 Mode Choice Results....................................................................................................................................67

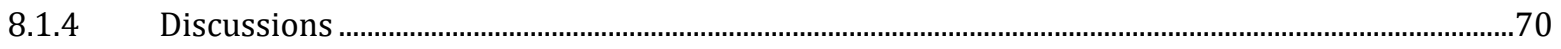

8.2 Transit and Auto Users' Mode Choice of Ridesourcing: The Role of Attitudes.........................71

8.2.1 Latent Attitudinal Factors ....................................................................................................................72

8.2.2 Mode Choice Results..............................................................................................................................................73

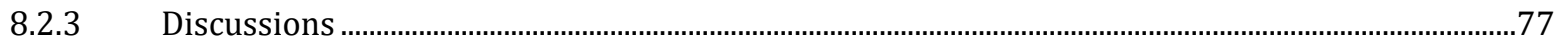

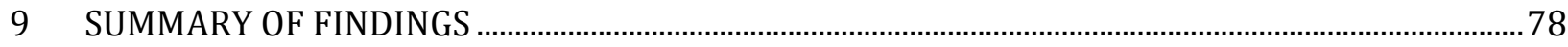

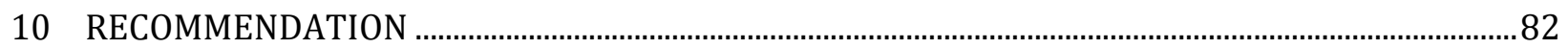

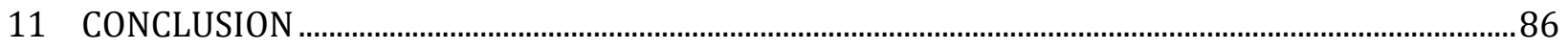

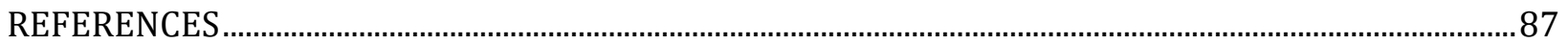




\section{LIST OF FIGURES}

Figure 1 Preferences for lifestyle and mobility options (AT1) ................................................18

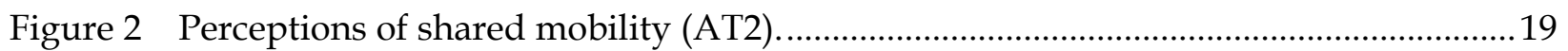

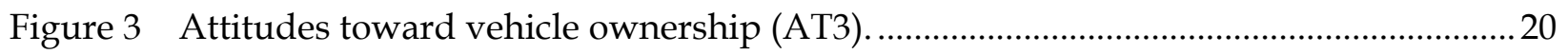

Figure 4 Motivations to adopt AV and desired features (AT4).................................................20

Figure 5 Principal component analysis illustration...............................................................2

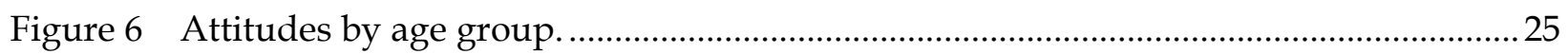

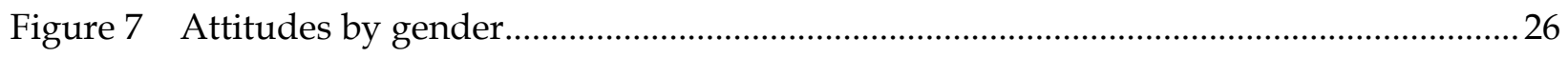

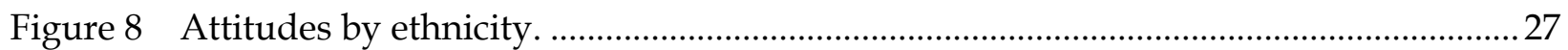

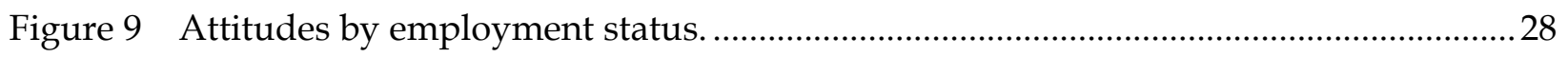

Figure 10 Attitudes by education level.....................................................................................28

Figure 11 Attitudes by household income level.....................................................................29

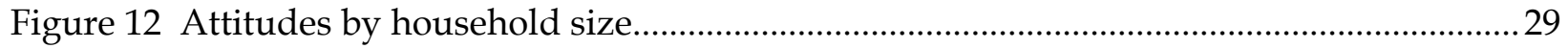

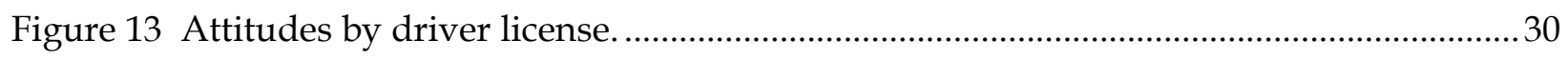

Figure 14 Attitudes by the number of household drivers.............................................................. 31

Figure 15 Attitudes by the number of household vehicles. ............................................................ 31

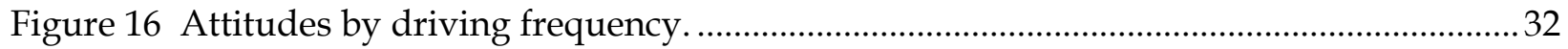

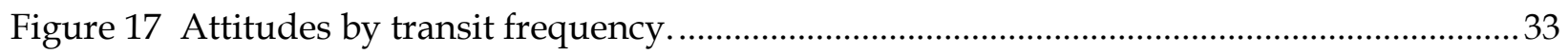

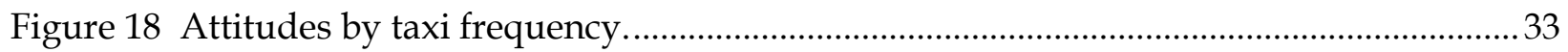

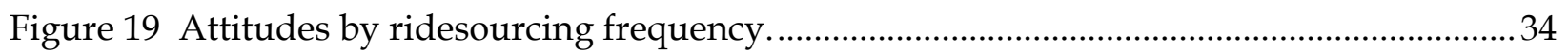

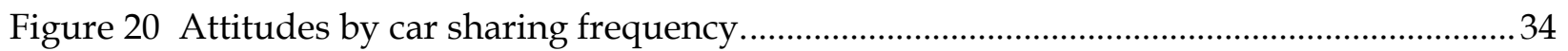

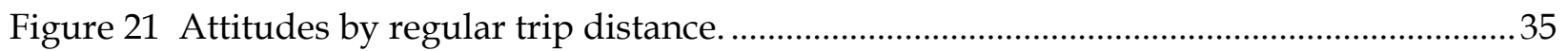

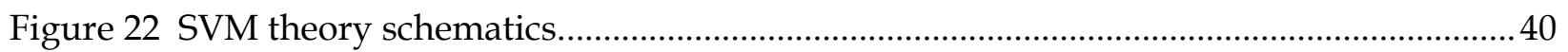

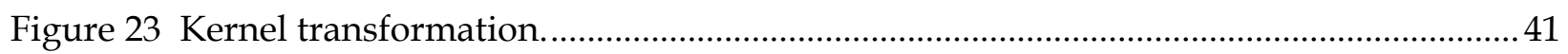

Figure 24 Impacts of personal and household variables on AV adoption and WTP...................46

Figure 25 Impacts of attitudinal variables on AV adoption and WTP........................................4 47

Figure 26 Minimum time and cost saving needed to switch to ridesourcing. ...............................4 49

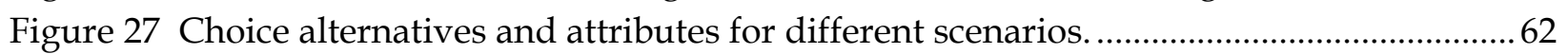

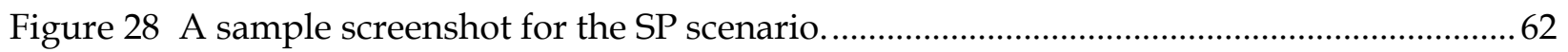

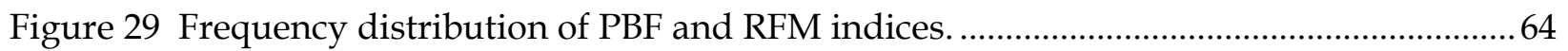

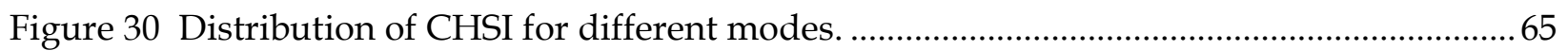

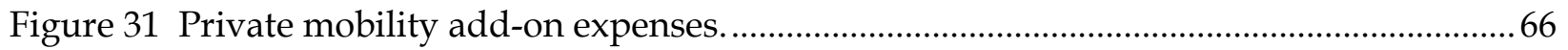

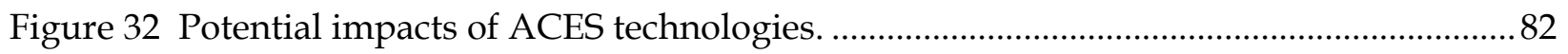

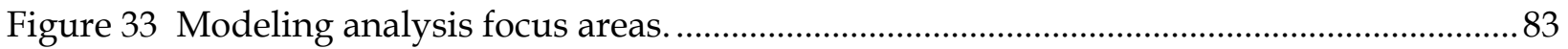




\section{LIST OF TABLES}

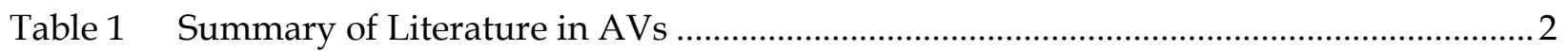

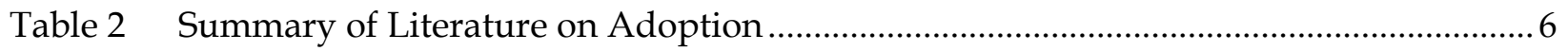

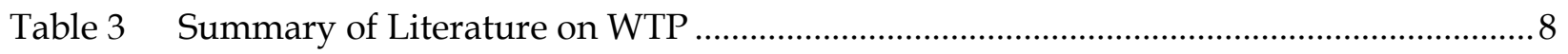

Table 4 Summary of Literature on Mode Choice....................................................................... 9

Table 5 Summary of Literature on Benefit and Concerns ........................................................10

Table 6 Summary of Literature on Perception of Technology and Operations..........................12

Table 7 Summary of Literature on Travel Demand .................................................................. 14

Table 8 Classification of Studies by Detailed Approach............................................................16

Table 9 PCA result for AT1 (preferences for lifestyle and mobility options) .............................22

Table 10 PCA result for AT2 (perceived benefits and concerns of shared mobility)..................23

Table 11 PCA result for AT3 (reasons toward or against private vehicle ownership)................24

Table 12 PCA result for AT4 (motivations for and desired features of AV) ...............................2 24

Table 13 Result of Measurement Equations for AV Adoption and WTP.................................... 44

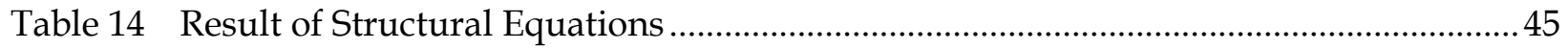

Table 15 Result of Measurement Equations …............................................................................. 50

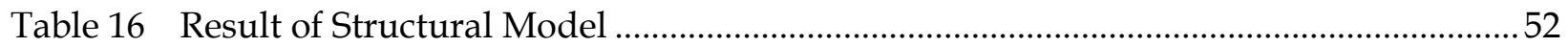

Table 17 Results of Factor Analysis for Mode Dependency ......................................................56

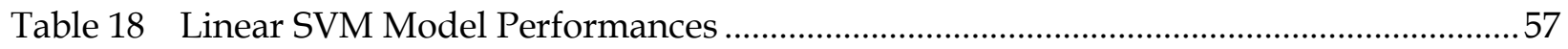

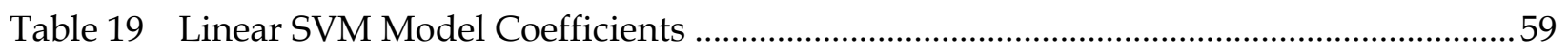

Table 20 Mode Choice Model Results for Regular Trips (t-ratios in brackets)............................68

Table 21 Mode Choice Model Results for Occasional Trips (t-ratios in brackets) .......................70

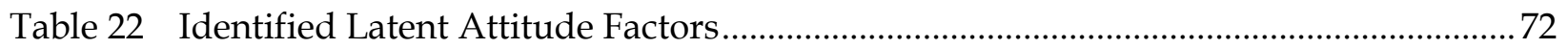

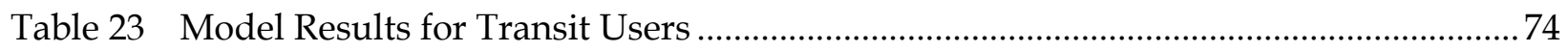

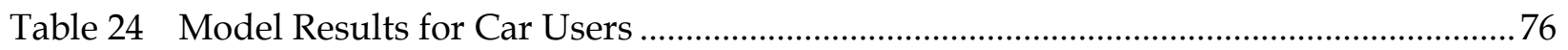

Table 25 Summary of Influential Attitudes to Emerging Mobility Options ................................81

Table 26 Summary of Influential Variables to Emerging Mobility Options ................................8 81

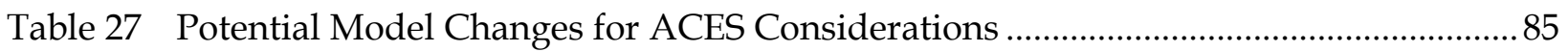




\section{INTRODUCTION}

Today's world is deeply influenced by the way new technology evolves. Advances in information and communication technologies have played an important role in how we live and travel and will continue to do so. Rapidly emerging mobile apps have contributed to the quick expansion of car sharing, ridesourcing, and various other on-demand services around the world. Similarly, connected and autonomous vehicle technologies are expected to bring a paradigm shift in how we define mobility.

It is essential to incorporate ridesourcing and automated vehicle (AV) considerations into current long-range transportation planning efforts, which usually extends to the next 20 to 30 years. On the other hand, there are a lot of uncertainties with respect to technology development, regulations, and user acceptance that make it challenging to draw a clear picture of how shared mobility and AVs may affect our daily travel and the potential implications on the society as a whole.

To address these challenges, a stated preference (SP) survey was designed and implemented in the first phase of this research effort, to examine travelers' mode choice behavior in the upcoming age of automated, connected, electric, and shared vehicles (ACES). The nationwide survey engaged in carefully designed choice experiments to measure the likelihood and extent of behavioral changes. Multiple scenario types were developed to gauge user response under different circumstances.

The survey data provided useful insights into travelers' mobility choice behavior from several aspects, including the willingness to shift to shared mobility at varying cost and time incentives, willingness to pay (WTP) for advanced vehicle technologies, views and concerns of vehicle automation, and attitudes and perceptions toward mobility options. Using these survey data, this study intends to investigate the factors that influence people's mobility choice behavior facing emerging mobility options, with a focus on exploring the role of user attitudes and perceptions. Advanced econometric models and data analytic methods will be explored to fuse multidimensional information and provide an approach to understand the likelihood and magnitude of behavior shifts toward AVs and shared mobility options.

This report is organized as follows. The next chapter summarizes recent literature in ACES analysis. The following chapter introduces the survey data and attitude analysis. The next chapter describes the study methodology, followed by modeling results from three main perspectives: AV adoption and WTP, shared mobility adoption, and mode choice behavior. Then recommendations on how to incorporate ACES considerations into the modeling framework are presented in the next chapter. The last chapter summarizes the study with major findings and conclusions. 


\section{LITERATURE REVIEW}

Various studies were conducted to examine the potential impacts of AVs, mainly from two perspectives. The first one focuses on the Perception toward $A V s$, which tries to understand adoption, willingness-to-pay (WTP), mode choice, perceived benefits and concerns and perception of technology and operations. In the second perspective, which focuses on the Impact from $A V s$, the objective is to understand the influence on travel behavior and demand, and potential impacts on traffic networks (Rahimi et al., 2020b).

Table 1 presents a summary of recent literature in AVs based on their approach, objective and methodology.

Table 1 Summary of Literature in AVs

\begin{tabular}{|c|c|c|c|c|c|c|}
\hline Study & $\begin{array}{l}\text { Study } \\
\text { year }\end{array}$ & Study area & $\begin{array}{l}\text { Sample } \\
\text { Size }\end{array}$ & Approach & Objective(s) & Methodology \\
\hline $\begin{array}{l}\text { Howard and } \\
\text { Dai (2014) }\end{array}$ & 2014 & California & 107 & Perception & $\begin{array}{l}\text { Investigate people's } \\
\text { attitudes toward AVs }\end{array}$ & $\begin{array}{l}\text { Descriptive } \\
\text { analysis }\end{array}$ \\
\hline $\begin{array}{l}\text { Schoettle } \\
\text { and Sivak } \\
(2014)\end{array}$ & 2014 & $\begin{array}{l}\text { US, UK, } \\
\text { Canada }\end{array}$ & 1,533 & Perception & $\begin{array}{l}\text { Understand the } \\
\text { perceptions of AVs in } \\
\text { different countries. }\end{array}$ & $\begin{array}{l}\text { Descriptive } \\
\text { analysis }\end{array}$ \\
\hline $\begin{array}{l}\text { Childress et } \\
\text { al. (2015) }\end{array}$ & 2015 & Seattle & NA & Impact & $\begin{array}{l}\text { To test a range of travel } \\
\text { behavior impacts from AV } \\
\text { technology development }\end{array}$ & $\begin{array}{l}\text { Activity-Based } \\
\text { Model }\end{array}$ \\
\hline $\begin{array}{l}\text { Bansal et al. } \\
\text { (2016) }\end{array}$ & 2016 & Austin & 347 & Perception & $\begin{array}{l}\text { Estimate the average WTP } \\
\text { for full and partial AVs. } \\
\text { Estimate adoption rates of } \\
\text { shared AVs }\end{array}$ & $\begin{array}{l}\text { Multivariate } \\
\text { ordered probit } \\
\text { models }\end{array}$ \\
\hline $\begin{array}{l}\text { Bansal and } \\
\text { Kockelman } \\
(2017)\end{array}$ & 2016 & US & 2,167 & $\begin{array}{l}\text { Perception } \\
\text { \& Impact }\end{array}$ & $\begin{array}{l}\text { Develop a framework to } \\
\text { forecast long term } \\
\text { adoption levels of CV and } \\
\text { AVs. Estimate adoption } \\
\text { rates of shared AVs using } \\
\text { different pricing scenarios }\end{array}$ & $\begin{array}{l}\text { Multinomial } \\
\text { logit models. } \\
\text { Different } \\
\text { simulation } \\
\text { scenarios for } \\
\text { long term } \\
\text { adoption }\end{array}$ \\
\hline $\begin{array}{l}\text { Zmud et al. } \\
\text { (2016) }\end{array}$ & 2016 & Austin & 556 & $\begin{array}{l}\text { Perception } \\
\text { \& Impact }\end{array}$ & $\begin{array}{l}\text { Investigate the intention to } \\
\text { use AVs and the factors } \\
\text { that are associated with it. } \\
\text { Explore potential benefits } \\
\text { and concerns of AVs }\end{array}$ & $\begin{array}{l}\text { Descriptive } \\
\text { analysis }\end{array}$ \\
\hline $\begin{array}{l}\text { Daziano et } \\
\text { al. (2017) }\end{array}$ & 2017 & US & 1,260 & Perception & $\begin{array}{l}\text { Estimate the WTP for fully } \\
\text { and partial AVs }\end{array}$ & $\begin{array}{l}\text { Conditional } \\
\text { logit models. } \\
\text { Parametric and } \\
\text { semi-parametric } \\
\text { logit models }\end{array}$ \\
\hline
\end{tabular}


Table 1, continued

\begin{tabular}{|c|c|c|c|c|c|c|}
\hline Study & $\begin{array}{l}\text { Study } \\
\text { year }\end{array}$ & Study area & $\begin{array}{l}\text { Sample } \\
\text { Size }\end{array}$ & Approach & Objective(s) & Methodology \\
\hline $\begin{array}{l}\text { Haboucha } \\
\text { et al. (2017) }\end{array}$ & 2017 & $\begin{array}{l}\text { US, Israel, } \\
\text { Canada }\end{array}$ & 721 & Perception & $\begin{array}{l}\text { Understand what } \\
\text { motivates the intention to } \\
\text { use AVs. Estimate long } \\
\text { term decision mode } \\
\text { choices }\end{array}$ & $\begin{array}{l}\text { Confirmatory } \\
\text { factor analysis. } \\
\text { Logit Kernel } \\
\text { model with } \\
\text { panel effect }\end{array}$ \\
\hline $\begin{array}{l}\text { Shabanpour } \\
\text { et al. (2017) }\end{array}$ & 2017 & Chicago & 1,253 & Perception & $\begin{array}{l}\text { Evaluate perception of the } \\
\text { benefits and concerns of } \\
\text { AVs. Examine the most } \\
\text { preferable vehicle option to } \\
\text { purchase }\end{array}$ & $\begin{array}{l}\text { Random } \\
\text { parameter logit } \\
\text { model }\end{array}$ \\
\hline $\begin{array}{l}\text { Rahmati } \\
\text { and } \\
\text { Talebpour } \\
\text { (2017) }\end{array}$ & 2017 & Atlanta & NA & Impact & $\begin{array}{l}\text { To characterize driver } \\
\text { behavior in unprotected } \\
\text { left turn maneuvers in a } \\
\text { connected, automated } \\
\text { driving environment. }\end{array}$ & Game theory \\
\hline $\begin{array}{l}\text { Sanbonmats } \\
\text { u et al. } \\
(2018)\end{array}$ & 2018 & US & 114 & Perception & $\begin{array}{l}\text { Examine beliefs and how } \\
\text { confident people think } \\
\text { about AV technology }\end{array}$ & $\begin{array}{l}\text { Descriptive and } \\
\text { correlation } \\
\text { analysis }\end{array}$ \\
\hline $\begin{array}{l}\text { Shabanpour } \\
\text { et al. (2018a) }\end{array}$ & 2018 & Chicago & 1,253 & Perception & $\begin{array}{l}\text { Explore adoption decisions } \\
\text { related } \\
\text { to attributes of } \mathrm{AVs}\end{array}$ & $\begin{array}{l}\text { Multinomial } \\
\text { logit model } \\
\text { using best-worst } \\
\text { analysis }\end{array}$ \\
\hline $\begin{array}{l}\text { Talebian } \\
\text { and Mishra } \\
\text { (2018) }\end{array}$ & 2018 & US & 327 & Impact & $\begin{array}{l}\text { Examine how WTP of } \\
\text { connected AVs changes } \\
\text { due to peer-to-peer } \\
\text { communication }\end{array}$ & $\begin{array}{l}\text { Agent-based } \\
\text { model }\end{array}$ \\
\hline $\begin{array}{l}\text { Perrine et } \\
\text { al. (2020) }\end{array}$ & 2018 & US & NA & Impact & $\begin{array}{l}\text { Impact of AV on inter- } \\
\text { regional travel and how } \\
\text { long-distance destination } \\
\text { and mode choices will } \\
\text { change. }\end{array}$ & $\begin{array}{l}\text { Demand Model } \\
\text { Nested logit } \\
\text { model }\end{array}$ \\
\hline $\begin{array}{l}\text { Shabanpour } \\
\text { et al. (2018b) }\end{array}$ & 2018 & Chicago & 1253 & Perception & $\begin{array}{l}\text { Estimation of the AV } \\
\text { market penetration }\end{array}$ & $\begin{array}{l}\text { Innovation } \\
\text { diffusion model }\end{array}$ \\
\hline $\begin{array}{l}\text { Nazari et al. } \\
(2018)\end{array}$ & 2018 & $\begin{array}{l}\text { Puget } \\
\text { Sound }\end{array}$ & 2726 & Perception & $\begin{array}{l}\text { To model public interest in } \\
\text { private AVs and multiple } \\
\text { SAV configurations (car } \\
\text { sharing, ridesourcing, ride } \\
\text { sharing, and access/egress } \\
\text { mode) in daily and } \\
\text { commute travel }\end{array}$ & $\begin{array}{l}\text { Multivariate } \\
\text { ordered probit } \\
\text { model }\end{array}$ \\
\hline $\begin{array}{l}\text { Spurlock et } \\
\text { al. (2019) }\end{array}$ & 2019 & $\begin{array}{l}\text { San } \\
\text { Francisco }\end{array}$ & 1026 & Perception & $\begin{array}{l}\text { Analyze adoption patterns } \\
\text { of vehicle automation }\end{array}$ & $\begin{array}{l}\text { Ordinary least } \\
\text { squares } \\
\text { regressions }\end{array}$ \\
\hline
\end{tabular}


Table 1, continued

\begin{tabular}{|c|c|c|c|c|c|c|}
\hline Study & $\begin{array}{l}\text { Study } \\
\text { year }\end{array}$ & Study area & $\begin{array}{c}\text { Sample } \\
\text { Size }\end{array}$ & Approach & Objective(s) & Methodology \\
\hline $\begin{array}{l}\text { Nadafian et } \\
\text { al. (2019) }\end{array}$ & 2019 & $\begin{array}{l}\text { New } \\
\text { Mexico }\end{array}$ & NA & Impact & $\begin{array}{l}\text { Analyze how land-use } \\
\text { changes spurred by AVs } \\
\text { may affect travel demand } \\
\text { and travel patterns }\end{array}$ & $\begin{array}{l}\text { Integrated land- } \\
\text { use and travel } \\
\text { demand } \\
\text { modeling } \\
\text { framework }\end{array}$ \\
\hline $\begin{array}{l}\text { Nazari et al. } \\
(2019 a)\end{array}$ & 2019 & California & 3574 & Perception & $\begin{array}{l}\text { To ascertain the causality } \\
\text { between the travelers' } \\
\text { safety concerns about the } \\
\text { AV technology and their } \\
\text { AV adoption behavior. }\end{array}$ & $\begin{array}{l}\text { Bivariate } \\
\text { ordered probit } \\
\text { model }\end{array}$ \\
\hline $\begin{array}{l}\text { Rahman et } \\
\text { al. (2019) }\end{array}$ & 2019 & Orlando & NA & Perception & $\begin{array}{l}\text { To investigate the safety } \\
\text { impact of connected } \\
\text { vehicles }\end{array}$ & $\begin{array}{l}\text { VISSIM } \\
\text { Logistic } \\
\text { regression } \\
\text { model }\end{array}$ \\
\hline $\begin{array}{l}\text { Xu et al. } \\
\text { (2019) }\end{array}$ & 2019 & Chicago & 34,170 & Impact & $\begin{array}{l}\text { To adopt and implement a } \\
\text { three-level ABM-DTA } \\
\text { integration framework. }\end{array}$ & $\begin{array}{l}\text { Activity-Based } \\
\text { Model }\end{array}$ \\
\hline $\begin{array}{l}\text { Cohn et al. } \\
\text { (2019) }\end{array}$ & 2019 & Washington & $2,613,483$ & Impact & $\begin{array}{l}\text { To evaluates outcomes of } \\
\text { AV scenarios within the for } \\
\text { disadvantaged populations }\end{array}$ & $\begin{array}{l}\text { regional } \\
\text { travel demand } \\
\text { model }\end{array}$ \\
\hline
\end{tabular}

\subsection{Perception toward AVs}

This section will discuss literature focusing on perception toward AVs.

\subsubsection{Adoption}

Shabanpour et al. (2018b) developed an innovation diffusion model to capture heterogeneity in survey data and found that adoption timing behavior is subject to notable degrees of heterogeneity, ignoring which could cause up to $54.1 \%$ underestimation or $70.8 \%$ overestimation of the cumulative adoption timing probabilities. This study suggested that that the market penetration of AVs in the Chicago metropolitan area would eventually be $71.3 \%$. The results reveal that increasing parking costs in urban areas with higher job opportunities would encourage people who work in those areas to adopt an AV. The study indicates that individuals with previous accident experiences are among the first who would reconsider riding an AV. The results also suggest that short-term marketing policies could focus more on long-distance travelers (e.g., those who live suburbs and work in CBD or vice versa).

Spurlock et al. (2019) found that although higher-income people are disproportionately represented among current adopters of most new technologies, low- to middle-income people are just as likely to have adopted pooled ride-hailing and AVs. The study suggests that younger generations have the potential to fuel AV market penetration, just as they are currently fueling 
ride-hailing uptake if given the means to do so. In addition, women are less likely to adopt and/or be interested in adopting most new transportation technologies, with the exception of ridehailing.

Haboucha et al. (2017) found that early AV adopters will likely be young, students, more educated, and spend more time in vehicles. Nazari et al. (2019a) tested the hypothesis that AV adoption is controlled by, among various factors, the safety concern of travelers, which is itself a function of exogenous factors. The framework simultaneously modeled AV adoption and safety concerns while considering the endogeneity between the two dependent variables. The study found a significant negative association between safety concerns and AV adoption.

Bansal and Kockelman (2017) proposed a simulation-based fleet evolution framework to forecast Americans' long-term (2015-2045) adoption levels of connected and automated vehicle (CAV) technologies under eight different scenarios based on 5\% and 10\% annual drops in technology prices; $0 \%, 5 \%$, and 10\% annual increments in Americans' WTP and changes in government regulations (e.g., mandatory adoption of connectivity on new vehicles). Long-term fleet evolution suggests that the privately held light-duty-vehicle fleet will have $24.8 \%$ Level $4 \mathrm{AV}$ penetration by 2045 if one assumes an annual 5\% price drop and constant WTP values (from 2015 forward). This share jumps to $87.2 \%$ if one uses a $10 \%$ annual rate of decline in prices and a $10 \%$ annual rise in WTP values. Overall, simulations suggest that, without a rise in most people's WTP, or policies that promote or require technologies, or unusually rapid reductions in technology costs, it is unlikely that the U.S. light-duty vehicle fleet's technology mix will be anywhere near homogeneous by the year 2045 .

Talebian and Mishra (2018) employed the concept of resistance to explain why individuals typically tend to defer the adoption of an innovation. The analysis revealed an individual decides to adopt when there is a need for new vehicles; WTP is greater than CAV price, and overall impression about CAVs reaches a cutoff value. The study suggested an agent-based framework that models the process in which peer-to-peer communication and media advertisement impact the determinants of adoption decision, i.e., resistances and incentives. Results showed that the automobile fleet would be near homogenous in about 2050 only if CAV prices decrease at an annual rate of $15 \%$ or $20 \%$. CAV market share will be close to $100 \%$ only if all adopters are satisfied with their purchases; therefore, the probability that an individual becomes a satisfied adopter plays an important role in the trend of adoption. Table 2 presents a summary of findings focusing on adoption of AVs. 
Table 2 Summary of Literature on Adoption

\begin{tabular}{|c|c|c|c|}
\hline Findings & & Detail & Reference \\
\hline \multirow[t]{19}{*}{ Adoption } & \multirow[t]{11}{*}{$\begin{array}{l}\text { Positive } \\
\text { Impact }\end{array}$} & Age, Youth & $\begin{array}{l}\text { Spurlock et al. (2019), Nazari et al. } \\
\text { (2019a) }\end{array}$ \\
\hline & & Age, Adults and seniors & Spurlock et al. (2019) \\
\hline & & $\begin{array}{l}\text { Employment type, Full-time and } \\
\text { self-employed }\end{array}$ & Nazari et al. (2019a) \\
\hline & & $\begin{array}{l}\text { HH income, Medium to high level } \\
\text { (75-200K) }\end{array}$ & Spurlock et al. (2019) \\
\hline & & $\begin{array}{l}\text { HH income, High level (more than } \\
200 \mathrm{~K})\end{array}$ & $\begin{array}{l}\text { Shabanpour et al. (2018b), Spurlock } \\
\text { et al. (2019), Nazari et al. (2019a) }\end{array}$ \\
\hline & & Number of vehicles purchased new & Nazari et al. (2019a) \\
\hline & & Vehicles leased & Nazari et al. (2019a) \\
\hline & & Heard of Internet of things & Shabanpour et al. (2018b) \\
\hline & & Frequent long-distance traveler & Shabanpour et al. (2018b) \\
\hline & & Parking cost & $\begin{array}{l}\text { Shabanpour et al. (2018b), Nazari et } \\
\text { al. (2019a) }\end{array}$ \\
\hline & & $\begin{array}{l}\text { Involvement in future vehicle } \\
\text { decisions, Sole decision maker }\end{array}$ & Nazari et al. (2019a) \\
\hline & \multirow{8}{*}{$\begin{array}{l}\text { Negative } \\
\text { Impact }\end{array}$} & Age, Seniors & Shabanpour et al. (2018b) \\
\hline & & Gender, Female & $\begin{array}{l}\text { Spurlock et al. (2019), Nazari et al. } \\
\text { (2019a) }\end{array}$ \\
\hline & & $\begin{array}{l}\text { HH income, Low level (less than } \\
75 \mathrm{~K})\end{array}$ & Nazari et al. (2019a) \\
\hline & & Find AVs stressful & Shabanpour et al. (2018b) \\
\hline & & Safety concern & Nazari et al. (2019a) \\
\hline & & Accident experiences & Spurlock et al. (2019) \\
\hline & & $\begin{array}{l}\text { Number of vehicles per number of } \\
\text { adults in } \mathrm{HH}\end{array}$ & Nazari et al. (2019a) \\
\hline & & $\begin{array}{l}\text { Involvement in future vehicle } \\
\text { decisions, Shared equally with other }\end{array}$ & Nazari et al. (2019a) \\
\hline \multirow[t]{8}{*}{$\begin{array}{l}\text { Early } \\
\text { Adopter }\end{array}$} & \multicolumn{2}{|c|}{ Younger generations } & $\begin{array}{l}\text { Haboucha et al. (2017), Spurlock et } \\
\text { al. (2019) }\end{array}$ \\
\hline & \multicolumn{2}{|c|}{ Men } & Spurlock et al. (2019) \\
\hline & \multicolumn{2}{|c|}{ Higher education level } & $\begin{array}{l}\text { Haboucha et al. (2017), Shabanpour } \\
\text { et al. (2018b) }\end{array}$ \\
\hline & \multicolumn{2}{|c|}{ Higher-income people } & $\begin{array}{l}\text { Shabanpour et al. (2018b), Spurlock } \\
\text { et al. (2019) }\end{array}$ \\
\hline & \multicolumn{2}{|c|}{ Low-to middle-income people } & Spurlock et al. (2019) \\
\hline & \multicolumn{2}{|c|}{ Employment type, Student } & Haboucha et al. (2017) \\
\hline & \multirow{2}{*}{\multicolumn{2}{|c|}{$\begin{array}{l}\text { People with the higher accepted purchase price } \\
\text { Long-distance travelers }\end{array}$}} & Shabanpour et al. (2018b) \\
\hline & & & $\begin{array}{l}\text { Haboucha et al. (2017), Shabanpour } \\
\text { et al. (2018b) }\end{array}$ \\
\hline
\end{tabular}


Table 2, continued

\begin{tabular}{|c|c|c|}
\hline Findings & Detail & Reference \\
\hline \multirow[t]{8}{*}{$\begin{array}{l}\text { Adoption Rate (Market } \\
\text { Penetration) }\end{array}$} & $71.3 \%$ (long range) & $\begin{array}{l}\text { Shabanpour et al. } \\
\text { (2018b) }\end{array}$ \\
\hline & $\begin{array}{l}\text { Close to } 100 \% \text { (by } 2050 \text { if prices decrease at an } \\
\text { annual rate of } 15 \% \text { or } 20 \% \text { ) }\end{array}$ & $\begin{array}{l}\text { Talebian and Mishra } \\
\text { (2018) }\end{array}$ \\
\hline & $\begin{array}{l}24.8 \% \text { (by } 2045 \text {, assumes } 0 \% \text { rise in WTP, } 5 \% \\
\text { drop in tech price) }\end{array}$ & Bansal et al. (2017) \\
\hline & $\begin{array}{l}43.4 \% \text { (by } 2045 \text {, assumes } 0 \% \text { rise in WTP, } 10 \% \\
\text { drop in tech price) }\end{array}$ & \\
\hline & $\begin{array}{l}43.2 \% \text { (by } 2045 \text {, assumes } 5 \% \text { rise in WTP, } 5 \% \\
\text { drop in tech price) }\end{array}$ & \\
\hline & $\begin{array}{l}70.7 \% \text { (by } 2045 \text {, assumes } 5 \% \text { rise in WTP, } 10 \% \\
\text { drop in tech price) }\end{array}$ & \\
\hline & $\begin{array}{l}59.7 \% \text { (by } 2045 \text {, assumes } 10 \% \text { rise in WTP, } 5 \% \\
\text { drop in tech price) }\end{array}$ & \\
\hline & $\begin{array}{l}87.2 \% \text { (by } 2045 \text {, assumes } 10 \% \text { rise in WTP, } 10 \% \\
\text { drop in tech price) }\end{array}$ & \\
\hline \multirow[t]{4}{*}{$\begin{array}{l}\text { Heterogeneity Issue in } \\
\text { Adoption }\end{array}$} & Significantly impact the result & $\begin{array}{l}\text { Shabanpour et al. } \\
(2017,2018 b)\end{array}$ \\
\hline & Cause $54.1 \%$ underestimation or & \\
\hline & $70.8 \%$ overestimation of the adoption & \\
\hline & Substantial heterogeneity & Daziano et al. (2017) \\
\hline
\end{tabular}

\subsubsection{Willingness to Pay}

Schoettle and Sivak (2014) reported that $25 \%$ of respondents were willing to pay at least \$2,000, and $10 \%$ would be willing to pay at least $\$ 5,800$ for AVs. However, the majority of respondents $(54.5 \%)$ said they would not be willing to pay extra for AV technology (level 4).

Bansal and Kockelman (2017) studied WTP for a different level of automation. It is evident that the majority ( $56.7 \%$ on average) of the respondents were willing to pay less than $\$ 100$ for partial automation features (level 2). 58.7\% of respondents also do not want to pay anything for full automation (level 4). For full automation, $14.4 \%$ willing to pay less than $\$ 6,000,10.3 \%$ willing to pay $\$ 6,000-13,999,9.3 \%$ willing to pay $\$ 14,000-25,999$, and $7.3 \%$ willing to pay more than $\$ 26,000$.

Bansal et al. (2016) reported that $48 \%$ and $38 \%$ of respondents were willing to pay less than $\$ 2,000$ for partial automation (level 3) and full automation (level 4), respectively. Interestingly, $41 \%$ of respondent were willing to use SAV more than at least once a week or entirely if they charge $\$ 1 /$ mile. This adoption reduced to only $4 \%$ if they charge $\$ 3 /$ mile.

Daziano et al. (2017) found substantial heterogeneity in preferences for automation and estimated that the average household is willing to pay a significant amount for automation: $\$ 3,500$ for partial automation and $\$ 4,900$ for full automation. Table 3 presents a summary of findings focusing on WTP. 
Table 3 Summary of Literature on WTP

\begin{tabular}{|c|c|c|c|c|}
\hline & Findings & Detail & Respondents & Reference \\
\hline \multirow[t]{15}{*}{ WTP } & Partial & $\$ 100$ or less & $56.7 \%$ & Bansal et al. (2017) \\
\hline & Automation & $\$ 2,000$ or less & $48 \%$ & \\
\hline & & $\begin{array}{l}\$ 3,500 \text { estimated for } \\
\text { average } \mathrm{HH}\end{array}$ & NA & Daziano et al. (2017) \\
\hline & $\begin{array}{l}\text { Full } \\
\text { Automation }\end{array}$ & $\$ 0$ & $54.5 \%, 58.7 \%$ & $\begin{array}{l}\text { Schoettle and Sivak (2014) } \\
\text { Bansal et al. (2017) }\end{array}$ \\
\hline & & $\$ 2,000$ & $25 \%$ & Schoettle and Sivak (2014) \\
\hline & & $\$ 2,000$ or less & $38 \%$ & Bansal et al. (2016) \\
\hline & & $\begin{array}{l}\$ 4,900 \text { estimated for } \\
\text { average } \mathrm{HH}\end{array}$ & NA & Daziano et al. (2017) \\
\hline & & $\$ 5,800$ & $10 \%$ & Schoettle and Sivak (2014) \\
\hline & & $\$ 6,000$ or less & $14.4 \%$ & Bansal et al. (2017) \\
\hline & & $\$ 6,000-13,999$ & $10.3 \%$ & \\
\hline & & $\$ 14,000-25,999$ & $9.3 \%$ & \\
\hline & & $\$ 26,000$ or more & $7.3 \%$ & \\
\hline & $\begin{array}{l}\text { Shared AV } \\
\text { SAV }\end{array}$ & $\begin{array}{l}\$ 1 / \text { mile (at least once a } \\
\text { week or entirely) }\end{array}$ & $41 \%$ & Bansal et al. (2016) \\
\hline & & $\begin{array}{l}\$ 2 / \text { mile (at least once a } \\
\text { week or entirely) }\end{array}$ & $15 \%$ & \\
\hline & & $\begin{array}{l}\$ 3 / \text { mile (at least once a } \\
\text { week or entirely) }\end{array}$ & $4 \%$ & \\
\hline
\end{tabular}

\subsubsection{Mode Choice}

Haboucha et al. (2017) presented individuals with various scenarios and asked them to choose the car they would use for their commute based on the characteristics of their current commutes. A vehicle choice model which includes three options is estimated: continue use a regular car; buy and shift to a privately-owned AV, or shift to SAV. Five latent variables were identified based on factor analysis: technology interest, environmental concern, enjoy driving, public transit attitude, and pro-AV sentiments. Only three of these factors played a significant role in estimating the choice decision: enjoy driving, environmental concern, and pro-AV attitude. The effects of the attitudinal variables were very significant and could be influenced by educational campaigns.

Shabanpour et al. (2017) asked respondents to choose the most preferable vehicle option to purchase among the four described alternatives: non-automated gasoline vehicle, non-automated electric vehicle, automated gasoline vehicle, and automated electric vehicle. Young adults, welleducated and tech-savvy respondents, those with high annual VMT and those who have longdistance work trips, are found to be more willing to choose automated and electric automated options. Table 4 presents a summary of findings focusing on mode choice. 
Table 4 Summary of Literature on Mode Choice

\begin{tabular}{|c|c|c|c|}
\hline Findings & & Detail & Reference \\
\hline \multirow{10}{*}{$\begin{array}{l}\text { Regular } \\
\text { Cars }\end{array}$} & Positive Impact & Escorting trip & Haboucha et al. (2017) \\
\hline & & Age, Seniors & Shabanpour et al. (2017) \\
\hline & & Licensed drivers & \\
\hline & & Enjoy driving & Haboucha et al. (2017) \\
\hline & & Do not telecommute & Shabanpour et al. (2017) \\
\hline & Negative Impact & Education & \\
\hline & & Experienced accidents & \\
\hline & & Residential location, downtown & \\
\hline & & $\begin{array}{l}\text { Residential location, suburban } \\
\text { (work in the city) }\end{array}$ & \\
\hline & & Parking price & Haboucha et al. (2017) \\
\hline \multirow[t]{11}{*}{ PAVs } & Positive Impact & Distance traveled (Travel time) & Haboucha et al. (2017), \\
\hline & & Pro-AV attitude & Shabanpour et al. (2017) \\
\hline & & Experienced accidents & \\
\hline & & Trip cost (If trip cost PAV $<$ & \\
\hline & & Regular car) & \\
\hline & & $\mathrm{HH}$ income & \\
\hline & & Education & \\
\hline & Negative Impact & $\begin{array}{l}\text { Purchase price (If Purchase } \\
\text { price }>\text { regular car) }\end{array}$ & \\
\hline & & Trip cost (If trip cost PAV > & \\
\hline & & Regular car) & \\
\hline & & Age, seniors & Haboucha et al. (2017) \\
\hline \multirow[t]{9}{*}{ SAVs } & Positive Impact & Distance traveled (Travel time) & \\
\hline & & Pro-AV attitude & \\
\hline & & Environmental concern & \\
\hline & Negative Impact & Subscription cost & \\
\hline & & Age, seniors & \\
\hline & & Commute frequency & \\
\hline & & Number of young children in & \\
\hline & & $\mathrm{HH}$ & \\
\hline & & Trip cost (If trip cost SAV $<$ & \\
\hline
\end{tabular}

\subsubsection{Benefits and Concerns}

Table 5 presents a summary of findings focusing on benefits and concerns. Schoettle and Sivak (2014) found that respondents were more likely to be concerned about: legal liability for drivers/owners, data privacy (location and destination tracking), interacting with non-selfdriving vehicles, system performance in poor weather, and self-driving vehicles not driving as well as human drivers in general. Females expressed higher levels of concern with self-driving vehicles than did males. Similarly, females were more cautious about their expectations concerning the benefits of using self-driving vehicles.

Shabanpour et al. (2018a) presented a new approach for modeling the adoption behavior of fully AVs using the profile-case best-worst scaling model. In this approach, an AV profile that is 
characterized in terms of the main vehicle attributes and their associated levels is presented to the decision-maker and he/she is asked to select the most and the least attractive attributes. Results indicate that more productive use of time in the vehicle and less stressful driving experience are the most expected benefits of driverless vehicles, and the high anticipated price of $\mathrm{AVs}$ and disclosure of personal information are the most expected downsides of AVs.

Table 5 Summary of Literature on Benefit and Concerns

\begin{tabular}{|c|c|c|c|}
\hline Findings & Detail & $\begin{array}{c}\text { Moderately or } \\
\text { completely agree }\end{array}$ & Reference \\
\hline \multirow[t]{11}{*}{ Benefit } & $\begin{array}{l}\text { Improved emergency } \\
\text { response to crashes }\end{array}$ & $71 \%$ & Schoettle and Sivak (2014) \\
\hline & Reduced severity of crashes & $69 \%$ & \\
\hline & Fuel efficiency & $69 \%-93 \%$ & Schoettle and Sivak (2014), Shabanpour et al. \\
\hline & Fewer crashes & $67 \%-83 \%$ & (2018a), Bansal et al. (2016), Shabanpour et \\
\hline & Lower vehicle emissions & $57 \%-88 \%$ & al. (2017) \\
\hline & Lower insurance rates & $53 \%-77 \%$ & $\begin{array}{l}\text { Schoettle and Sivak (2014), Shabanpour et al. } \\
\text { (2018a) }\end{array}$ \\
\hline & Less traffic congestion & $49 \%-77 \%$ & $\begin{array}{l}\text { Schoettle and Sivak (2014), Shabanpour et al. } \\
\text { (2018a), Bansal et al. (2016) }\end{array}$ \\
\hline & Shorter travel time & $46 \%$ & Schoettle and Sivak (2014) \\
\hline & No parking demand & $55 \%-78 \%$ & $\begin{array}{l}\text { Shabanpour et al. (2018a), Shabanpour et al. } \\
\text { (2017) }\end{array}$ \\
\hline & $\begin{array}{l}\text { Less stressful driving } \\
\text { experience }\end{array}$ & $75 \%$ & Shabanpour et al. (2018a) \\
\hline & Multitasking & $46 \%-77 \%$ & Shabanpour et al. (2018a), Bansal et al. (2016) \\
\hline \multirow[t]{10}{*}{ Concern } & $\begin{array}{l}\text { Riding in a vehicle with no } \\
\text { driver controls available }\end{array}$ & $86 \%$ & Schoettle and Sivak (2014) \\
\hline & High Price & $73 \%-85 \%$ & $\begin{array}{l}\text { Shabanpour et al. (2018a), Bansal et al. } \\
\text { (2016), Shabanpour et al. (2017) }\end{array}$ \\
\hline & $\begin{array}{l}\text { Commercial vehicles heavy } \\
\text { trucks that are self-driving }\end{array}$ & $83 \%$ & Schoettle and Sivak (2014) \\
\hline & $\begin{array}{l}\text { AVs getting confused by } \\
\text { unexpected situations }\end{array}$ & $82 \%-85 \%$ & $\begin{array}{l}\text { Schoettle and Sivak (2014), Shabanpour et al. } \\
\text { (2018a) }\end{array}$ \\
\hline & $\begin{array}{l}\text { Safety consequences of } \\
\text { equipment/system failure }\end{array}$ & $41 \%-91 \%$ & $\begin{array}{l}\text { Schoettle and Sivak (2014), Shabanpour et al. } \\
\text { (2018a), Bansal et al. (2016), Zmud et al. } \\
\text { (2016) Shabanpour et al. (2017) }\end{array}$ \\
\hline & $\begin{array}{l}\text { Public transportation such as } \\
\text { buses that are self-driving }\end{array}$ & $78 \%$ & Schoettle and Sivak (2014) \\
\hline & $\begin{array}{l}\text { Legal liability for } \\
\text { drivers/owners }\end{array}$ & $68 \%-78 \%$ & $\begin{array}{l}\text { Schoettle and Sivak (2014), Shabanpour et al. } \\
\text { (2018a), Bansal et al. (2016) }\end{array}$ \\
\hline & Taxis that are self-driving & $77 \%$ & Schoettle and Sivak (2014) \\
\hline & $\begin{array}{l}\text { Interacting with non-self- } \\
\text { driving vehicles }\end{array}$ & $76 \%-88 \%$ & $\begin{array}{l}\text { Schoettle and Sivak (2014), Shabanpour et al. } \\
\text { (2018a), Bansal et al. (2016) Shabanpour et al. } \\
\text { (2017) }\end{array}$ \\
\hline & $\begin{array}{l}\text { Interacting with pedestrians } \\
\text { and bicyclists }\end{array}$ & $75 \%-78 \%$ & $\begin{array}{l}\text { Schoettle and Sivak (2014), Shabanpour et al. } \\
\text { (2018a) }\end{array}$ \\
\hline
\end{tabular}


Table 5, continued

\begin{tabular}{llll}
\hline Findings & Detail & $\begin{array}{l}\text { Moderately or } \\
\text { completely } \\
\text { agree }\end{array}$ & Reference \\
\hline Concern & $\begin{array}{l}\text { System performance in } \\
\text { poor weather }\end{array}$ & $73 \%$ & Schoettle and Sivak (2014) \\
& $\begin{array}{l}\text { AVs not driving as well as } \\
\text { human drivers in general } \\
\text { AVs moving while }\end{array}$ & $73 \%$ & \\
$\begin{array}{l}\text { unoccupied } \\
\text { System security from } \\
\text { hackers }\end{array}$ & $73 \%$ & \\
$\begin{array}{l}\text { Vehicle security from } \\
\text { hackers }\end{array}$ & $71 \%-74 \%$ & $\begin{array}{l}\text { Schoettle and Sivak (2014), Bansal et al. } \\
\text { (2016) }\end{array}$ \\
Data privacy & $68 \%-82 \%$ & $\begin{array}{l}\text { Schoettle and Sivak (2014), Shabanpour } \\
\text { et al. (2018a), Bansal et al. (2016), } \\
\text { Shabanpour et al. (2017) } \\
\text { Schoettle and Sivak (2014), Bansal et al. } \\
\text { (2017), Shabanpour et al. (2018a), } \\
\text { Bansal et al. (2016) }\end{array}$ \\
\hline & & $7 \%-60 \%$ &
\end{tabular}

Bansal et al. (2016) stated that respondents believe fewer crashes to be AVs' biggest or most likely benefit, and less congestion to be the least likely benefit. Multitasking was reported among likely benefits, and the top two activity picks while riding in an AV are looking out the window and talking with friends. Sleep and working are reported as the least popular activity for multitasking.

\subsubsection{Perception of Technology and Operations}

Based on Howard and Dai (2014), 46\% of respondents believe that self-driving cars should operate with normal traffic, $38 \%$ agree with separate lanes, and $11 \%$ had no opinion. To build infrastructure for self-driving cars, $43 \%$ of the participants were neutral, $35 \%$ agreed, and $22 \%$ opposed the option. Schoettle and Sivak (2014) examined public opinion regarding self-drivingvehicle technology. $70.9 \%$ of respondents had previously heard of autonomous or self-driving vehicles, and $56.3 \%$ had a positive initial opinion of the technology and had high expectations about the benefits of the technology.

Bansal et al. (2016) found that as the public learns more about AVs and more technological experiences start spilling into the public domain, the perceptions and potential behavioral responses are apt to change. For example, a large proportion (more than 50\%) of individuals who do not want to pay anything for advanced automation technologies may change their perspectives as the technology becomes proven and they see their neighbors, friends, and coworkers adopt AVs, with great success. Alternatively, a well-publicized catastrophe (such as a multi-vehicle, multi-fatality cyber-attack) could set adoption rates back years. 
Bansal and Kockelman (2017) revealed that $47 \%$ of respondents have heard about AVs and only $7 \%$ of respondents were apprehensive about learning to use AVs.

Table 6 presents a summary of findings focusing on the perception of technology and operations.

Table 6 Summary of Literature on Perception of Technology and Operations

\begin{tabular}{|c|c|c|c|}
\hline Findings & $\begin{array}{c}\text { Detail } \\
\end{array}$ & Respondent & Reference \\
\hline Perception of & AVs operate with normal traffic & $46 \%$ & Howard and Dai (2014) \\
\hline \multirow[t]{3}{*}{ Operation } & AVs operate in separate lanes & $38 \%$ & \\
\hline & New infrastructure needed, Agreed & $35 \%$ & \\
\hline & New infrastructure needed, Opposed & $22 \%$ & \\
\hline \multirow[t]{7}{*}{$\begin{array}{l}\text { Perception of } \\
\text { Technology }\end{array}$} & Heard of AVs & $\begin{array}{l}70.9 \%, 53 \%, \\
47 \%\end{array}$ & $\begin{array}{l}\text { Schoettle and Sivak (2014), } \\
\text { Bansal et al. (2016), Bansal et al. } \\
\text { (2017) }\end{array}$ \\
\hline & $\begin{array}{l}\text { Apprehensive about learning to use } \\
\text { AVs }\end{array}$ & $7 \%$ & Bansal et al. (2017) \\
\hline & $\begin{array}{l}\text { The positive initial opinion of the } \\
\text { technology }\end{array}$ & $56.3 \%$ & Schoettle and Sivak (2014) \\
\hline & Lack of trust in technology & $41 \%$ & Zmud et al. (2016) \\
\hline & $\begin{array}{l}\text { As the public learns more, the } \\
\text { perceptions of technology change }\end{array}$ & NA & Bansal et al. (2016) \\
\hline & $\begin{array}{l}\text { The decision of not adopting AVs } \\
\text { changes as technology becomes } \\
\text { proven }\end{array}$ & $50 \%$ & \\
\hline & $\begin{array}{l}\text { A well-publicized catastrophe will } \\
\text { reduce adoption }\end{array}$ & NA & \\
\hline
\end{tabular}

\subsection{Impact of AVs}

This section will discuss literature focusing on the impact of AVs.

\subsubsection{Travel Demand}

Childress et al. (2015) used Seattle, Washington, region's activity-based travel model to test a range of travel behavior impacts from AV technology development. The existing activity-based model was not originally designed with AVs in mind so some modifications to the model assumptions are described in areas of roadway capacity, user values of time, and parking costs. To model potential impacts of AVs in the Puget Sound region, four scenarios are considered. Results show that improvements in roadway capacity and in the quality of the driving trip may lead to large increases in VMT, while a shift to per-mile usage charges may counteract that trend.

Zmud et al. (2016) used the Capital Area Metropolitan Planning Organization (CAMPO) 2010 travel-demand forecasting model. The model is founded on a trip-based approach which uses individual trips as the unit of analysis and applies the traditional four-step process. Assuming that the travel time will be less onerous with the introduction of automation, different scenarios were tested. The result did not reveal a significant change in terms of VMT. 
Perrine et al. (2020) used the journey demand model, including records of 1.17 billion longdistance trips to investigate inter-regional travel and how long-distance destination and mode choices will change, assuming an increase of AVs. The result showed an increase in VMT for all trip purposes.

Nadafian et al. (2019) used an integrated travel demand and land-use modeling system to evaluate how AVs may affect congestion, travel demand and land use. The findings demonstrated significant reductions in traffic congestion, an increase in VMT, toxic, and greenhouse gas emissions. It also found that AVs may shift population and employment growth to more suburban and fringe areas. While congestion is decreased on average with the introduction of AVs, some roadways will become more congested. The study concluded that the change in development patterns alters traffic patterns and can increase travel demand enough in some areas to offset increases in roadway capacity.

Xu et al. (2019) assessed the impact of AVs on network performance by applying the ABM-DTA integration framework, which established an activity-based equilibrium state model. The results showed an increase in VMT and VHT, which leads to severe congestion in the evening peak hour.

Cohn et al. (2019) presented a regional travel demand model to quantify how transportation outcomes may differ for disadvantaged populations in the Washington, D.C., area under a variety of future scenarios considering AVs. The model evaluated changes in indicators for disadvantaged and non-disadvantaged communities under scenarios which AVs were primarily single-occupancy or high-occupancy and according to whether transit agencies responded to AVs by maintaining the status quo, removing low-performing routes, or applying AV technology to transit vehicles. The result showed that VMT increased across all AV scenarios, compared with the future baseline. VMT was significantly higher in EEAs than NEEAs for all scenarios, indicating greater exposure and risk for persons living in EEAs.

Table 7 presents a summary of findings focusing on travel demand. 


\begin{tabular}{|c|c|c|c|c|c|c|c|c|}
\hline \multirow{2}{*}{$\begin{array}{l}\text { Scenario } \\
\text { (increase/decrease) }\end{array}$} & \multicolumn{7}{|c|}{ Change from the base condition } & \multirow{2}{*}{$\begin{array}{l}\text { च } \\
0 \\
0 \\
0 \\
0 \\
0 \\
0 \\
0\end{array}$} \\
\hline & 岁 & 㞼 & 㿣. & 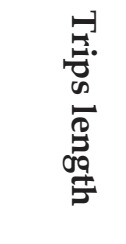 & 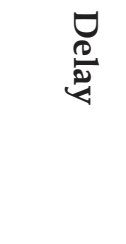 & $\begin{array}{l}\infty \\
\substack{\infty \\
0} \\
2\end{array}$ & 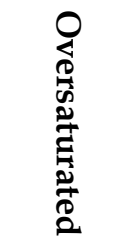 & \\
\hline Capacity (+30\%) & $3.6 \%$ & $-3.9 \%$ & $2.4 \%$ & $1.4 \%$ & $-17.3 \%$ & $7.5 \%$ & NA & \multirow{4}{*}{$\begin{array}{l}\text { Child } \\
\text { ress et } \\
\text { al. } \\
(2015)\end{array}$} \\
\hline $\begin{array}{l}\text { Capacity }(+30 \%) \\
\text { VOTT }(-65 \%) \text { for highest income } \\
\text { HH }\end{array}$ & $5.0 \%$ & $-2.1 \%$ & $2.4 \%$ & $4.3 \%$ & $-14.0 \%$ & $7.2 \%$ & NA & \\
\hline $\begin{array}{l}\text { Capacity }(+30 \%) . \\
\text { VOTT for all HH }(-65 \%) \\
\text { Parking cost }(-50 \%)\end{array}$ & $19.6 \%$ & $17.3 \%$ & $4.9 \%$ & $14.5 \%$ & $17.7 \%$ & $1.8 \%$ & NA & \\
\hline $\begin{array}{l}\text { 100\% SAV Adoption } \\
\text { Cost: } \$ 1.65 / \mathrm{mi} \\
\text { No AV ownership } \\
\text { Capacity ( } \% \text { ) (To reflect a worst- } \\
\text { case) }\end{array}$ & $-35.4 \%$ & $-40.9 \%$ & $0.0 \%$ & $-15.9 \%$ & $-58.6 \%$ & $9.0 \%$ & NA & \\
\hline VOTT (-25\%) & $0.1 \%$ & NA & NA & NA & NA & NA & NA & \multirow{4}{*}{$\begin{array}{c}\text { Zmud } \\
\text { et al. } \\
\text { (2016) } \\
\text { Nadaf } \\
\text { ian et } \\
\text { al. } \\
(2019)\end{array}$} \\
\hline VOTT $(-75 \%)$ & $0.0 \%$ & NA & NA & NA & NA & NA & NA & \\
\hline $\begin{array}{l}\text { Capacity }(+100 \%) \\
\text { VOTT }(-60 \%) \\
\text { Intersection delay }(-100 \%)\end{array}$ & $11.9 \%$ & NA & NA & 11.4 & NA & $101.9 \%$ & $-87.3 \%$ & \\
\hline $\begin{array}{l}\text { Capacity }(+60 \%) \\
\text { VOTT }(-40 \%) \\
\text { Intersection delay }(-60 \%)\end{array}$ & $10.8 \%$ & NA & NA & $10.2 \%$ & NA & $76.6 \%$ & $-73.2 \%$ & \\
\hline $\begin{array}{l}\text { Capacity }(+30 \%) \\
\text { VOTT }(-20 \%) \\
\text { Intersection delay }(-30 \%)\end{array}$ & $8.5 \%$ & NA & NA & $7.8 \%$ & NA & 41.0 & $-50.0 \%$ & \\
\hline $100 \% \mathrm{AV}$ adoption & $22.6 \%$ & $22.0 \%$ & $27.4 \%$ & NA & NA & NA & NA & \multirow{2}{*}{$\begin{array}{c}\text { Xu et } \\
\text { al. } \\
(2019)\end{array}$} \\
\hline VOTT $(-50 \%)$ & $24.1 \%$ & $23.7 \%$ & $30.9 \%$ & NA & NA & NA & NA & \\
\hline $\begin{array}{l}\text { AV adoption with single } \\
\text { occupancy } \\
100 \% \text { adoption rate }\end{array}$ & $66.0 \%$ & $-15.0 \%$ & NA & NA & NA & NA & NA & \multirow[t]{6}{*}{$\begin{array}{l}\text { Cohn } \\
\text { et al. } \\
(2019)\end{array}$} \\
\hline $\begin{array}{l}\text { AV adoption with HOV incentive } \\
100 \% \text { adoption rate }\end{array}$ & $49.0 \%$ & $-28.0 \%$ & NA & NA & NA & NA & NA & \\
\hline $\begin{array}{l}\text { AV adoption with single } \\
\text { occupancy } \\
100 \% \text { adoption rate } \\
\text { Limited transit }\end{array}$ & $66.0 \%$ & $-15.0 \%$ & NA & NA & NA & NA & NA & \\
\hline $\begin{array}{l}\text { AV adoption with HOV incentive } \\
100 \% \text { adoption rate } \\
\text { Limited transit }\end{array}$ & $49.0 \%$ & $-27.0 \%$ & NA & NA & NA & NA & NA & \\
\hline $\begin{array}{l}\text { AV adoption with single } \\
\text { occupancy } \\
100 \% \text { adoption rate } \\
\text { Enhanced transit }\end{array}$ & $63.0 \%$ & $-18.0 \%$ & NA & NA & NA & NA & NA & \\
\hline $\begin{array}{l}\text { AV adoption with HOV incentive } \\
100 \% \text { adoption rate } \\
\text { Enhanced transit }\end{array}$ & $46.0 \%$ & $-30.0 \%$ & NA & NA & NA & NA & NA & \\
\hline
\end{tabular}


Table 7, continued

\begin{tabular}{|c|c|c|c|c|c|c|c|c|}
\hline \multirow{2}{*}{$\begin{array}{l}\text { Scenario } \\
\text { (increase/decrease) }\end{array}$} & \multicolumn{7}{|c|}{ Change from the base condition } & \multirow{2}{*}{$\begin{array}{l}20 \\
0 \\
0 \\
0 \\
0 \\
0 \\
0\end{array}$} \\
\hline & $\sum_{3}$ & 志 & 孛. & 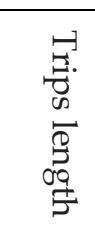 & 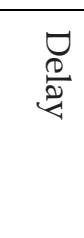 & $\begin{array}{l}\infty \\
\mathbb{D} \\
\mathbb{D} \\
2\end{array}$ & 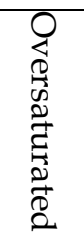 & \\
\hline $\begin{array}{l}\text { AV adoption } \\
51 \% \text { adoption rate } \\
\text { All trip propose }\end{array}$ & $9.7 \%$ & NA & NA & NA & NA & NA & NA & $\begin{array}{c}\text { Perrin } \\
\text { e et } \\
\text { al }\end{array}$ \\
\hline $\begin{array}{l}\text { AV adoption } \\
51 \% \text { adoption rate } \\
\text { Operating cost } \$ 0.1 / \text { mile } \\
(-50 \%) \\
\text { Leisure trip }\end{array}$ & $5.4 \%$ & NA & NA & NA & NA & NA & NA & $(2020)$ \\
\hline $\begin{array}{l}\text { AV adoption } \\
51 \% \text { adoption rate } \\
\text { Operating cost } \$ 0.5 / \text { mile }(250 \%) \\
\text { Leisure trip }\end{array}$ & $10.2 \%$ & NA & NA & NA & NA & NA & NA & \\
\hline $\begin{array}{l}\text { AV adoption, } \\
51 \% \text { adoption rate } \\
\text { VOTT (-50\%) } \\
\text { Leisure trip }\end{array}$ & $5.7 \%$ & NA & NA & NA & NA & NA & NA & \\
\hline $\begin{array}{l}\text { AV adoption } \\
51 \% \text { adoption rate } \\
\text { VOTT }(150 \%) \\
\text { Leisure trip }\end{array}$ & $8.2 \%$ & NA & NA & NA & NA & NA & NA & \\
\hline $\begin{array}{l}\text { SAV adoption } \\
51 \% \text { adoption rate } \\
\text { Operating cost } \$ 1.65 / \text { mile }\end{array}$ & $10.6 \%$ & NA & NA & NA & NA & NA & NA & \\
\hline
\end{tabular}

\subsubsection{Traffic Operation}

Rahmati and Talebpour (2017) developed a game theory-based framework to characterize driver behavior in unprotected left turn maneuvers in a connected, automated driving environment. A two-person nonzero-sum non-cooperative game under complete information is selected to model the underlying decision-making. The results indicated that this framework could effectively capture vehicle interactions when performing conflicting turning movements while achieving relatively high accuracy in predicting vehicles' real choice.

Rahman et al. (2019) investigated the safety impact of CAVs and CAVs with a lower level of automation features under vehicle-to-vehicle (V2V) and infrastructure-to-vehicle (I2V) communication technologies. A logistic regression model was also developed to quantify the crash risk in terms of observed conflicts obtained in the intersection influence areas. The results indicated a significant safety improvement resulting from implementing CAVs technologies at both segments and intersections on arterials. 


\subsection{Summary of Findings}

Table 8 presents the classification of reviewed studies based on their detailed approaches.

Table 8 Classification of Studies by Detailed Approach

\begin{tabular}{|c|c|c|c|c|c|c|c|}
\hline \multirow[t]{2}{*}{ Study } & \multicolumn{5}{|c|}{ Perception toward AVs } & \multicolumn{2}{|c|}{ Impact from AVs } \\
\hline & Adoption & WTP & $\begin{array}{l}\text { Mode } \\
\text { Choice }\end{array}$ & $\begin{array}{l}\text { Benefits/ } \\
\text { Concerns }\end{array}$ & Perception & $\begin{array}{c}\text { Travel } \\
\text { Demand }\end{array}$ & $\begin{array}{c}\text { Traffic } \\
\text { Operation }\end{array}$ \\
\hline Howard and Dai (2014) & & & & & - & & \\
\hline Schoettle and Sivak (2014) & & घ & & - & घ & & \\
\hline Childress et al. (2015) & & & & & & घ & \\
\hline Bansal et al. (2016) & & घ & & - & घ & & \\
\hline Bansal et al. (2017) & & घ & & & घ & & \\
\hline Zmud et al. (2016) & & & & - & & - & \\
\hline Daziano et al. (2017) & & - & & & & & \\
\hline Haboucha et al. (2017) & & & घ & & & & \\
\hline Shabanpour et al. (2017) & & & - & - & & & \\
\hline Rahmati et al. (2017) & & & & & & & - \\
\hline Sanbonmatsu et al. (2018) & & & & & घ & & \\
\hline Shabanpour et al. (2018a) & & & & - & & & \\
\hline Talebian and Mishra (2018) & - & & & & & & \\
\hline Perrine et al. (2020) & & & & & & - & \\
\hline Shabanpour et al. (2018b) & - & & & & & & \\
\hline Nazari et al. (2018) & & & & & & & \\
\hline Spurlock et al. (2019) & घ & & & & & & \\
\hline Nadafian et al. (2019) & & & & & & - & \\
\hline Nazari et al. (2019a) & घ & & & & & & \\
\hline Rahman et al. (2019) & & & & & & & - \\
\hline Xu et al. (2019) & & & & & & - & \\
\hline Cohn et al. (2019) & & & & & & घ & \\
\hline
\end{tabular}

For studies focusing on perception toward AVs, the study topic is transforming from analysis of public attitudes (Howard and Dai, 2014; Schoettle and Sivak, 2014; Bansal et al., 2016) to more advanced analysis of cognitive underpinnings of consumers' beliefs (Sanbonmatsu et al., 2018), capturing heterogeneity (Daziano et al., 2017; Shabanpour et al., 2018b), and analyzing endogeneity in survey data (Nazari et al., 2019a). The methodology applied also transformed from descriptive statistics (Howard and Dai, 2014; Schoettle and Sivak, 2014) to more advanced frameworks, including confirmatory factor analysis, logit kernel model with panel effect (Haboucha et al., 2017), random parameter logit model (Shabanpour et al., 2017) and innovation diffusion model (Shabanpour et al., 2018b).

For impacts of AVs, the study topics mostly focused on network performance measures like VMT, VHT, congestion, etc. (Nadafian et al., 2019; Xu et al., 2019; Cohn et al., 2019); and investigating traffic operation in the era of AVs (Rahmati et al., 2017; Rahman et al., 2019). The methodology is evolving from a four-step demand model (Zmud et al., 2016) to a more advanced multi-modal activity-based model (Xu et al., 2019) and integrated land use and demand model (Nadafian et al., 2019). 
Based on the review of the existing literature, a few knowledge gaps can be identified. First, although it has been recognized that adoption and perception of AVs are strongly related to users' behavior, behavioral models that comprehensively encompass the internal and external factors that affect a user choice have not been applied. Second, the impact of AVs on minorities like transit users, disabled people, or students need to be addressed due to their specific characteristics and needs. Thirdly, the transferability or geographic applicability of the findings has not been studied. 


\section{SURVEY DATA}

This study used the nationwide stated preference (SP) survey conducted in spring 2017. We focus on the questions that evaluate respondents' attitudes. Removing records with missing values, the total sample for this attitude analysis is 1,198. Four sets of questions were included in the questionnaire, each focused on one unique aspect of user attitudes, including:

- Preferences for lifestyle and mobility options (labeled here as AT1),

- Perceived benefits and concerns of shared mobility option (AT2),

- Reasons toward or against private vehicle ownership (AT3), and

- Motivations for and desired features of automated vehicles (AT4).

Figure 1 shows the responses to general mobility preferences. A majority of the respondents would like to learn about and use new technologies (65.6\%), regularly used smartphones (59.4\%), and considered themselves highly engaged in online activities (60.7\%). Around $48.7 \%$ of the respondents preferred concentrating on one activity at a time, while $43.1 \%$ preferred multitasking on commute trips.

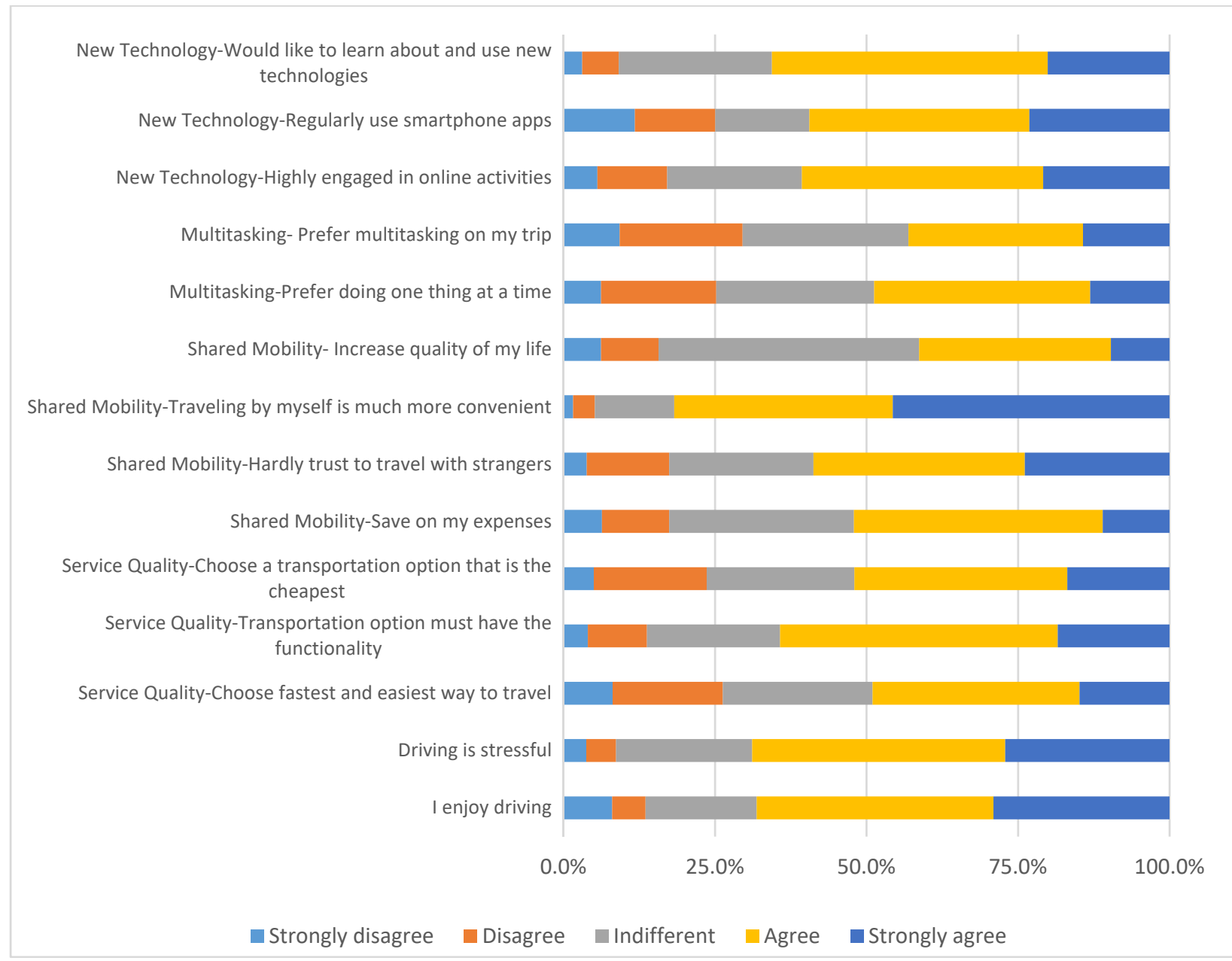

Figure 1 Preferences for lifestyle and mobility options (AT1). 
A significant portion of the sample (81.8\%) preferred to travel alone due to convenience, $41.3 \%$ believed that shared mobility would increase the quality of life, and $52.1 \%$ believe that shared mobility would help save expenses. $58.8 \%$ of individuals expressed severe concerns about traveling with strangers.

The most popular benefits of ridesourcing were found to be cost-effectiveness (56.2\%) and reducing driving stress $(54.0 \%)$ as presented in. Surprisingly, almost half of the respondents ranked multitasking and on-demand service with low priority. The top concerns were reported as higher travel time due to waiting and multiple pickups $(64.8 \%)$, and data privacy $(58.4 \%)$.

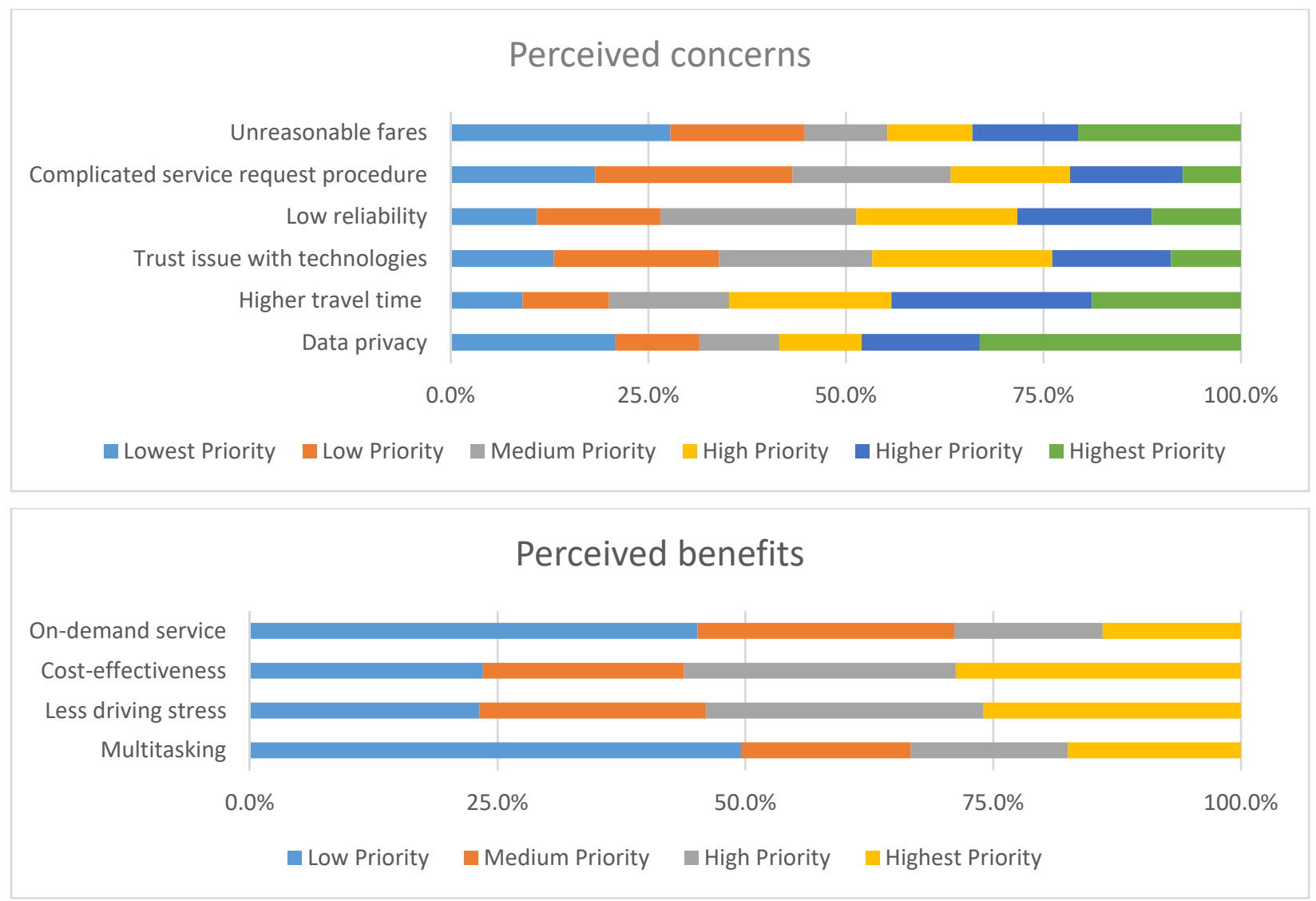

Figure 2 Perceptions of shared mobility (AT2).

Figure 3 shows the reasons for or against private vehicle ownership (AT3). The top reasons for own or lease a vehicle were reported as privacy $(44.2 \%)$, convenience $(20.5 \%)$, car affinity luxury $(15.1 \%)$, the joy of driving $(11.1 \%)$, and lower cost $(9.1 \%)$.

On the other hand, the most important reasons for not owning or leasing a vehicle were ranked as ownership cost/affordability (37.8\%), operational/maintenance cost (22.3\%), short travel distance $(16.5 \%)$, lack of parking space $(13.5 \%)$, and preference for transit, walking or biking $(9.8 \%)$. 

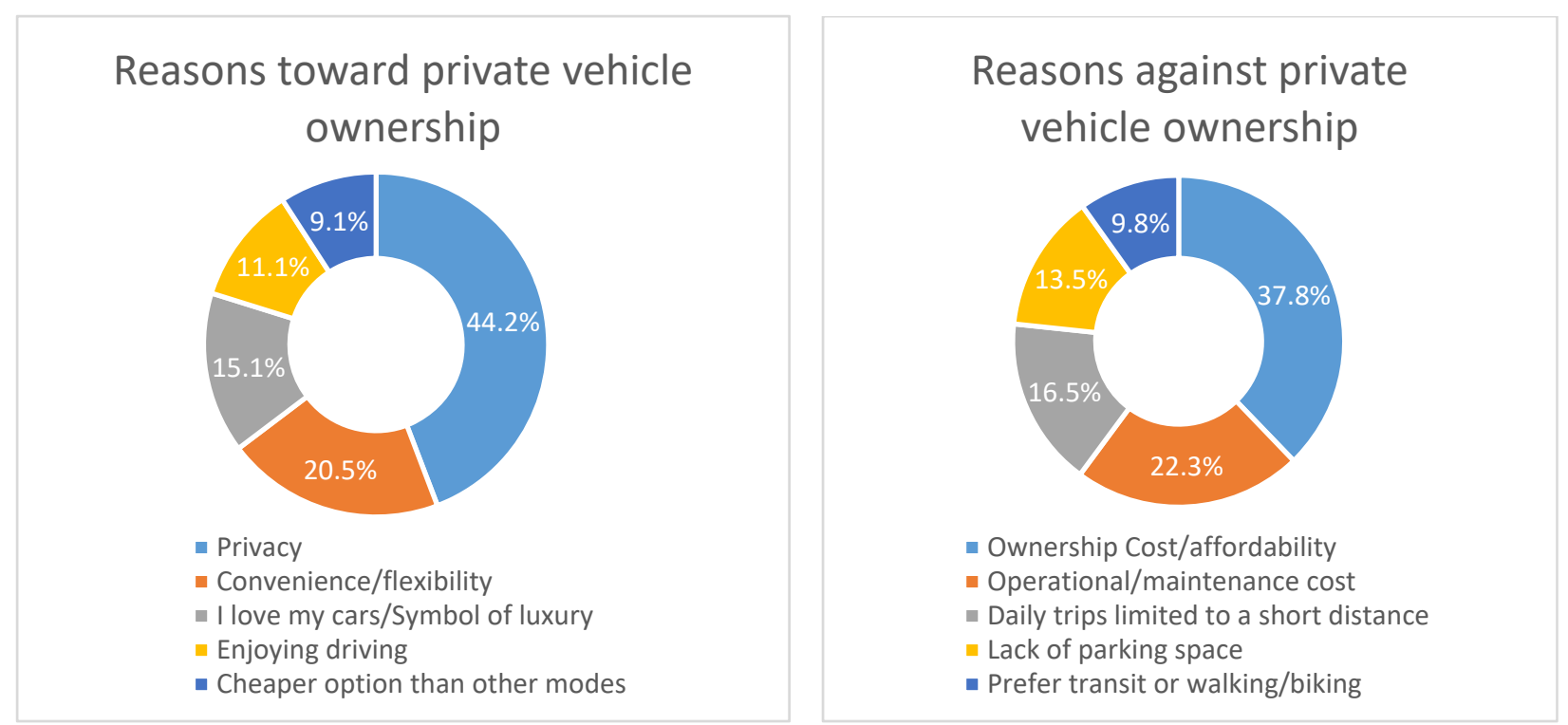

\section{Figure 3 Attitudes toward vehicle ownership (AT3).}

Figure 4 shows the responses on motivations to drive or ride in AVs and the most desired features. It shows that respondents were motivated to adopt AV because of reduced driving stress $(13.3 \%)$, increased road capacity/reduced traffic congestions/reduced delays (10.6\%), mobility for non-drivers $(7.5 \%)$, improved safety $(5.3 \%)$, better technology $(5.0 \%)$, no need for parking (4.5\%), and multitasking (3.1\%). The top desired AV features were reported as self-parking assist (25.6\%), lane-keeping assist (16.4\%), fuel efficiency (16.3\%), avoid collision or reduce the severity of collision $(10.9 \%)$, fully connected $(9.6 \%)$, drive themselves $(9.2 \%)$, adaptive cruise control $(7.9 \%)$, and help with steering $(4.0 \%)$.

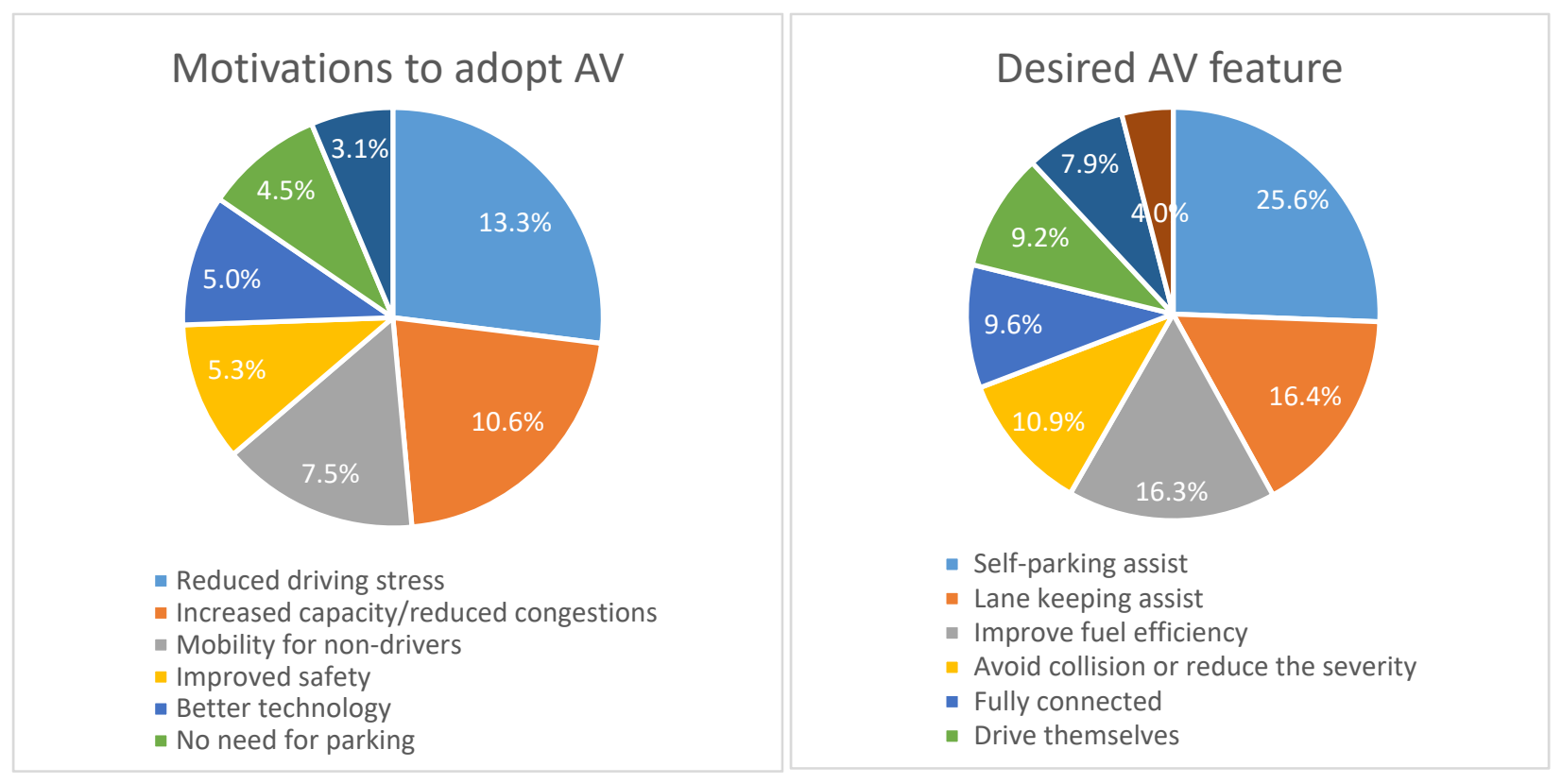

Figure 4 Motivations to adopt AV and desired features (AT4). 


\section{ATTITUDE ANALYSIS}

\subsection{Principal Component Analysis}

PCA is a statistical approach that converts a set of observed correlated variables into a group of linearly uncorrelated variables called factors or principal components using orthogonal transformation (John Lu, 2010). This approach is particularly useful in dealing with attitude questions, as many of the attitudes may be correlated, especially when there is a large number of attitudinal questions. This approach has been widely used for travel behavior application to identify individuals' attitudes using a large number of responses to the SP surveys (Alemi et al., 2018; Azad et al., 2019; Charness et al., 2018; Haboucha et al., 2017; Malokin et al., 2019; Payre et al., 2014; Sharda et al., 2019; von Behren et al., 2018; Mahdinia et al., 2017; Yap et al., 2016; Ye \& Titheridge, 2017; Yen et al.,1994). The next section will elaborate on PCA and the procedure to identify attitudes.

Consider a data matrix $X$ where each of the $N$ rows represents a respondent's opinion, and each of the $p$ columns shows different questions in the SP survey. $X$ can be decomposed as $X=U D V^{T}$ using singular value decomposition transformation where $U$ is an $N \times p$ orthogonal matrix, the columns are the orthonormal basis of the column space of $X . V$ is a $p \times p$ orthogonal matrix and called the principal component directions of $X$. Finally, $D$ is a $p \times p$ diagonal matrix with diagonal entries called the singular values of $X$. The principal components of $X$, as shown with green lines in Figure 5, can be computed as $z_{m}=X v_{m}$. Each principal component $\left(z_{m}\right)$ explains a portion of the variance in data which is calculated as $\operatorname{Var}\left(z_{j}\right)=d_{j}^{2} / N$. In the example illustrated in Figure 5, most of the variance is explained by the first principle component and the data can be described with the first principle component, $z_{i, 1}$, instead of original attributes $\left(x_{i, 1}, x_{i, 2}\right)$. Interestingly, diagonal entries of $D$ has the ordered nature, $d_{1} \geq d_{2} \geq \ldots d_{p} \geq 0$, and as a result variance explained by each principal will be smaller as components increases (John Lu, 2010; Kong et al., 2017).

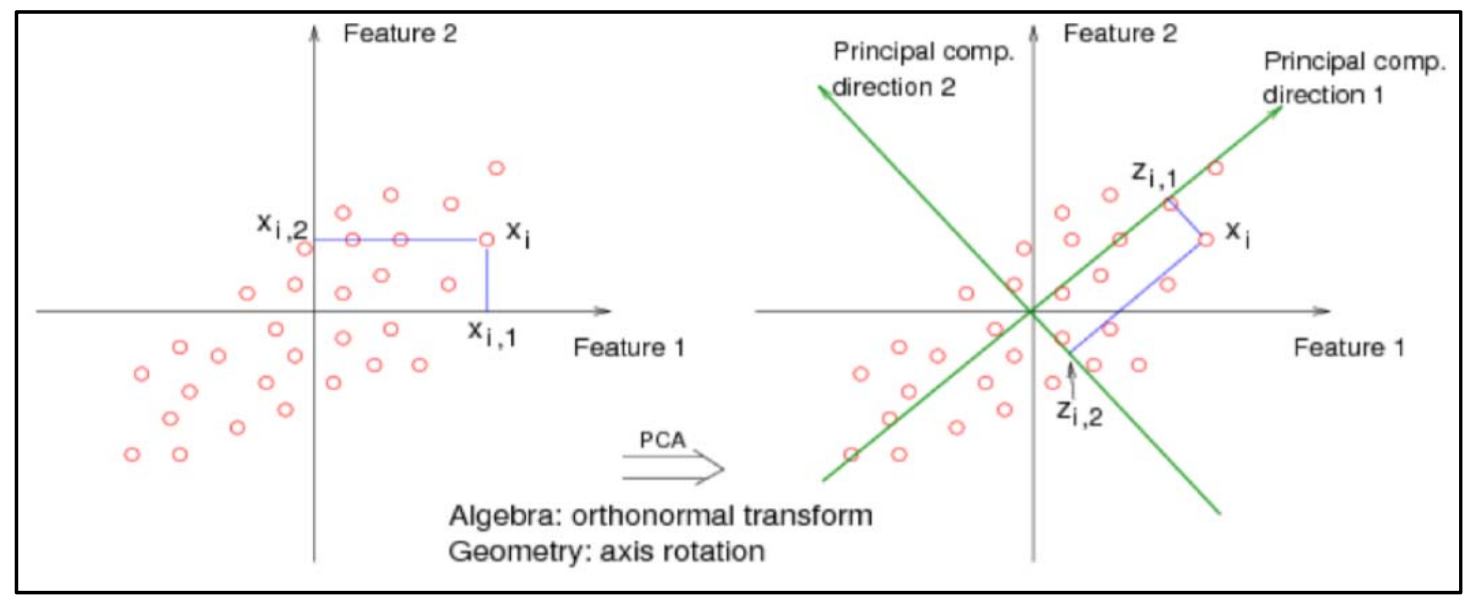

Figure 5 Principal component analysis illustration. 


\subsection{Identified Attitudes}

Separate PCA analysis was conducted for each aspect of attitudes. The results were presented in Table 9 through Table 12. The values in the tables represent the coefficients or the loading of each factor. Higher absolute loading values indicate a higher impact on the factors of the corresponding attitude variables. The sign of the loading shows a positive or negative contribution. Loadings with absolute values greater than 0.5 were highlighted in the tables, indicating that these attitude variables represent most of the variance of the factor.

Table 9 shows the results for general mobility preferences. Four factors were identified based on the 14 attitude questions. The factors can be interpreted as F1-Technology, F2- Choice reasoning, F3- Travel with strangers, and F4- Joy of driving.

- F1- Technology: represents individuals' engagement with online activities, the use of smartphone apps, and eagerness to learn about and use new technologies.

- F2- Choice Reasoning: refers to the consideration of service quality (ranging from travel time, cost, functionality, to convenience) in mobility decisions.

- F3- Travel with Strangers: indicates individuals' concerns on traveling with strangers.

- F4- Joy of Driving: positively associated with the joy of driving and individuals' unwillingness to multitask.

Table 9 PCA result for AT1 (preferences for lifestyle and mobility options)

\begin{tabular}{|c|c|c|c|c|}
\hline & $\begin{array}{c}\text { F1- } \\
\text { Technology }\end{array}$ & $\begin{array}{l}\text { F2- Choice } \\
\text { Reasoning }\end{array}$ & $\begin{array}{c}\text { F3- Travel } \\
\text { with Strangers }\end{array}$ & $\begin{array}{c}\text { F4- Joy of } \\
\text { Driving }\end{array}$ \\
\hline New Technology-Highly engaged in online activities & 0.805 & 0.113 & 0.061 & 0.081 \\
\hline New Technology-Regularly use smartphone apps & 0.777 & 0.188 & -0.005 & -0.024 \\
\hline $\begin{array}{l}\text { New Technology-Would like to learn about and use new } \\
\text { technologies }\end{array}$ & 0.748 & 0.207 & 0.045 & 0.077 \\
\hline Multitasking- Prefer multitasking on my trip & 0.498 & 0.382 & -0.007 & -0.305 \\
\hline Service Quality-Choose a transportation option that is the cheapest & 0.036 & 0.654 & 0.076 & 0.033 \\
\hline Service Quality-Choose fastest and easiest way to travel & 0.247 & 0.651 & -0.138 & 0.094 \\
\hline Shared Mobility-Save on my expenses & 0.294 & 0.604 & -0.264 & 0.094 \\
\hline Driving is stressful & 0.056 & 0.573 & 0.266 & -0.228 \\
\hline Shared Mobility- Increase quality of my life & 0.388 & 0.549 & -0.205 & 0.165 \\
\hline Service Quality-Transportation option must have the functionality & 0.195 & 0.5 & 0.322 & 0.154 \\
\hline Shared Mobility-Hardly trust to travel with strangers & -0.045 & -0.026 & 0.826 & 0.092 \\
\hline Shared Mobility-Traveling by myself is much more convenient & 0.086 & 0.019 & 0.777 & 0.129 \\
\hline Multitasking-Prefer doing one thing at a time & -0.217 & 0.228 & 0.171 & 0.747 \\
\hline I enjoy driving & 0.269 & -0.038 & 0.099 & 0.652 \\
\hline
\end{tabular}


Regarding perceptions of shared mobility option, five factors were identified as shown in Table 10. The factors can be described as:

- F5- Trust and Data Privacy: positively associated with individuals' concern on data privacy and trust with technologies and negatively associated with concerns on cost and service request procedure.

- F6- On-Demand Service: reflects people's positive beliefs in on-demand services and negative interest in multitasking during the trips.

- F7- System Reliability: represents individuals' concerns on system reliability and negatively associated with concerns on data privacy.

- F8- Travel Time: indicates individuals' positive concerns on travel time due to multiple pickups and waiting time and negative concerns on technology (trust and procedure).

- F9- Stress Relief and Cost-Effectiveness: refers to the beliefs in reducing driving stress and cost-effectiveness.

PCA result for AT2 (perceived benefits and concerns of shared mobility)

\begin{tabular}{lccccc}
\hline & $\begin{array}{c}\text { F5- Trust \& } \\
\text { Data } \\
\text { Privacy }\end{array}$ & $\begin{array}{c}\text { F6- On- } \\
\text { Demand } \\
\text { Service }\end{array}$ & $\begin{array}{c}\text { F7- System } \\
\text { Reliability }\end{array}$ & $\begin{array}{c}\text { F8- Travel } \\
\text { Time }\end{array}$ & $\begin{array}{c}\text { F9- Stress } \\
\text { Relief \& } \\
\text { Cost- } \\
\text { Effectiveness }\end{array}$ \\
\hline $\begin{array}{l}\text { Concerns - Trust issue with the } \\
\text { machines/technologies }\end{array}$ Concerns -Unreasonable fares & .753 & .047 & -.089 & -.402 & .097 \\
Concerns - Complicated service request procedure & -.690 & .166 & .111 & -.189 & .201 \\
Benefits -On-demand service & -.618 & .075 & -.158 & -.358 & -.138 \\
Benefits -Multitasking & -.056 & .777 & .057 & .024 & -.146 \\
Concerns - Low reliability & .095 & -.743 & -.065 & .039 & -.166 \\
Concerns - Data privacy & .067 & .013 & .945 & -.023 & -.068 \\
Concerns - Higher travel time due to waiting time & .461 & -.274 & -.582 & .046 & -.109 \\
and multiple pickups & .091 & .008 & -.070 & .940 & -.003 \\
Benefits - Less driving stress & .102 & -.211 & -.017 & .056 & .748 \\
Benefits -Cost-effectiveness & -.124 & .249 & .000 & -.056 \\
\hline
\end{tabular}

In terms of reasons for or against private vehicle ownership, the following four factors were identified, as shown in Table 11.

- F10- Utility of Private Vehicle: refers to the positive preference for a private vehicle due to privacy, reliability, the joy of driving, flexibility, and attachment to cars.

- F11- Green Travel Pattern: indicates the preference for transit, walking, or biking. Interestingly, the lack of parking space significantly contributed to this factor.

- F12- Ownership Cost: represents the concern on ownership and maintenance costs, which may act as a barrier toward ownership.

- F13- Travel Cost: indicates the consideration of cost as a dominant factor for ownership decisions. 


\begin{tabular}{lrrrr}
\hline & $\begin{array}{c}\text { F10- Utility of } \\
\text { Private Vehicle }\end{array}$ & $\begin{array}{c}\text { F11- Green } \\
\text { Travel } \\
\text { Pattern }\end{array}$ & $\begin{array}{c}\text { F12- Ownership } \\
\text { Cost }\end{array}$ & $\begin{array}{c}\text { F13- Travel } \\
\text { Cost }\end{array}$ \\
\hline Own a vehicle-Privacy & .768 & -.044 & -.036 & .068 \\
Own a vehicle-Reliability & .761 & -.175 & -.071 & .040 \\
Own a vehicle-Enjoying driving & .650 & .309 & .014 & .101 \\
Own a vehicle-Convenience/flexibility & .602 & -.271 & .246 & -.313 \\
Own a vehicle-I love my cars/Symbol of luxury & .514 & .385 & -.151 & .283 \\
Don't own a vehicle-Prefer transit or walking/biking & -.103 & .643 & .184 & .069 \\
Don't own a vehicle-Lack of parking space & .059 & .540 & -.116 & -.098 \\
\hline $\begin{array}{l}\text { Do not own vehicle-Daily trips limited to a short } \\
\text { distance }\end{array}$ & -.018 & .443 & .067 & -.070 \\
Don't own a vehicle-Operational/maintenance cost & .021 & .196 & .830 & -.096 \\
\hline Own a vehicle-Cheaper option than other modes & .165 & -.060 & -.100 & .750 \\
Don't own a vehicle-Affordability & -.125 & -.240 & .511 \\
\hline
\end{tabular}

Regarding motivations for and desired features of AVs, four factors were identified, as shown in Table 12.

Table 12 PCA result for AT4 (motivations for and desired features of AV)

\begin{tabular}{|c|c|c|c|c|}
\hline & $\begin{array}{c}\text { F14- Driving } \\
\text { Assistance \& } \\
\text { Safety }\end{array}$ & $\begin{array}{c}\text { F15- } \\
\text { Automation }\end{array}$ & $\begin{array}{l}\text { F16- Mobility } \\
\text { for Non- } \\
\text { Drivers }\end{array}$ & $\begin{array}{c}\text { F17- } \\
\text { Efficiency \& } \\
\text { Technology }\end{array}$ \\
\hline Desired AV features-Lane keeping assist & .761 & .092 & -.028 & -.037 \\
\hline Desired AV features-Avoid collision or reduce the severity & .627 & -.122 & .200 & .307 \\
\hline Desired AV features-Self parking assist & .605 & -.008 & .173 & -.091 \\
\hline Desired AV features-Adaptive cruise control & .604 & .300 & -.288 & .059 \\
\hline Motivations for AV-Improved safety & .583 & -.049 & .125 & .413 \\
\hline $\begin{array}{l}\text { Motivations for AV-Increased capacity/reduced } \\
\text { congestions }\end{array}$ & .527 & .012 & .188 & .154 \\
\hline Motivations for AV-Reduced driving stress & .436 & .199 & .304 & .326 \\
\hline Desired AV features-Fully connected & .079 & .667 & .050 & -.123 \\
\hline Desired AV features-Help with steering & -.053 & .600 & .032 & .047 \\
\hline Motivations for AV-Multitasking & .054 & .504 & .153 & .189 \\
\hline Desired AV features-Drive themselves & -.003 & .225 & .719 & .097 \\
\hline Motivations for AV-Mobility for non-drivers & .242 & -.003 & .648 & -.006 \\
\hline Desired AV features-Improve fuel efficiency & .255 & .101 & .109 & .601 \\
\hline Motivations for AV-Better technology & .066 & .516 & .003 & .570 \\
\hline Motivations for AV-No need for parking & .220 & .353 & .347 & -.485 \\
\hline
\end{tabular}

- F14- Driving Assistance and Safety: indicates the desire for driving assistance features, such as lane-keeping, self-parking, adaptive cruise control, as well as safety features of, like collision avoidance.

- F15- Automation: represents the preferences for better technology and full connectivity.

- F16- Mobility for Non-drivers: refers to the desire for auto-driving feature, especially for those how cannot drive. 
- F17- Efficiency and Technology: is positively associated with the desire for higher efficiency and better technology, while negatively associated with the motivation on no parking needs.

\subsection{Attitude Patterns}

This section explores the underlying patterns of attitudes focusing on socio-economic and demographic (SED) attributes, as shown in Figure 6 to Figure 21. Analysis of variance (ANOVA) was conducted to compare the means of factor values to determine whether there is statistical evidence that the associated population means are significantly different between the SED segments. The highlighted patterns in the figures (dashed lines) indicate those factors that showed significantly different $(P<0.05)$ values between at least one pair of the SED segments.

\subsubsection{Age}

Looking at the distribution of attitudes by age groups, Figure 6 shows that seniors (aged 65 or above) had the highest positive attitudes toward ridesourcing in terms of on-demand services (F6), stress relief and cost-effectiveness (F9), while the driving assistance and safety features (F14) of AVs were the most attractive to them.

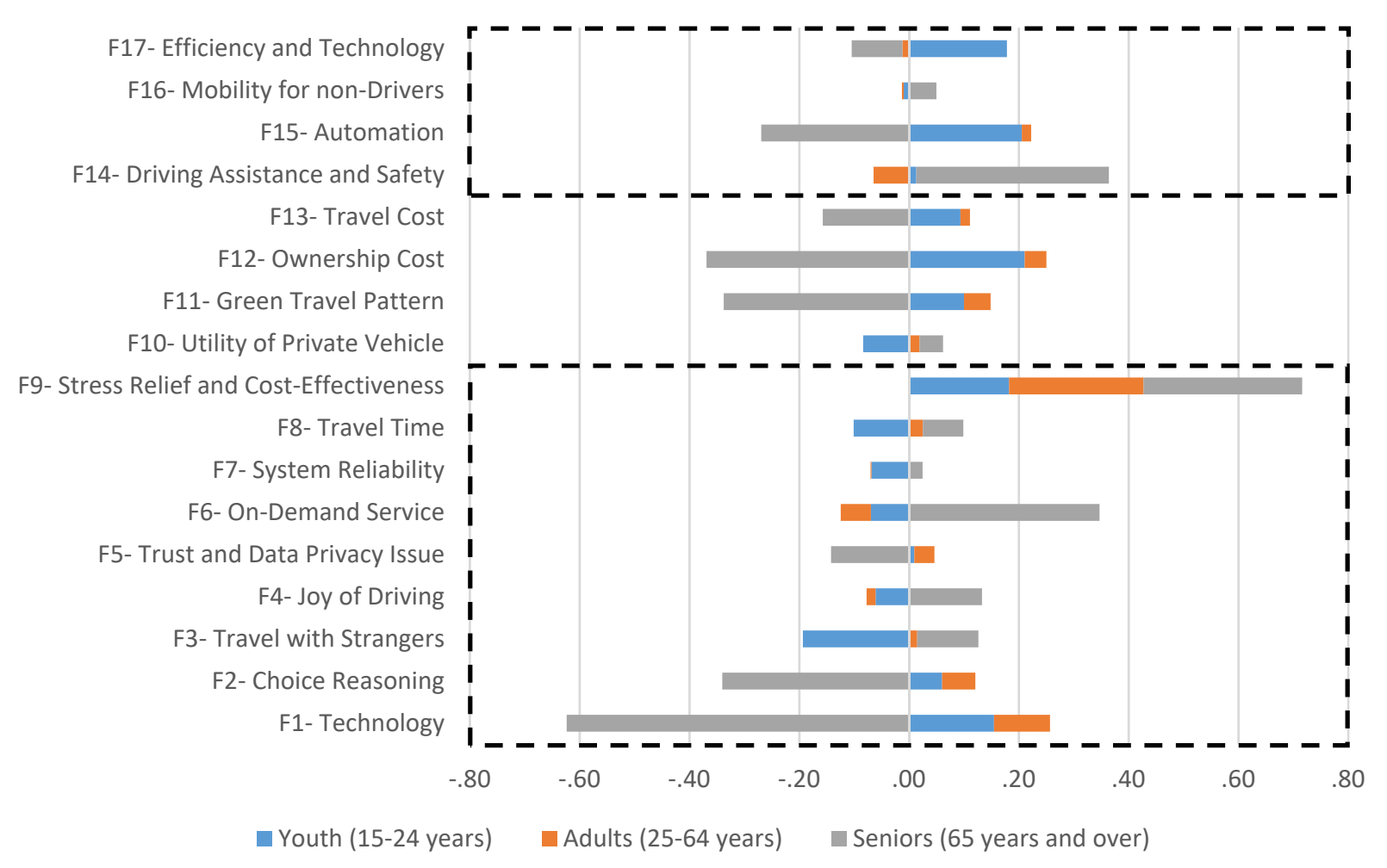

\section{Figure $6 \quad$ Attitudes by age group.}

Compared to other age groups, seniors were also more likely to enjoy driving (F4) and have concerns about traveling with strangers (F3), system reliability (F7) and wait time (F8). On the other hand, seniors were less likely to be attracted to technology and efficiency (F1, F15, and F17), 
do choose reasoning (F2), or have concerns about the technology or data privacy (F5) of ridesourcing. For adults (between 25 and 64), the highest positive attitudes were stress relief and the cost-effectiveness of ridesourcing (F9). Interestingly, adults were the least likely to be motivated by the driving assistance and safety features of AVs (F14). They were also more likely to have concerns about technology and data privacy (F5).

As expected, youth (between 15 and 24) showed the highest positive attitudes toward technology and automation (F1, F15, and F17). The choice reasoning was the most critical factor in their mobility decision (F2) while traveling with strangers (F3), system reliability (F7), and additional wait time for multiple pickups (F8) were less likely to be a concern for them. They were also less likely to be attached to driving (F4).

\subsubsection{Gender}

Figure 7 shows the distribution of Attitudes by gender groups. On average, both male and female respondents had a high tendency to believe in stress relief and cost-effectiveness as the top benefits of ridesourcing, especially females (F9). Interestingly, males and females showed opposite attitudes, in similar magnitudes, for almost all other factors. However, the differences between males and females were not statistically significant for any of the attitude factors.

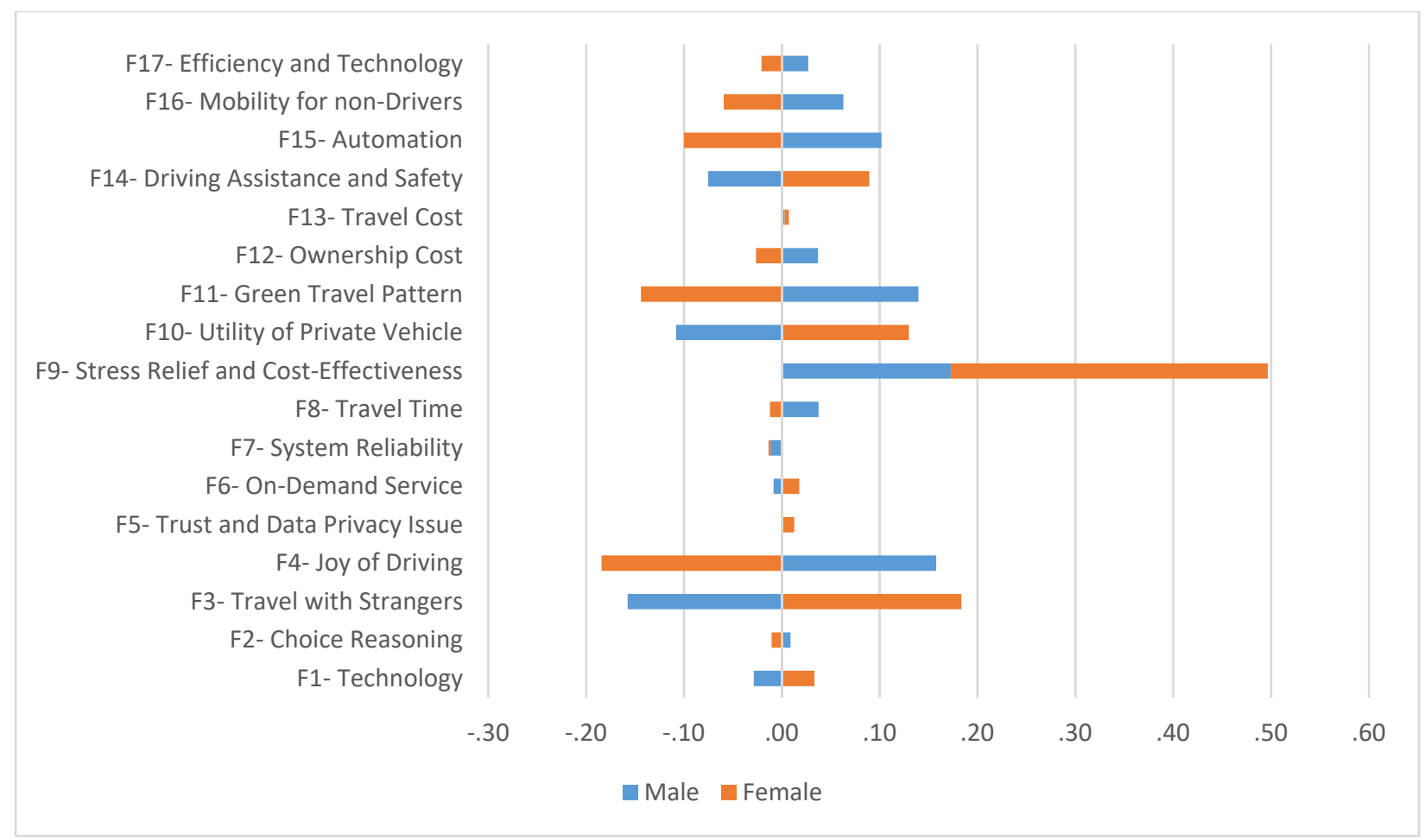

\section{Figure $7 \quad$ Attitudes by gender.}

\subsubsection{Ethnicity}

While Figure 8 shows a large magnitude of attitudinal factor values for Native Americans, the sample size is very small (5), which means the results may not be generalized. $73.7 \%$ of the sample 
consists of the White population. In general, White travelers were the least likely to prefer green travel (F11) or have concerns on ownership cost (F12), whereas they were highly interested in the utility of private vehicles (F10). Hispanic and Latinos showed the highest positive attitudes toward green travel (F11), while Black or African American respondents were highly inclined toward the cheapest travel mode (F13).

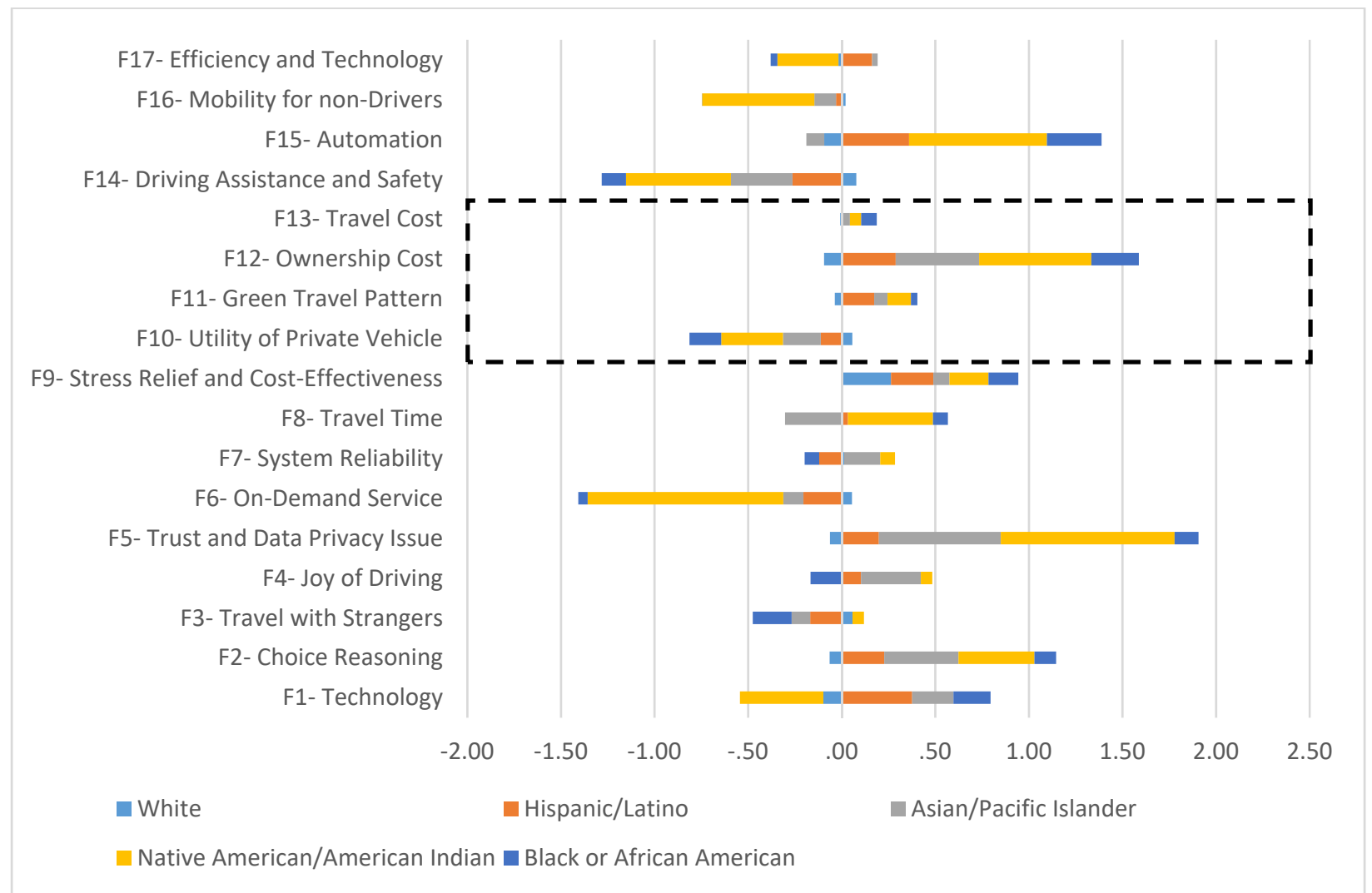

\section{Figure $8 \quad$ Attitudes by ethnicity.}

\subsubsection{Employment}

In terms of employment status, retired people had the highest positive views on joy of driving (F4) while they showed the highest negative propensity to technology engagement (F1), choice reasoning (F2), green travel pattern (F11), and concerns on cost (F12, F13). Students showed the highest positive views on technology (F1), the highest concerns on ownership cost (F12), and least concerns on traveling with strangers (F3). Unemployed people showed the least interest in the utility of private vehicles (F10) and the highest concerns on traveling with strangers (F3). Fulltime and part-time employed people were in-between students and retired for the most part.

\subsubsection{Education}

In general, people with higher education (associate degree or above) exhibited higher levels of green travel (F11), while enjoying the utility of private vehicle (F10). Interestingly, they also showed higher concerns of ownership cost (F12). 


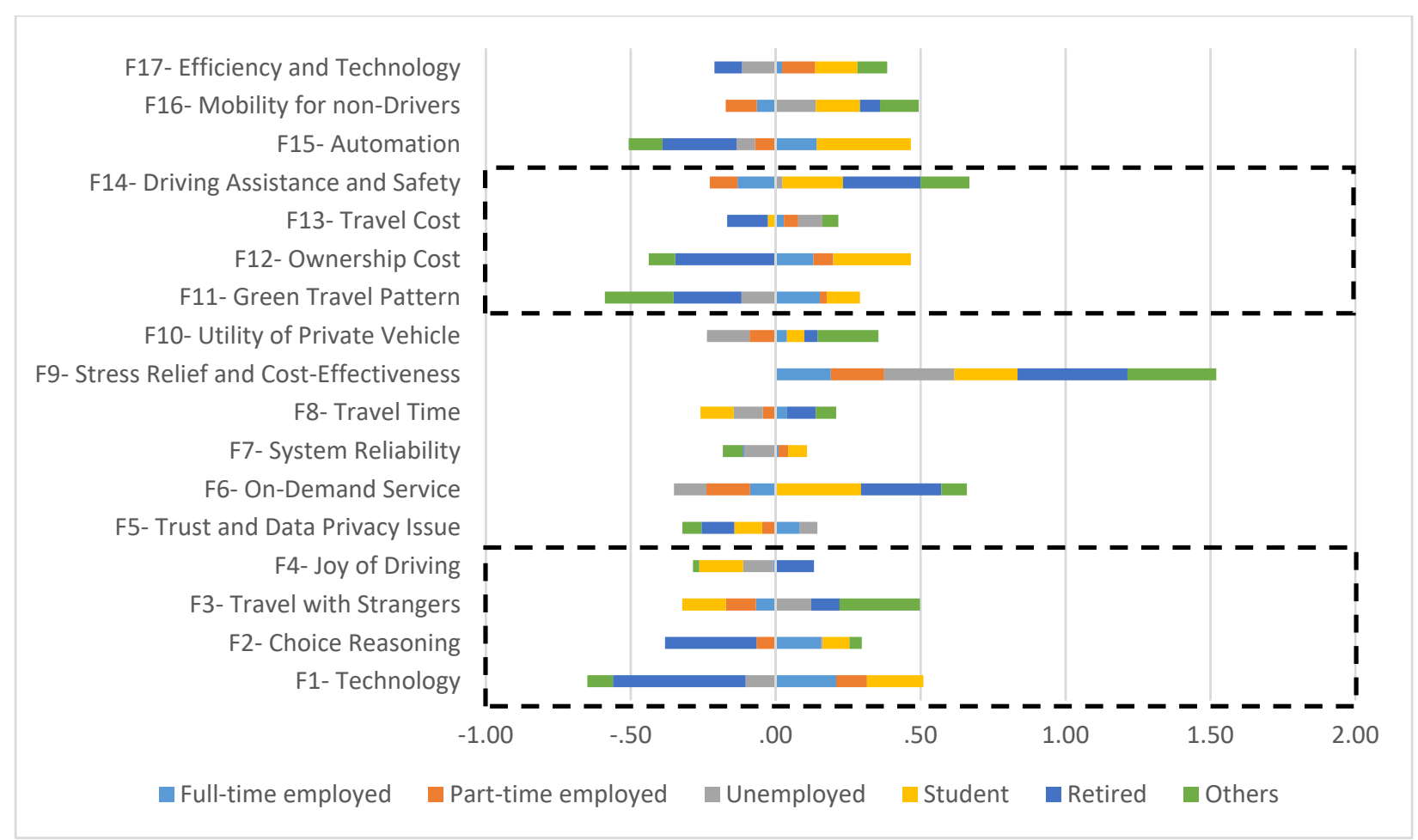

Figure 9 Attitudes by employment status.

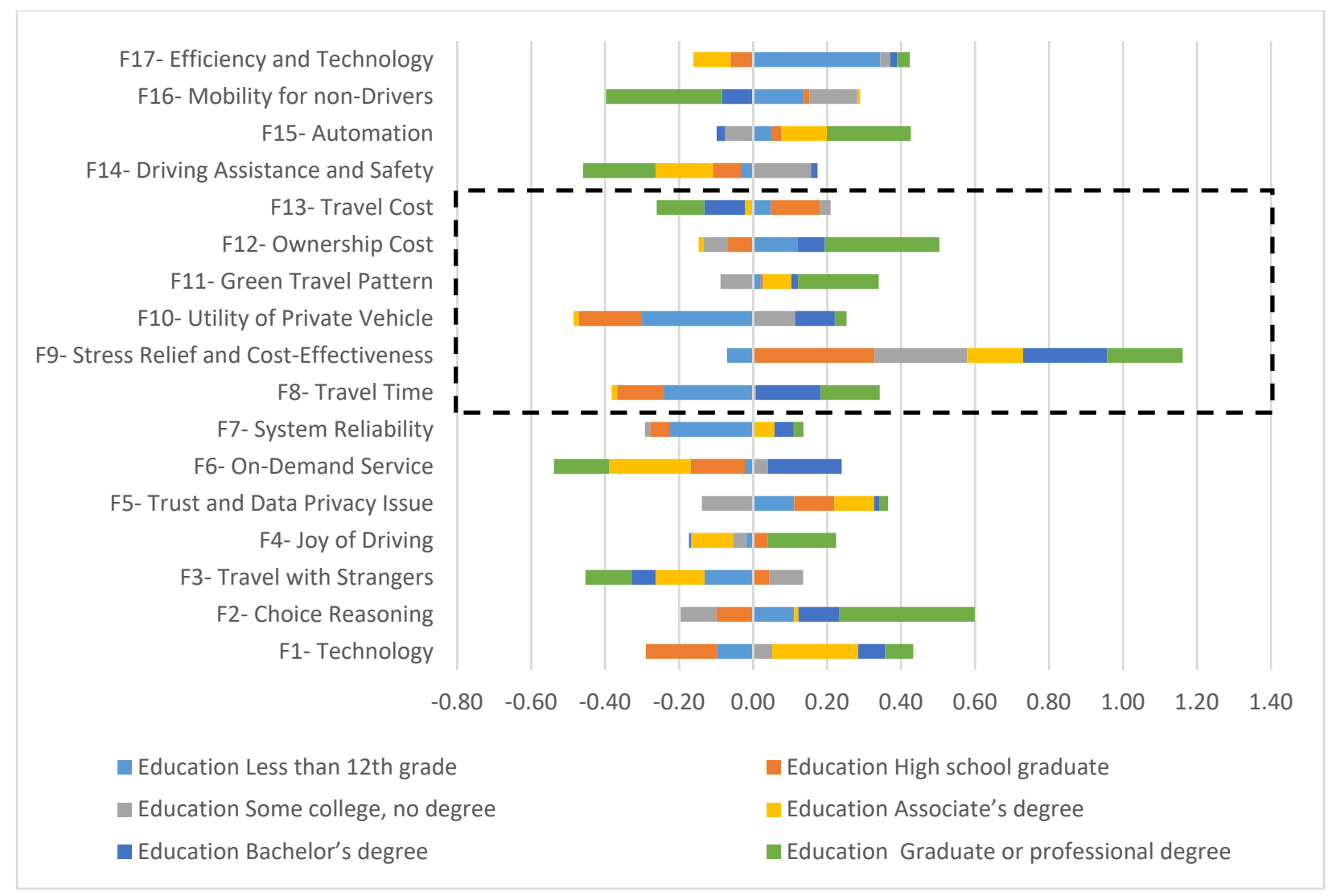

\section{Figure $10 \quad$ Attitudes by education level.}




\subsubsection{Household Income}

Surprisingly, the ANOVA test was not able to detect significant differences between the income groups for any of the factors. Figure 11 shows the attitude factors by income groups.

F17- Efficiency and Technology

F16- Mobility for non-Drivers

F15- Automation

F14- Driving Assistance and Safety

F13- Travel Cost

F12- Ownership Cost

F11- Green Travel Pattern

F10- Utility of Private Vehicle

F9- Stress Relief and Cost-Effectiveness

F8- Travel Time

F7- System Reliability

F6- On-Demand Service

F5- Trust and Data Privacy Issue

F4- Joy of Driving

F3- Travel with Strangers

F2- Choice Reasoning

F1- Technology

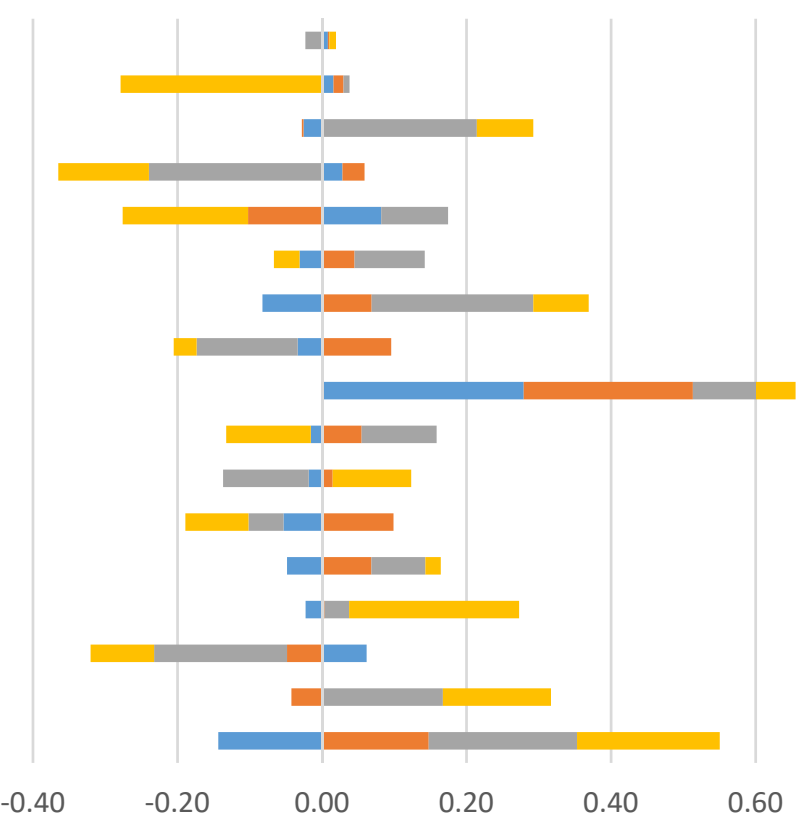

0.80

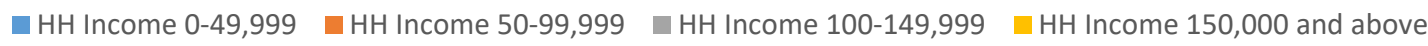

\section{Figure 11 Attitudes by household income level.}

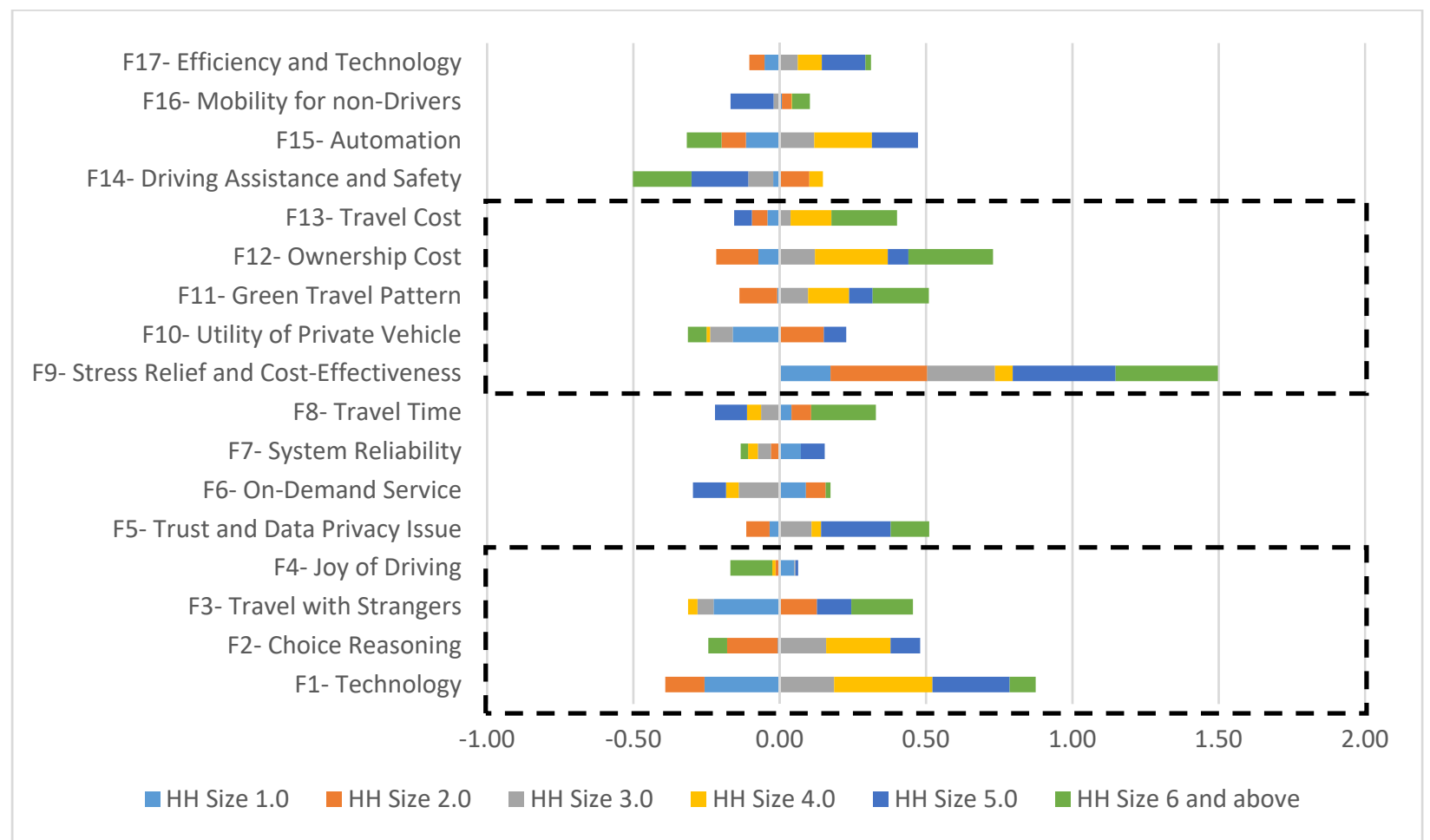

Figure 12 Attitudes by household size. 


\subsubsection{Household Size}

Single-member households had the least concern on traveling with strangers (F3) and the least interest in technology (F1) or utility of private vehicles (F10). Households with two members showed the least inclination toward choice reasoning (F2) or green travel (F11) as they highly enjoyed the utility of private vehicles (F10) with the least concern on ownership cost (F12). Those having a middle-sized family (4 members) were more likely to be interested in technology (F1) and choice reasoning (F2). Very large households (six members or above) expressed high concerns about traveling with strangers (F3) while preferring green travel or cheapest modes (F11, F13) mostly because of ownership cost (F12) or lack of interest in driving (F4).

\subsubsection{Driver License}

As expected, those without a driver's license had a negative opinion toward the utility of private vehicles (F10) and efficiency (F17) while be motivated in mobility for non-drivers (F16). They were more likely to select the cheapest travel mode (F13), mostly because of ownership cost (F12).

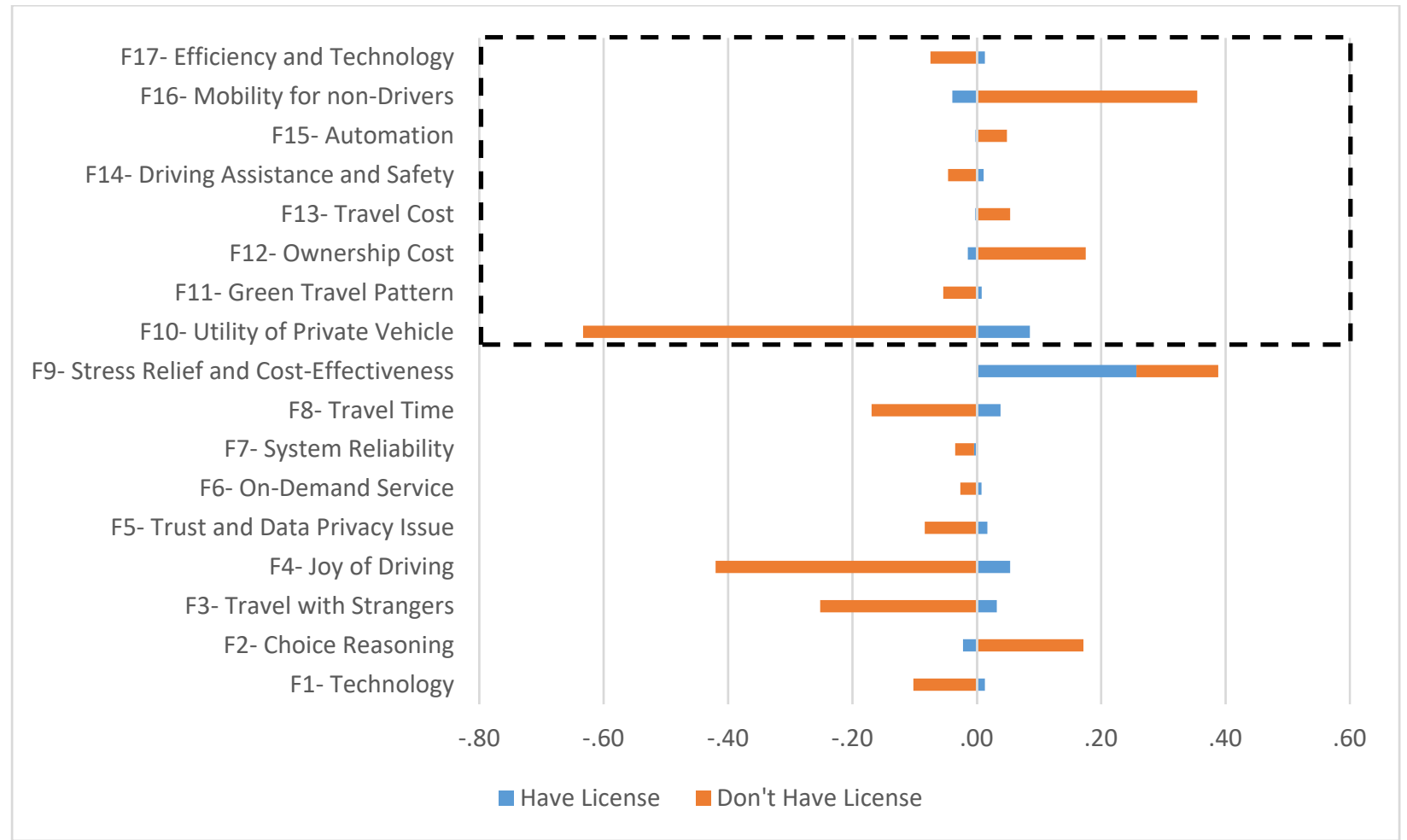

\section{Figure 13 Attitudes by driver license.}

\subsubsection{Number of Household Drivers}

As expected, households with no driver had the least interest in the utility of private vehicles (F10) while preferring green travel (F11). The utility of private vehicles (F10) was highly appreciated by the household with two drivers while they were least concerned about ownership cost (F12). Households with four or more drivers mostly preferred the cheapest travel mode (F13) due to the ownership cost (F12), and they were not interested in green travel (F11). 


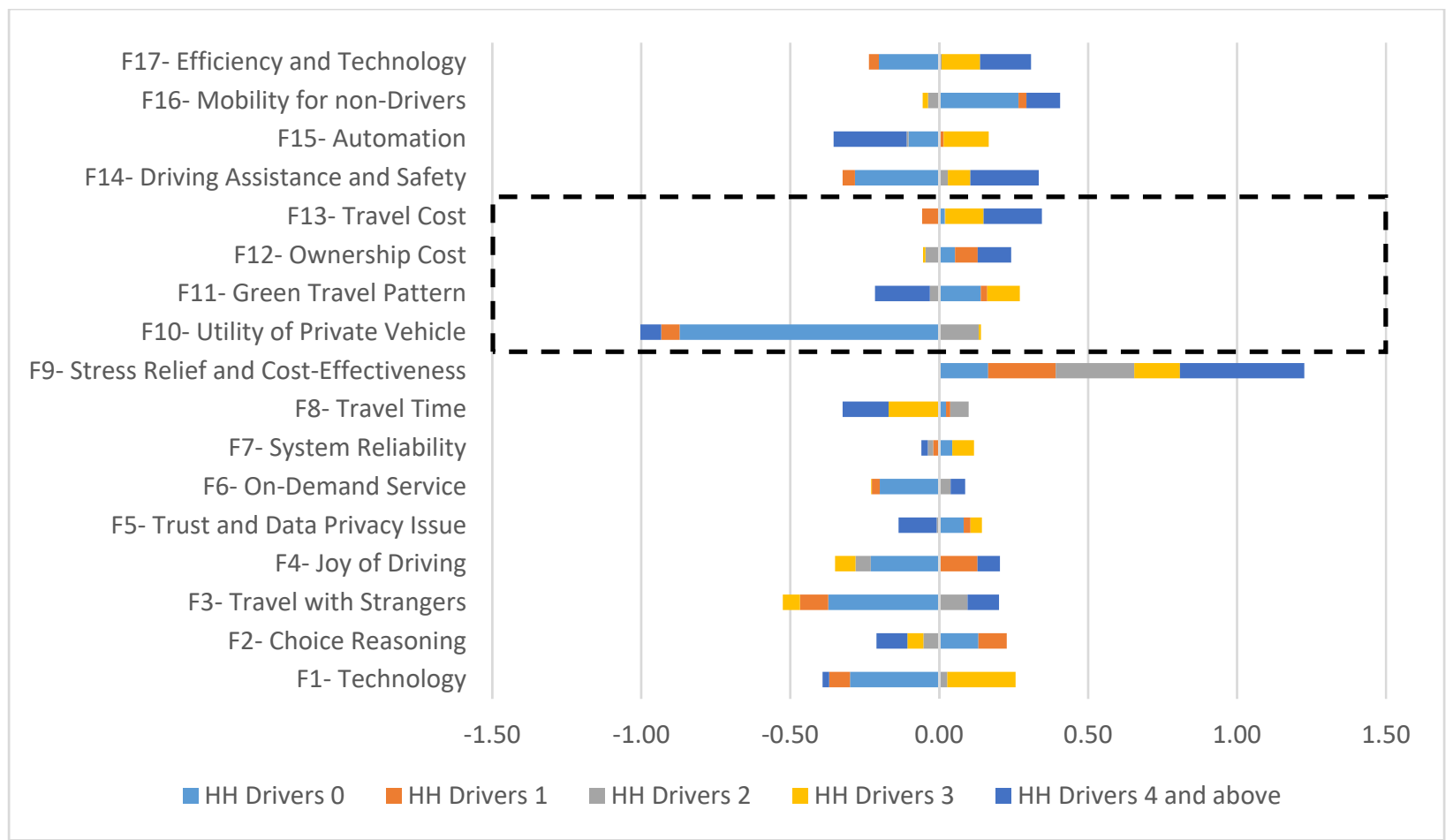

Figure 14 Attitudes by the number of household drivers.

F17- Efficiency and Technology

F16- Mobility for non-Drivers

F15- Automation

F14- Driving Assistance and Safety

F13- Travel Cost

F12- Ownership Cost

F11- Green Travel Pattern

F10- Utility of Private Vehicle

F9- Stress Relief and Cost-Effectiveness

F8- Travel Time

F7- System Reliability

F6- On-Demand Service

F5- Trust and Data Privacy Issue

F4- Joy of Driving

F3- Travel with Strangers

F2- Choice Reasoning

F1- Technology
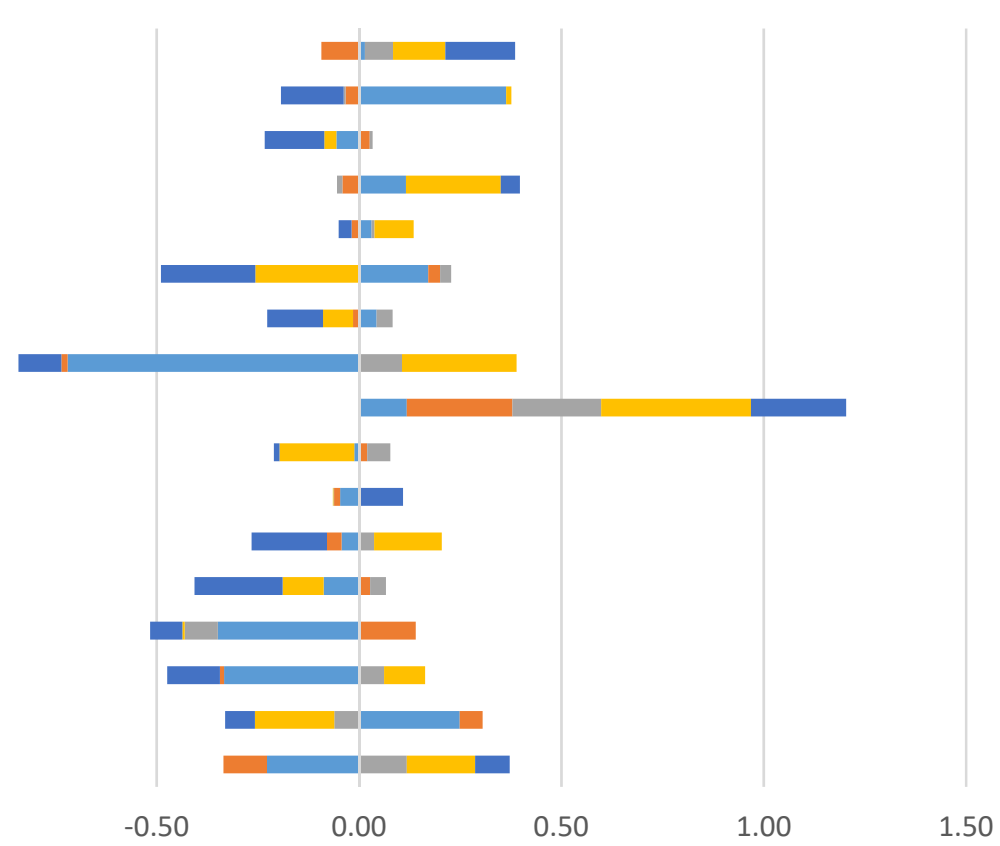

$\square \mathrm{HH}$ vehicles $0 \quad \mathrm{HH}$ vehicles $1 \quad \mathrm{HH}$ vehicles $2 \square \mathrm{HH}$ vehicles $3 \quad \mathrm{HH}$ vehicles 4 and above

Figure 15 Attitudes by the number of household vehicles.

ANOVA test didn't find any significant difference in attitudes among households with different numbers of vehicles. 


\subsubsection{Mode Usage}

We defined frequency of mode usage into two groups: frequent users who use the mode at least once a week, and infrequent users who use the mode less than once a week or never used it.

Figure 16 shows attitudes for drivers. As expected, those drove frequently were highly interested in the utility of private vehicles (F10) and the least interested in green travel (F11) while not being concerned about costs (F12, F13). Frequent and infrequent passenger users didn't show different attitudes according to the ANOVA test.

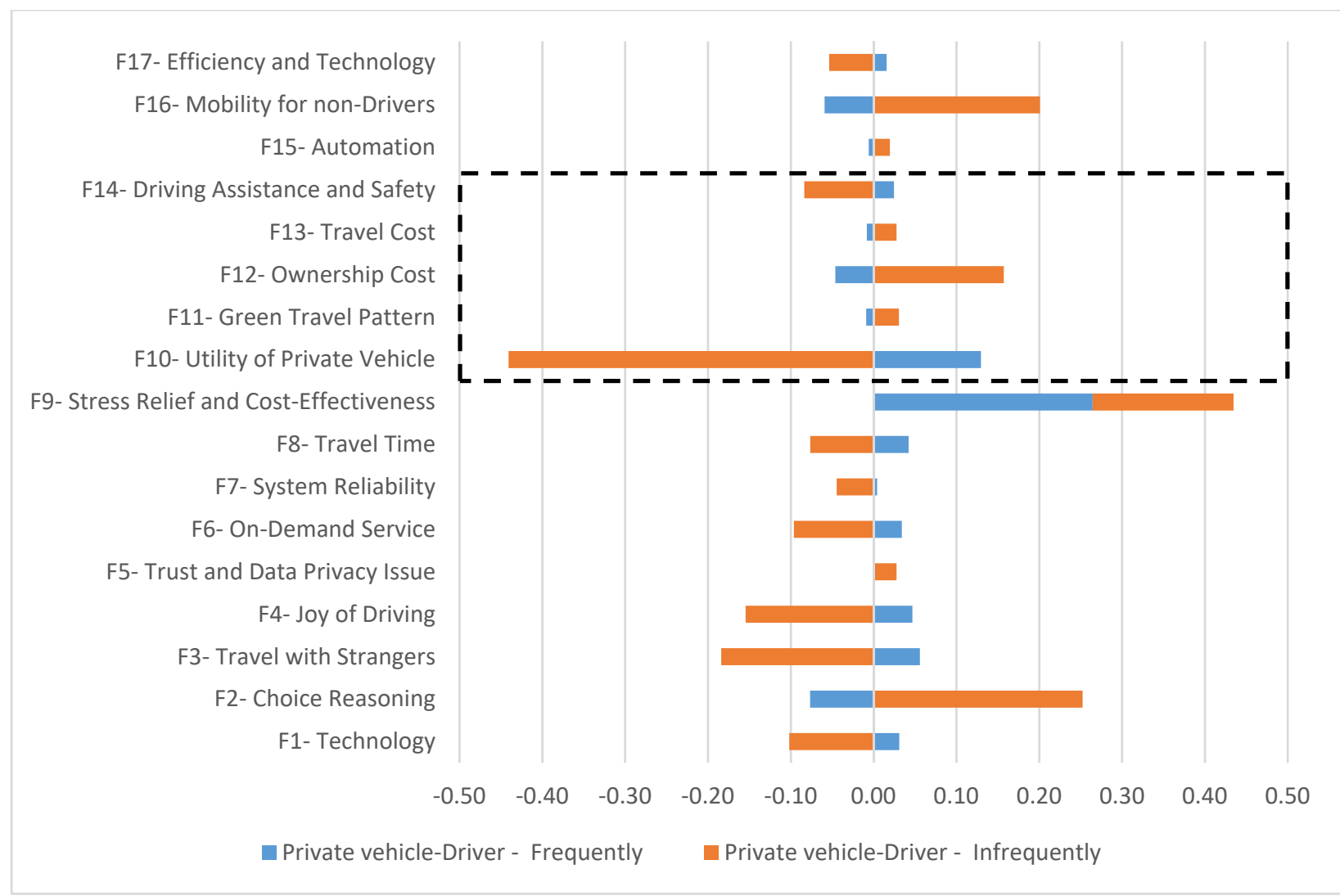

Figure 16 Attitudes by driving frequency.

Frequent and infrequent passenger users didn't show different attitudes according to the ANOVA test.

As shown in Figure 17 to Figure 20, frequent and infrequent users of all non-private vehiclerelated modes (transit, taxi, ridesourcing, and car sharing) revealed similar patterns. Respondents who frequently use these modes were more motivated for green travel pattern (F11), and automation (F15) while expressing serious concern about cost (F12, F13). Frequent users also showed less interest in driving assistant features (F14), and mobility for non-drivers (F16). 


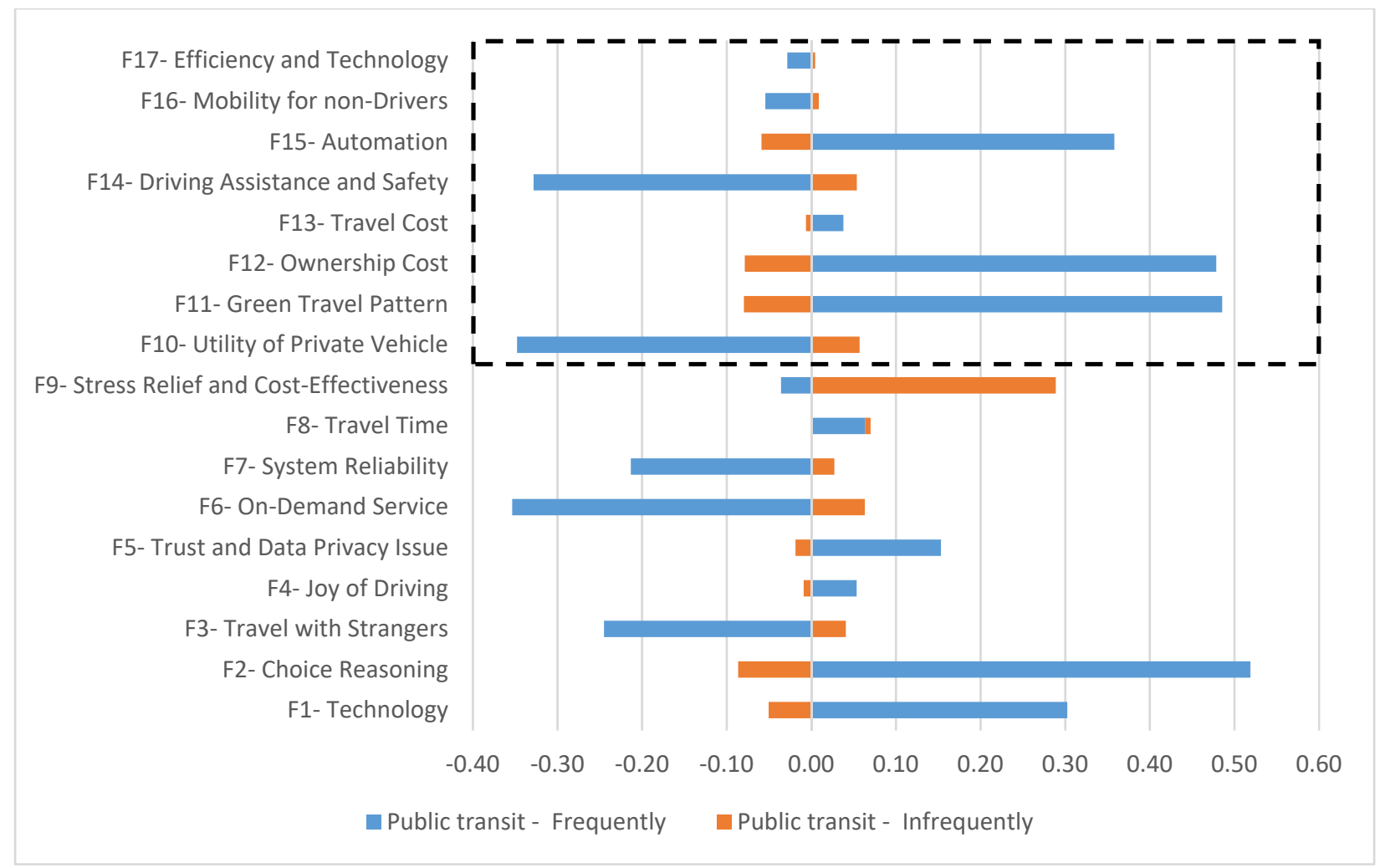

\section{Figure 17 Attitudes by transit frequency.}

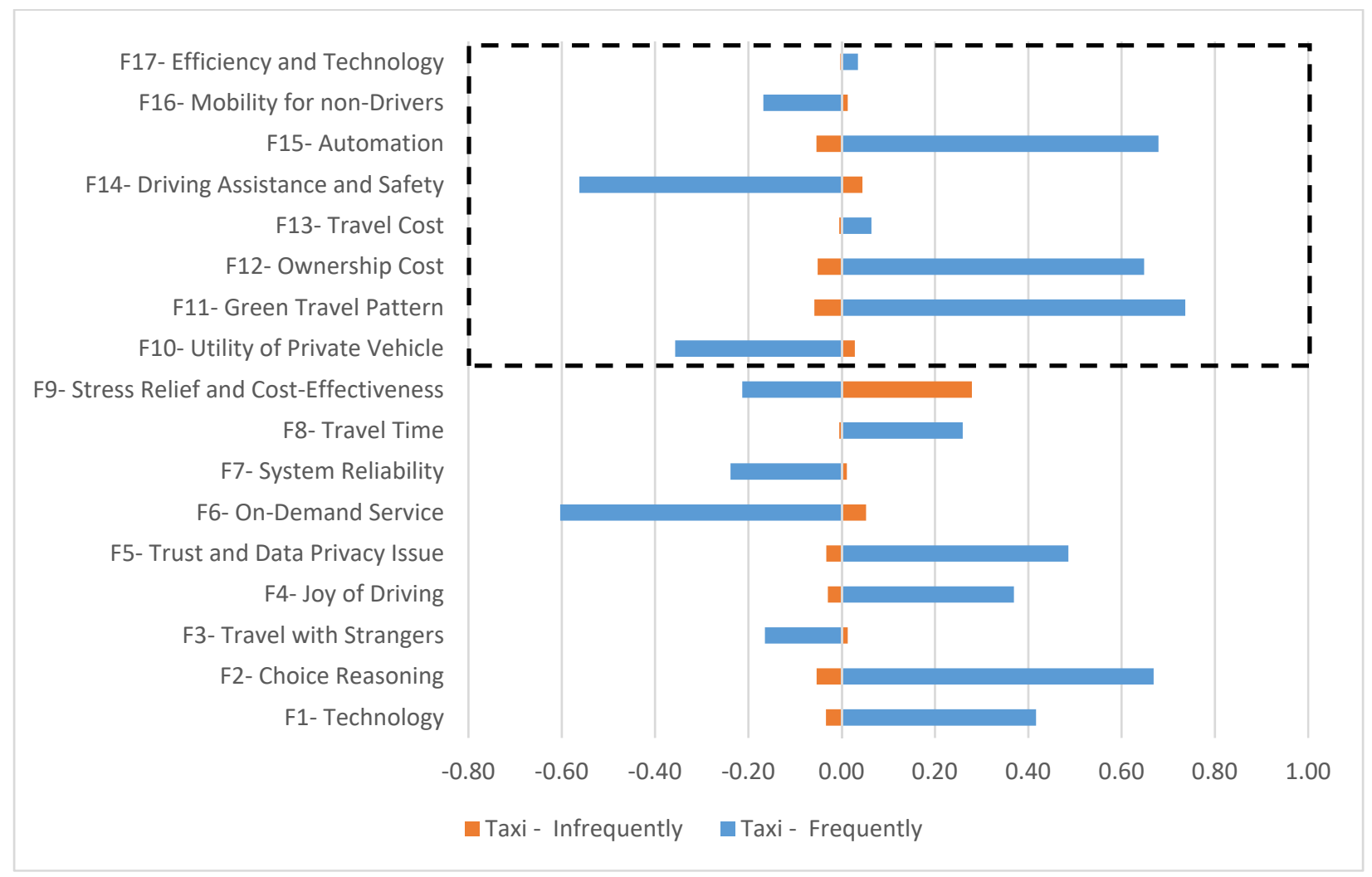

Figure 18 Attitudes by taxi frequency. 


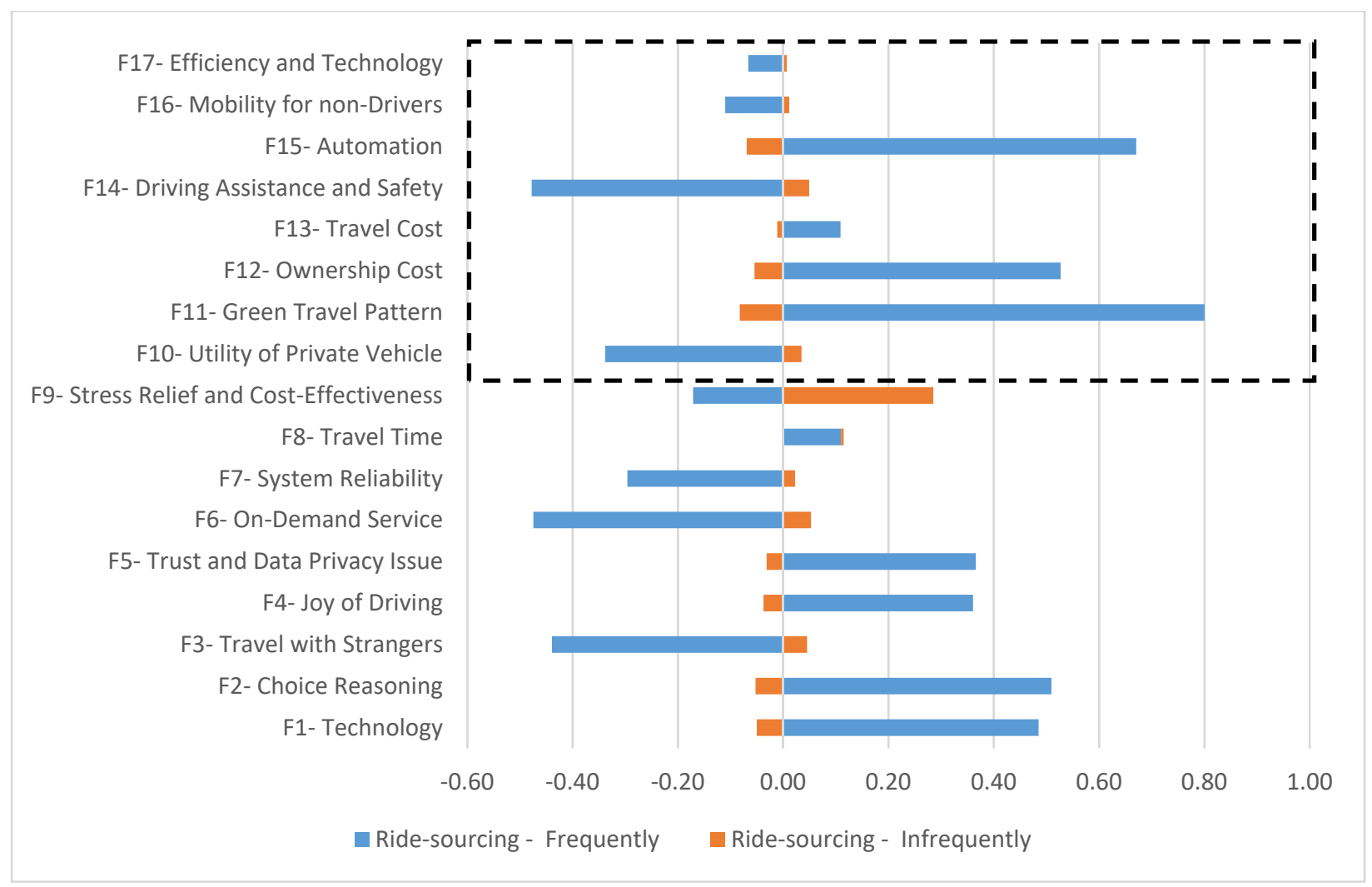

\section{Figure 19 Attitudes by ridesourcing frequency.}

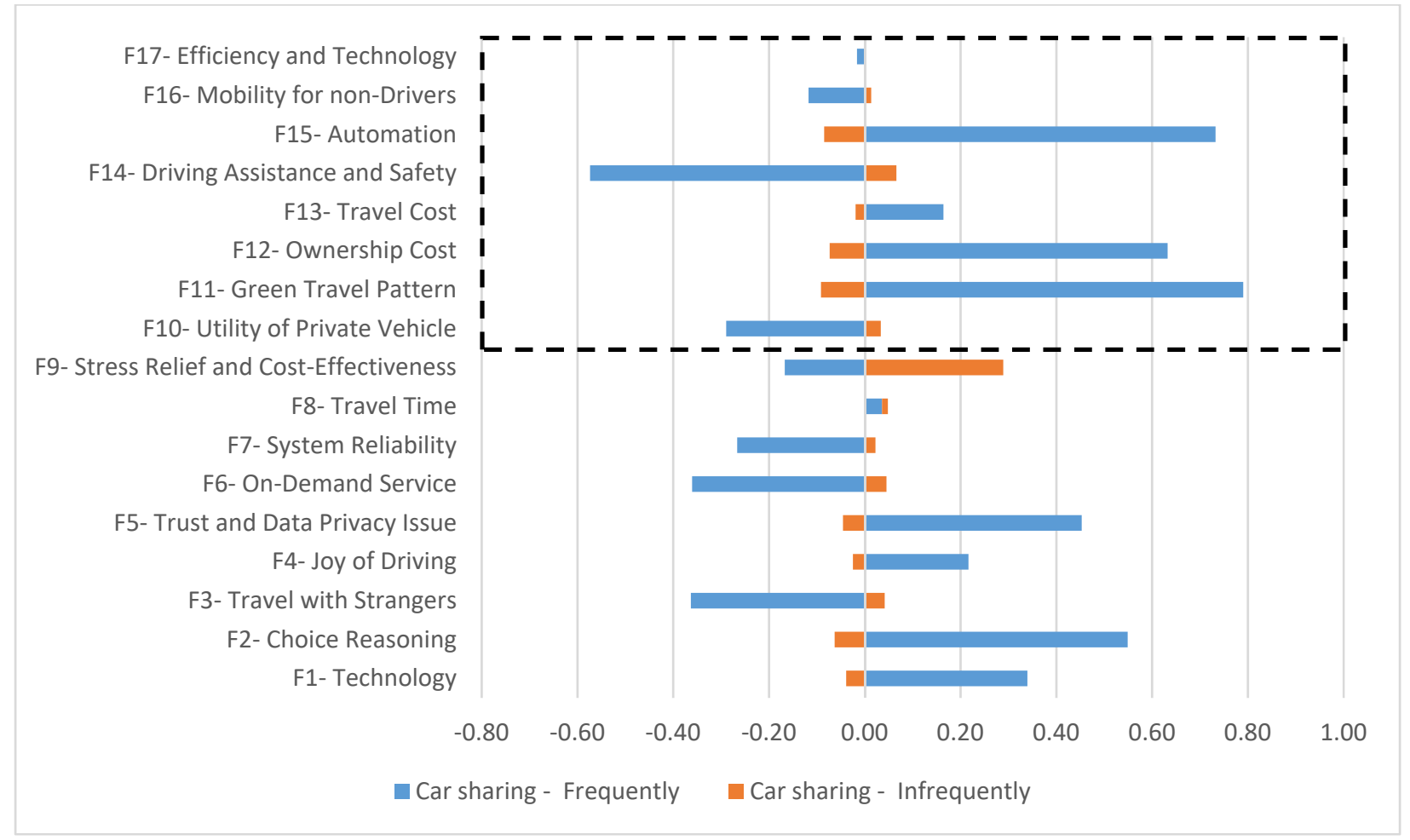

\section{Figure $20 \quad$ Attitudes by car sharing frequency.}




\subsubsection{Regular Trip Distance}

Users with short travel distances (less than 10 miles) were not interested in technology (F1) or choice reasoning (F2) while highly appreciate on-demand services (F6) in terms of reliability (F7), stress relief and cost-effectiveness (F9). Respondents who regularly travel medium distances (10 to 20 miles) were more likely to be interested in technology (F1) and choice reasoning (F2) while expressing the least desire for driving (F4) or traveling with strangers (F3). These users were highly concerned about travel time (F8) but least worried about system reliability (F7) or stress relief and cost-effectiveness (F9) of shared mobility. Those having long travel distance (20 miles or above) had serious trust issues with strangers or technology (F3, F5) while being least interested in on-demand services (F6). Interestingly, the ANOVA test did not identify any significant difference in attitudes by regular trip travel time.

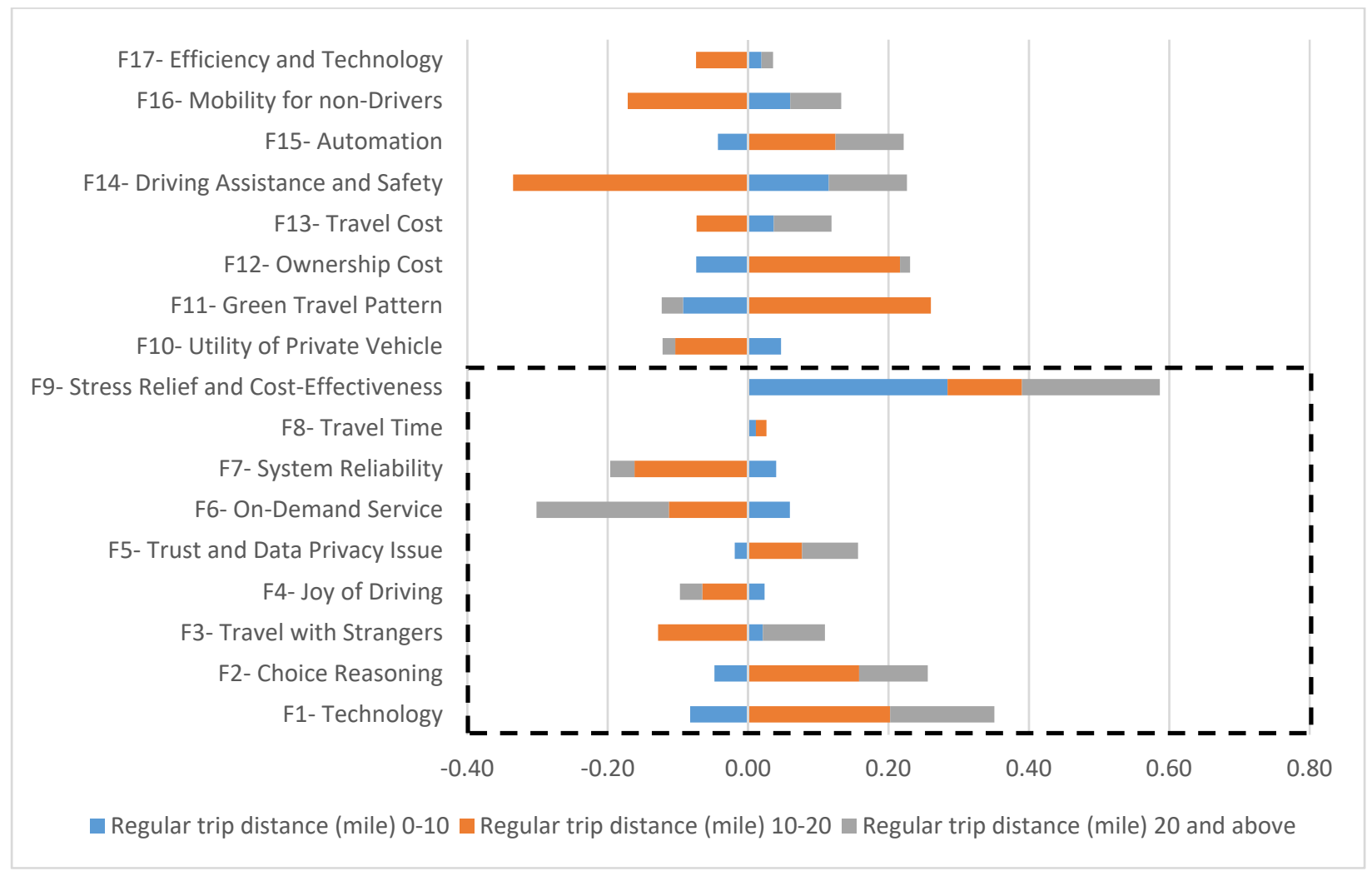

Figure $21 \quad$ Attitudes by regular trip distance.

The factor analysis provided the opportunity to understand respondents' attitudes regarding mode choice, shared mobility, vehicle ownership, and AV features. Pattern analysis provided useful insights in terms of how travelers' attitudes differ by SED segments. Build up this attitude analysis, the next step will focus on developing models that account for these attitudes in the estimation of AV adoption and WTP, vehicle ownership, and mode choice decisions. 


\section{METHODOLOGY}

This chapter describes the main modeling and analysis methods used in the model development process.

\subsection{Error Component Model}

In the survey, respondents were asked to choose between hypothetical mode choice scenarios. Considering the panel structure of the scenario data (multiple scenarios for every single individual), an error component model was selected to account for heterogeneity through random parameters. The model was suggested by (Hensher et al., 2005) to capture taste variations across individuals within a survey.

\subsubsection{Error Component Model with Multinomial Logit Structure}

The error component model was applied to investigate the traveler's mode choice in two distinct market segments: transit users in a regular context and auto users in occasional situations when a private vehicle is not available. The focus was on the choice between public transit and ondemand services, so respondents were faced with three alternatives in each scenario: public transit, exclusive on-demand transit, and shared on-demand transit. Various socio-economic and demographic attributes, as well as the attitudinal factors, were explored as independent variables, and their impacts on the mode choice behavior were investigated.

Assume the utility that individual $i$ perceives from alternative $j$ is $U_{i j}$. This utility is assumed to be stochastic and could be expressed as the combination of two different terms: the deterministic portion, which is a linear form of explanatory variables, such as socio-economic and demographic characteristics and trip attributes and the stochastic portion (error term), $\varepsilon_{i j}$. The utility function can be shown as:

$$
U_{i j}=\alpha_{j}+\beta x_{i j}+\varepsilon_{i j}(1)
$$

$\beta$ is the vector of coefficients that need to be estimated. $x_{i j}$ is the vector of explanatory variables, $\alpha_{j}$ is the alternative-specific constant measuring the mean impact of alternatives' unobserved utility ( $J-1$ alternative-specific constant should be estimated), and $\varepsilon_{i j}$ is the random error. There are various assumptions about $\varepsilon_{i j}$, one of them is that $\varepsilon_{i j}$ is independently and identically distributed (IID), which produces the multinomial logit model (MNL) (McFadden 1973, Rahimi et al., 2020c).

We assume that individuals choose the alternative that maximizes their utility. To allow for the possibility of underlying heterogeneity in individuals' mode choice between alternatives, we added error components to the utility of each alternative. The error component, $\mu_{i j}$, is assumed to follow a normal distribution, $N\left(0, \sigma^{2}\right)$. The utility function can be represented as below: 


$$
U_{i j}=\alpha_{j}+\beta x_{i j}+\mu_{i j} z_{i j}+\varepsilon_{i j}
$$

$z_{i j}$ is the vector of observed data for individual $i$ or alternative $j$ For mixed logit models, $z_{i j}$ is a subset of explanatory variables that have random distributions among individuals. Only heterogeneity of travel time and travel costs among different individuals are accounted for. Thus, the utility function becomes:

$$
U_{i j t}=\alpha_{j}+\left(\beta x_{i j}\right)+\left(\overline{\beta_{T T}}+\sigma_{T T} \mu_{i, T T}\right) T T_{j t}+\left(\overline{\beta_{T C}}+\sigma_{T C} \mu_{i, T C}\right) T C_{j t}+\varepsilon_{i j t}
$$

Where,

$\begin{array}{ll}U_{i j t}= & \text { Utility of individual } i \text { choosing alternative } j \text { in scenario } t \\ \alpha_{j}= & \text { Alternative-specific constant (ASC) } \\ \beta= & \text { Vector of fixed coefficients } \\ x_{i j}= & \text { Observed variables (fixed) for individual } i \text { choosing alternative } j \\ \overline{\beta_{T T}}, \overline{\beta_{T C}}= & \text { Mean of travel time and travel cost coefficients } \\ \sigma_{T T}, \sigma_{T C}= & \text { Standard deviations of travel time and travel cost coefficients } \\ T T_{j t}= & \text { Travel time for alternative } j \text { in scenario } t \\ T C_{j t}= & \text { Travel cost for alternative } j \text { in scenario } t \\ \mu_{i, T T}, \mu_{i, T C}= & \text { Standard normal random effects } \sim \mathrm{N}(0,1) \\ \varepsilon_{i j t}= & \text { IID error term }\end{array}$

\subsubsection{Error Component Model with Nested Structure}

The error component nested logit model was applied to assess the impacts of habitual behavior and private mobility expenses on the propensity to shift from conventional modes (Auto driver, auto passenger, or public transit) to emerging modes (exclusive and shared on-demand services). Respondents were faced three alternatives in each scenario: conventional modes, exclusive ondemand services, and shared on-demand services. Socio-economic and demographic attributes, habits associated with existing modes, and private mobility auxiliary expenses were considered as the independent variables.

To account for the similarities between exclusive and shared on-demand services, it is reasonable to assume that a nested structure would fit the data better. Therefore, one nest for the emerging modes, including exclusive and shared on-demand services was considered. To account for the nested structure, one term must be added to Eq. 3, so the utility function would be as follow (Hensher et al., 2005): 


$$
U_{i j t}=\beta^{\prime} x_{i j}+\left(\bar{\gamma}_{T T}+\sigma_{T T} \cdot \mu_{i, T T}\right) T T_{j t}+\left(\bar{\gamma}_{T C}+\sigma_{T C} \cdot \mu_{i, T C}\right) T C_{j t}+d_{j} \sigma_{n} u_{i, n}+\varepsilon_{i j t}(4)
$$

Where

$U_{i j t}=\quad$ Utility of individual i selecting alternative $\mathrm{j}$ in scenario $\mathrm{t}$

$\beta^{\prime}=\quad$ vector of fixed coefficients (to be estimated)

$x_{i j}=\quad$ observed explanatory variables

$\bar{\gamma}_{T T}, \bar{\gamma}_{T C}=\quad$ mean of travel time and travel cost coefficients (to be estimated)

$\sigma_{T T}, \sigma_{T C}=\quad$ standard deviations of travel time and travel cost coefficients (to be estimated)

$T T_{j t}=\quad$ travel time for alternative $\mathrm{j}$ in scenario $\mathrm{t}$

$T C_{j t}=\quad$ travel cost for alternative $\mathrm{j}$ in scenario $\mathrm{t}$

$d_{j}=\quad 1$ if alternative $\mathrm{j}$ belongs to the emerging mode nest, 0 otherwise

$\sigma_{n}=\quad$ The covariance parameter within the nest (to be estimated)

$\mu_{i, T T}, \mu_{i, T C}, u_{i, n}=$ standard normal random effects $\sim \mathrm{N}(0,1)$

$\varepsilon_{i j t}=\quad$ Independent and identically distributed error term

Since three alternatives in each scenario, there would be three utility functions, each associated with one alternative.

\subsection{Structural Equations Model}

In this project, Structural Equations Model (SEM) was employed in two different models for different purposes. In the first case, SEM was estimated to study the willingness to adopt and willingness to pay (WTP) for different levels of autonomous vehicle (AV). Adoption and WTP levels were simultaneously estimated against a variety of available variables, including socioeconomic and demographic attributes, private car usage habits, and attitudinal preferences/personal opinions.

In the second context, a SEM was used to estimate the desired travel time and travel cost saving that would motivate people to switch to ridesourcing options. The expected time and cost saving were estimated, considering various socio-economic and demographic variables and personal attitudes.

Besides its capability to provide a simultaneous estimation of multiple correlated decisions, SEM was chosen because it allows the user to incorporate unobserved constructs (latent attitudes) into the model structure (Skrondal and Rabe-Hesketh, 2014; Nazari et al., 2019b; Rahimi et al., 2020a). 
SEM consists of two sets of equations. The structural equation shows the causal effects between endogenous variables (variables to be predicted) and their predictors (either as observed exogenous variables or latent factors) as shown in the equation below (Bollen, 1989; Finney and DiStefano, 2013; Asgari and Jin, 2019):

$$
\eta=B \eta+\Gamma X+\psi Y+\xi(5)
$$

Where

$\eta=m \times 1 \quad$ vector of endogenous variables, here including adoption and willingness to pay for AVs or time and cost saving to switch from private mobility

$X=q \times 1 \quad$ vector of observed exogenous variables, including socio-economic, demographic, and habit indices

$Y=p \times 1 \quad$ vector of latent factors

$\xi=m \times 1 \quad$ vector of error terms

$B=m \times m \quad$ coefficient matrix of direct effects among endogenous variables

$\Gamma=m \times q \quad$ coefficient matrix of direct regression effects of $X$ on $\eta$

$\psi=m \times p \quad$ coefficient matrix of direct regression effects of $Y$ on $\eta$

The measurement equation indicates how well latent factors are explained through personal attitudinal indicator:

$$
Y=\Lambda \phi+\zeta(6)
$$

Where

$\phi=r \times 1 \quad$ vector of Likert scale attitudinal responses

$\Lambda=p \times r \quad$ coefficient matrix of regression effects of $\phi$ on $Y$

$\zeta=p \times 1 \quad$ vector of error terms

\subsection{Support Vector Machine}

Machine learning methods have shown promising results in travel mode choice analysis (Tang et al., 2015, Sekhar and Madhu, 2016; Shamshiripour et al., 2019). Support Vector Machine (SVM) is one of the machine learning methods that have gained considerable attention in recent years (Hagenauer and Helbich 2017, Omrani 2015).

In its simplest form, SVM relies on the fact that in a binary-labeled data, there exists an optimum linear boundary (also known as a hyperplane in an n-dimensional space) that fully separates the 
two different classes. The term "optimum" refers to the situation where the distance between the boundary and the closest points from each class to the boundary is maximized. In technical terms, such distance is usually called the "margin", while the closest points from each class are referred to as "support vectors" (Figure 22).

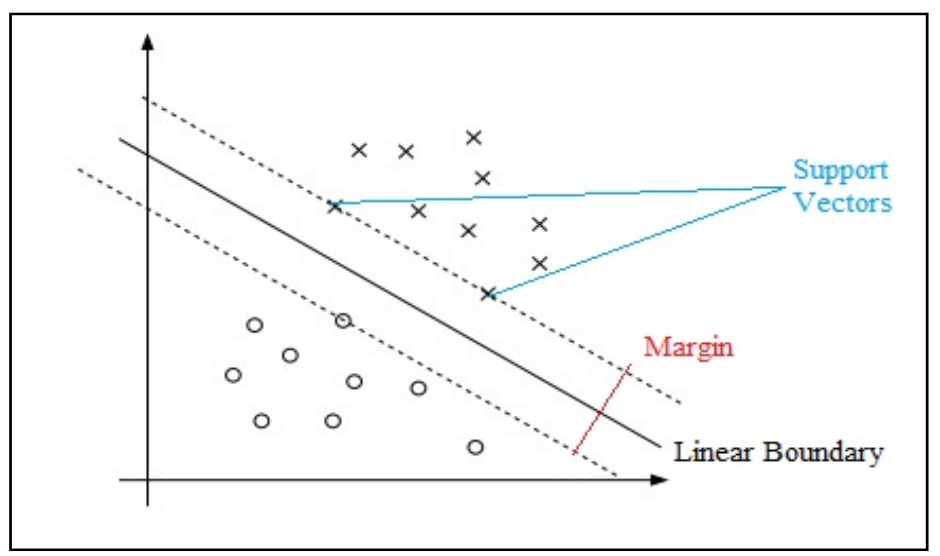

\section{Figure 22 SVM theory schematics.}

Mathematically speaking, the hyperplane boundary could be formulated as $\omega^{T} x+b=0$, with $\omega$ being the normal vector perpendicular to the hyperplane. With the assumption of linearly separable data, the margin, which could be defined as the linear distance between $\omega^{T} x+b=+1$ and $\omega^{T} x+b=-1$ will be derived as $\frac{2}{\|\omega\|}$. Hence, the problem could be formulated as maximizing the margin, i.e. $\frac{2}{\|\omega\|^{\prime}}$, which is equivalent to minimizing the inverse value, $\frac{\|\omega\|}{2}$. In a vector space, the problem could be written as:

$$
\min _{\omega, b} \quad \frac{1}{2} \omega^{T} \omega(7)
$$

s.t. $y_{i}\left(\omega^{T} x_{i}+b\right) \geq 1, \forall\left(x_{i}, y_{i}\right) \in S$

where

$y_{i}=$ binary class labels, $y_{i} \in\{-1,+1\}$

$x_{i}=$ vector of explanatory variables

Considering a simple transformation as $\vec{x}=(x, 1)$ and $\vec{\omega}=(\omega, b)$ the optimization problem could be rewritten as:

$$
\min _{\vec{\omega}} \quad \frac{1}{2} \vec{\omega}^{T} \vec{\omega}(8)
$$

s. t. $y_{i} \vec{\omega}^{T} x_{i} \geq 1, \forall\left(x_{i}, y_{i}\right) \in S$

The above formulation is usually referred to as "hard" SVM, since it is looking for a rigid optimum solution where all the points are correctly labeled by maintaining a minimum distance 
equal to the margin from the boundary. However, this might not be $100 \%$ feasible in real-life examples. The data might not be linearly separable, i.e., an optimum linear boundary that leaves all the data points outside some marginal path might not be found. In order to solve this, the SVM formulation constraint usually needs to be relaxed or, in technical terms, needs to be "softened". In practice, this is usually done by introducing some error term into the constraints as:

$$
y_{i} \omega^{T} x_{i} \geq 1-\xi_{i}, \xi_{i} \geq 0(9)
$$

Now, instead of solving the previous problem, we need to solve:

$$
\begin{aligned}
& \min _{\omega, \xi_{i}} \quad \frac{1}{2} \omega^{T} \omega+C \sum_{i} \xi_{i}(10) \\
& \text { s. t. } \quad y_{i} \omega^{T} x_{i} \geq 1-\xi_{i}, \xi_{i} \geq 0 \quad \forall i
\end{aligned}
$$

The term C, sometimes referred to as the "penalty parameter", is added to the formulation in order to weigh the components of the objective function based on their importance to the analyst.

In optimum, $\xi_{i}=\max \left(0,1-y_{i} \omega^{T} x_{i}\right)$. Then, the objective function will turn to a simple form of:

$$
\min _{\omega} \frac{1}{2}\|\omega\|^{2}+C \sum_{\left(x_{i}, y_{i}\right) \in S} \max \left(0,1-y_{i} \omega^{T} x_{i}\right)
$$

As can be seen, the objective function consists of two different parts. The second term is called the "hinge loss", i.e., the error caused by the model due to misclassification or violating the boundary. The first term is the "regularization parameter" which tries to avoid overfitting by keeping the norm of $\|\omega\|$ as small as possible. The hyperparameter $C$ controls the tradeoff between the hinge loss and the regularization term and is used as an input to the model.

The linear formulation of SVM is expected to provide reasonable predictions when the data is fairly linearly-separable. However, it is quite likely to encounter highly non-linear datasets. The solution in such a case is to transform the data from the initial feature space into a new space using a transformation function $\Phi($.$) , where the transformed data \Phi(x)$ is linearly separable (Figure 23).

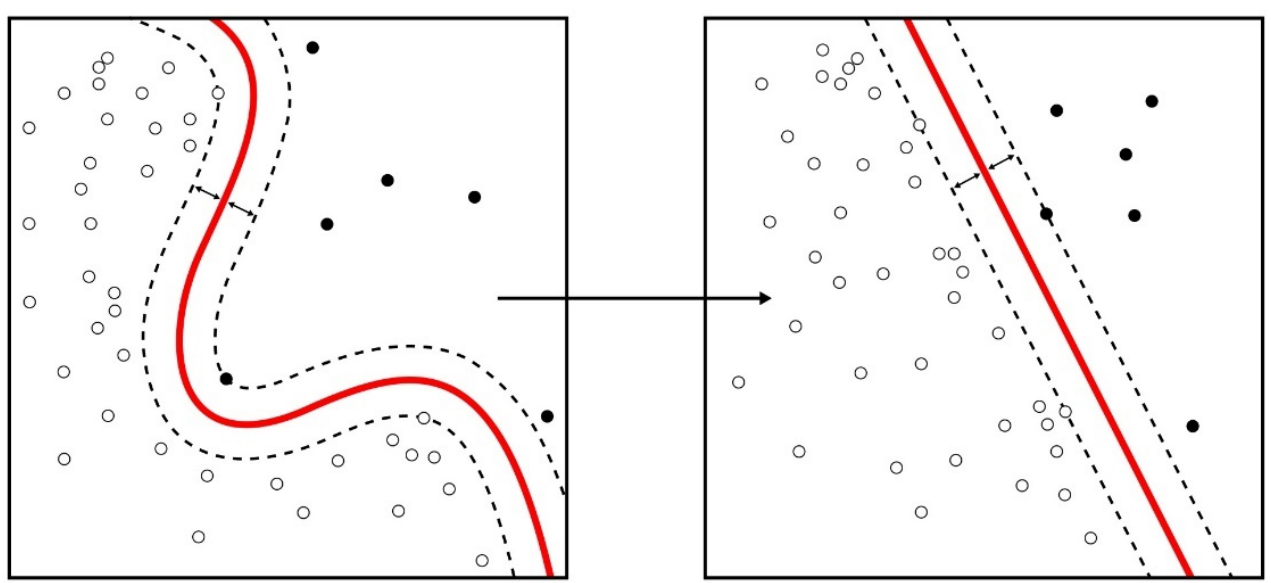

Figure 23 Kernel transformation. 
For our purpose, an SVM model is applied to classify the data sample into frequent versus nonfrequent ride-hailers, and then the performance of the model was evaluated.

The predictors included several socio-economic variables as well as attitudinal and modedependency factors. The socio-economic and demographic variables were all categorical variables and were encoded into binary values. The factors were derived from factor analysis and therefore were standard normal values. Hence, no scaling of the parameters was required.

A lasso regularization approach was used to select the best predictors for the SVM model. L1 regularization adds a penalty of $\alpha \sum_{i=1}^{n}\left|\omega_{i}\right|$ to the loss function (L1-norm). Since each non-zero coefficient adds to the penalty, it forces weak features to have zero as coefficients. Thus, L1 regularization produces sparse solutions, inherently performing feature selection.

Hyperparameters $\mathrm{C}$ and $\gamma$ were optimized using a grid-search approach. In machine learning, a hyperparameter is a parameter whose value is set before the learning process begins (in contrast to other parameters that are derived via training). Grid search is a widely-used approach in the fine-tuning of machine learning models. Conceptually, the function takes different pairs of $(C, \gamma)$ from a given input list and builds a SVM model with any given kernels. The function then evaluates the model through a k-fold cross-validation. The pair that comes up with the best crossvalidation results will be reported as the optimum pair. The grid-search algorithm was iterated for different class weights to come up with the best model. The best model is decided based on the overall accuracy of the model, as well as precision and recall values for both the majority (nonfrequent ride-hailing users) and minority (frequent ride-hailing users) classes.

These methods were used in modeling analysis of travelers' mobility choices in three aspects as indicated previously:

- Adoption and WTP for autonomous vehicles (AVs)

- The willingness to use ridesourcing instead of private vehicles

- Mode choice between conventional modes (driving private vehicle or transit) and emerging mobility options (exclusive ride or shared ride)

The modeling results and findings are presented in the following chapters. 


\section{AV ADOPTION AND WTP}

This section aims to investigate the public's AV adoption and WTP behavior with a specific focus on incorporating attitudinal factors. Adoption and WTP for AVs were investigated based on the following two questions in the survey:

I see myself driving/riding in these vehicles in ten years.

- Basic vehicles (the driver is in the complete and sole control of the primary vehicle functions)

- Advanced features (such as adaptive cruise control, lane centering, crash warning, etc.)

- Partial automation (allows the vehicle to take over only under certain conditions and returns control to the driver when conditions change)

- Full automation (allows the vehicle to take over all driving functions for an entire trip)

I'm willing to pay $\$ \_$more for these features
a) 500
b) 1,000
c) 1,500
d) 2,000
e) 3,000
f) 4,000
g) other

The survey results revealed that the majority of the respondents were either willing to maintain basic vehicle utilization (36\%), or at most, add some advanced features (37\%) such as adaptive cruise control. Only $12 \%$ of the respondents expected themselves to be riding in a fully autonomous vehicle in the next ten years.

The average WTP increased along with the level of adoption, ranging from $\$ 652$ for basic vehicles to $\$ 1,192$ for advanced features, $\$ 1,542$ for partial automation, and $\$ 1,769$ for fully automated alternatives. Interestingly, the survey showed that around $20 \%$ of those who expected full AVs in the next ten years were willing to pay $\$ 4,000$ or more for the new technology, and $43.8 \%$ of them were willing to pay $\$ 2,000$ or more.

\subsection{Model Results}

To explore the public's AV adoption and WTP behavior, an SEM approach was employed. The measurement portion of the model is presented in

Table 133. It revealed four major latent factors. Accordingly, Factor 1 is positively associated with the joy of driving and individuals' unwillingness to multitask. Factor 2 indicates how individuals count on the utility they obtain from their mobility choices, ranging from monetary and time costs to functionality and convenience. Hence, we label this factor as "mode choice reasoning". Factor 3 expresses individuals' trust issues when using shared mobility. Finally, Factor 4 represents a combination of multitasking and technology savviness. Interestingly, attitudes related to benefits/concerns of private ownership did not show any significant contribution to the model. 
Table 13 Result of Measurement Equations for AV Adoption and WTP

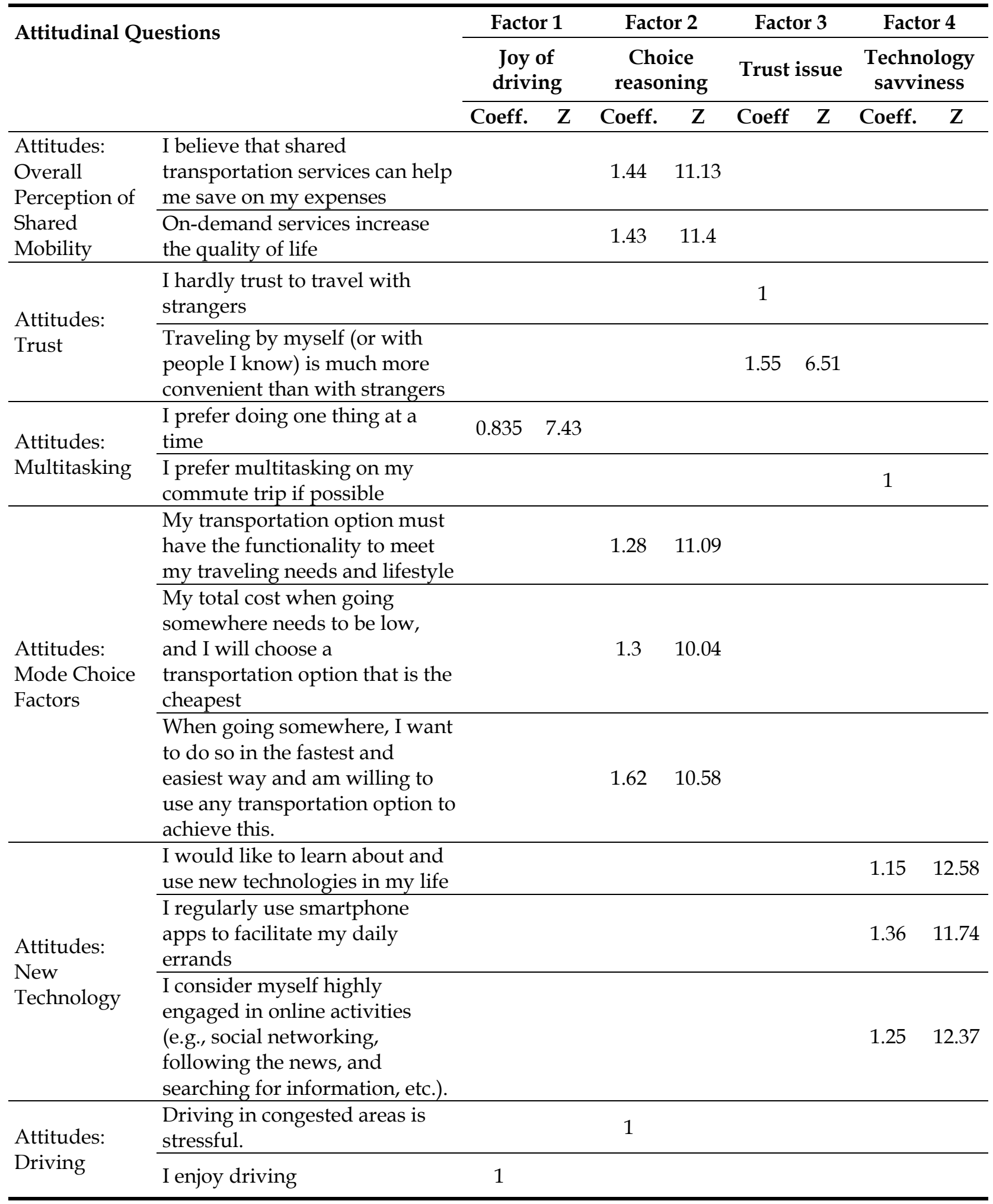

Table 14 presents the structural part of the model. A positive coefficient reflects either the adoption of higher automation levels or higher WTP. In general, most variables only affected one 
of the two decisions, which might indicate that the underlying mechanism for these two decisions is somewhat different. Only two variables, income, and joy of driving, affected both decisions, and in both cases, a commonality effect (similar signs) was observed. Likewise, the positive correlation associated with the two endogenous variables of Adoption and WTP reflects a commonality effect of unobserved variables on these two decisions. In other words, higher adoption levels lead to higher WTP and vice versa.

\section{Table $14 \quad$ Result of Structural Equations}

\begin{tabular}{|c|c|c|c|c|c|}
\hline \multirow{3}{*}{ Variables } & & \multicolumn{4}{|c|}{ Endogenous Variables } \\
\hline & & \multicolumn{2}{|c|}{ Adoption } & \multicolumn{2}{|c|}{ WTP } \\
\hline & & Coeff. & Z & Coeff. & $\mathrm{Z}$ \\
\hline \multirow[t]{3}{*}{ Threshold } & Full automation & 0.703 & 4.73 & & \\
\hline & Partial automation & 0.091 & 0.148 & & \\
\hline & Advanced features & -0.927 & -6.18 & & \\
\hline \multirow[t]{4}{*}{ Age } & Age 50-54 & & & -0.434 & -2.36 \\
\hline & Age 55-59 & -0.285 & -2.55 & & \\
\hline & Age 60-64 & 0.305 & 2.56 & & \\
\hline & Age 75 or older & & & -0.697 & -2.1 \\
\hline Education & High school graduate & -0.23 & -2.99 & & \\
\hline Ethnicity & Black/African American & & & 0.424 & 2.79 \\
\hline \multirow[t]{2}{*}{ Employment } & Full-time student & & & 0.483 & 2.53 \\
\hline & Other & & & 0.501 & 2.59 \\
\hline \multirow[t]{3}{*}{ Income } & $0-25 \mathrm{k}$ & -0.433 & -4.21 & -1.114 & -6.94 \\
\hline & $25-50 \mathrm{k}$ & -0.207 & -2.34 & -0.733 & -6.14 \\
\hline & $50-75 \mathrm{k}$ & & & -0.49 & -4 \\
\hline \multirow[t]{2}{*}{ Habits } & $\begin{array}{l}\text { CHSI_Private Vehicle } \\
\text { Driver }\end{array}$ & -0.065 & -2.82 & & \\
\hline & $\begin{array}{l}\text { CHSI_Private Vehicle } \\
\text { Passenger }\end{array}$ & -0.102 & -3.12 & & \\
\hline \multirow[t]{4}{*}{ Current Mobility Profile } & Parking time: $15-20$ mins & -1.171 & -2.68 & & \\
\hline & Online shopping & & & 0.136 & 4.4 \\
\hline & Ride-sharing experience & & & 0.303 & 2.91 \\
\hline & Driver's license & -0.331 & -2.91 & & \\
\hline \multirow[t]{4}{*}{ Latent Attitudinal Factors } & F1 - joy of driving & -0.489 & -4.11 & -2.46 & -2.89 \\
\hline & F2 - choice reasoning & & & 2.052 & 3.92 \\
\hline & F3 - Trust issue & & & 1.106 & 2.37 \\
\hline & F4 - Technology Savviness & 0.56 & 6.57 & & \\
\hline $\begin{array}{l}\text { Covariance between } \\
\text { Endogenous Variables }\end{array}$ & & 0.482 & 9.69 & & \\
\hline $\begin{array}{l}\text { The goodness of fit } \\
\text { measures }\end{array}$ & $\mathrm{N}=1198, \chi^{2}=1588.239, \mathrm{df}=6$ & $d f=$ & RMSE & & \\
\hline
\end{tabular}


Figure 24 presents the coefficient values of personal and household variables. In view of AV adoption, the negative coefficients associated with individuals 55-59 years old, high school graduates, low-income groups $(<\$ 50 \mathrm{k})$, and those with driver's license showed that these people were less likely to adopt partial or fully AVs, compared to their counterparts.

In terms of WTP, one can observe that full-time students, self-employed individuals, Black Americans, and those who already experienced ride-sharing options were willing to pay more. As expected, low-income groups (less than \$75k) showed lower WTP. Certain age categories (5054 and 75 or older) had negative impacts on WTP, implying that senior individuals were probably less likely to spend on new technologies in their vehicles. In addition, results showed that those with frequent online shopping activities were also likely to spend more on AV technologies.

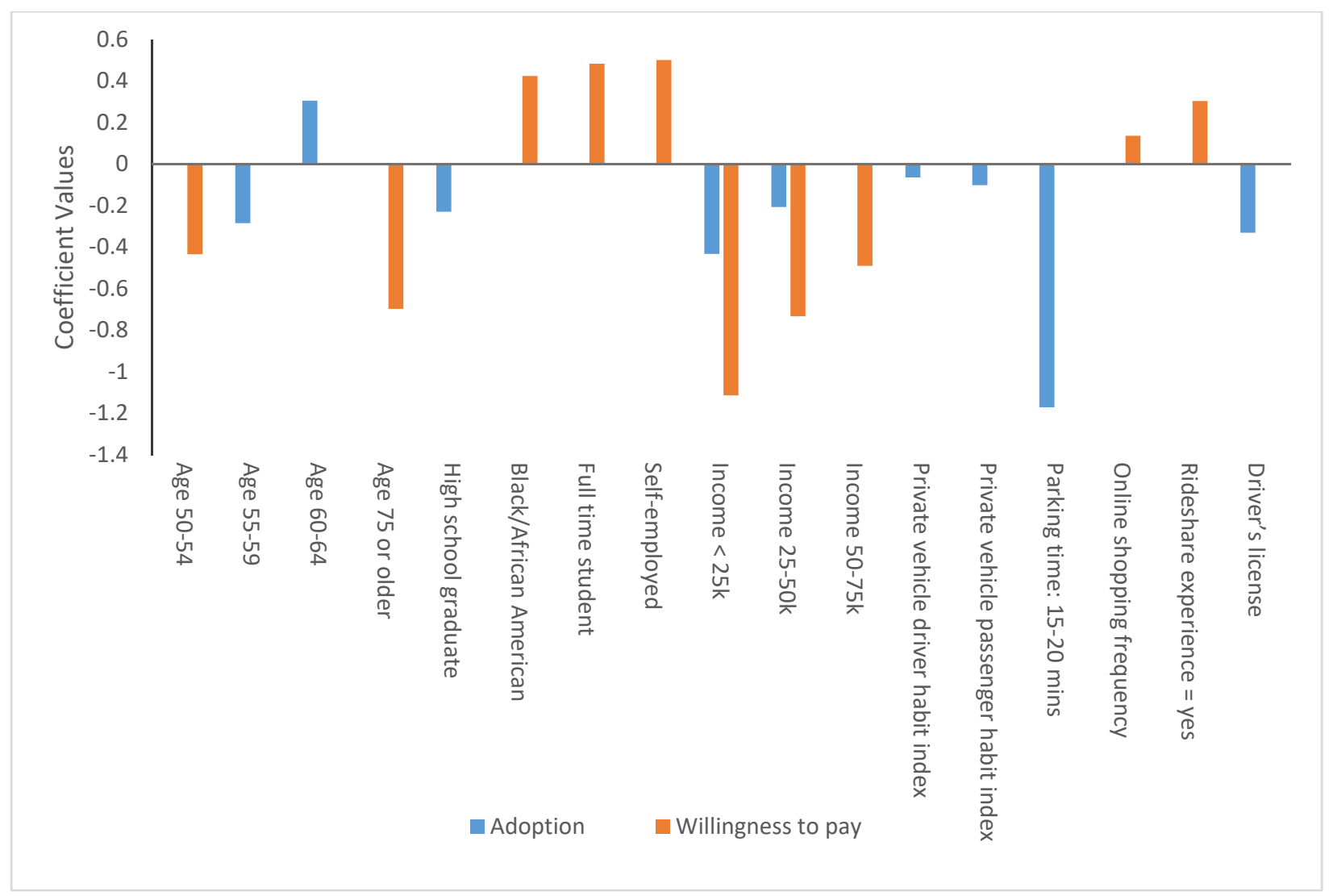

Figure 24 Impacts of personal and household variables on AV adoption and WTP.

Figure 25 presents the coefficient values of attitudinal variables. It shows that the decision to adopt automated vehicles/features was the result of a tradeoff between the joy of driving and technology savviness. While the joy of driving hindered both adoption and WTP for automated features, the tendency to use new technologies motivated individuals toward higher automation levels. Interestingly, mode choice reasoning led to higher WTP levels. This may indicate that people are willing to pay more for automated features when they believe that these features and services will provide them better utility in terms of time and cost saving, convenience, stress 
reduction, and quality of life, etc. Those who preferred to travel by themselves also showed higher WTP. Details of the modeling can be found in a previous effort by the authors (Asgari and Jin, 2019).

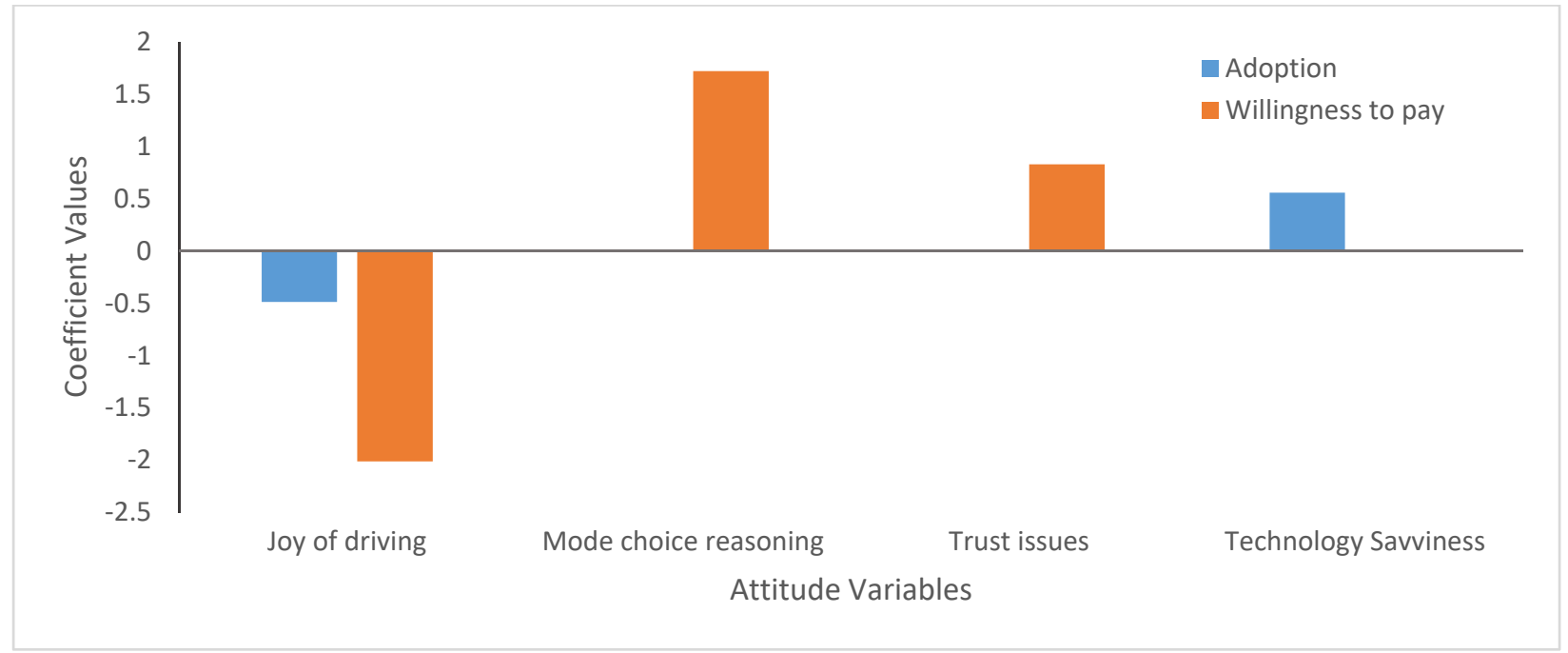

Figure 25 Impacts of attitudinal variables on AV adoption and WTP.

\subsection{Discussions}

With the aim of incorporating attitudinal factors in investigating travelers' choices in AV adoption and WTP, the model revealed four major latent attitudinal factors, respectively labeled as "joy of driving", "mode choice reasoning", "trust", and "technology savviness". The results showed that these attitudinal factors played significant roles in AV adoption and WTP decisions. Specifically, those who enjoyed driving were the hardest to persuade toward AV adoption or to pay for automated features. On the other hand, technology-savvy people showed a higher tendency toward AV adoption. The positive coefficient associated with "mode choice reasoning" factor may suggest that people are willing to pay more for automated features when they believe that these features and services will provide them better utility, in relation to time and cost saving, convenience, stress reduction, and quality of life, and so forth. Interestingly, individuals with trust concerns showed higher WTP values, which may indicate that the market believes AVs will bring more privacy and protection, at least compared with existing shared mobility or public transit options.

The results of this study shed light on the current state of the AV market in the United States, specifically by taking into account individuals' attitudes and preferences in addition to the conventional socio-economic and demographic information. It is expected that incorporating attitudinal factors will increase the predictive power of the models and that the results of this study will help provide a better understanding of the market, which then leads to more efficient estimates of AV technology adoption rates and its successive impacts. The results could be implemented in the existing model framework to estimate the share of AVs in the near future. 


\section{RIDESOURCING ADOPTION}

In this section, two distinct approaches have been considered to investigate individuals' propensity to switch to ridesourcing services. The first approach explored the desired travel time and travel cost saving that would motivate people to switch to ridesourcing options. The second approach analyzed the ride-hailing market with a focus on frequent users (i.e., use ride-hailing services at least once a week or more), who may hold a higher propensity of shifting to ridesourcing options instead of private vehicle ownership. Specifically, the latter study focused on an individual's mode-dependency patterns and attitudinal factors as additional explanatory variables and investigates their impacts on ride-hailing usage frequency.

\subsection{Expected Travel Time and Cost saving to Switch from Private Mobility to Ridesourcing}

This section explicitly looks into the desired travel time and travel cost saving that would motivate travelers to switch to ridesourcing from private vehicle ownership. Focusing on general mobility decision making, the survey asked each respondent the following questions:

Q: I will use ridesourcing if it saves me minutes (such as time saved in finding parking or walking from parking or transit station to your destination).
a) 5
b) 10
c) 15
d) 20
e) 25
f) 30 or more

Q: I would use ridesourcing if driving cost increases by __ dollars per month (e.g., you can think of fuel cost, parking cost, or fare).
a) $\$ 50$
b) $\$ 100$
c) $\$ 150$
d) $\$ 200$
e) $\$ 250$ or more

These questions were designed in a way to replicate the decision-making process in view of time and cost saving. It sounds rational that when travelers plan for a long term period, they add up their travel costs for a specific duration (e.g., their payment period) and then assign a specific portion of their budget to that means of transportation. Hence, when asking about cost saving, the study used one month as the study unit and asked about users' expected monthly savings. This is expected to provide a clear picture of a long-term or permanent replacement of private vehicle ownership. In view of travel time, single trips remain as the major unit of analysis. When targeting a destination, time indices such as travel time, delay, reliability, etc. are all meaningful within a unit trip framework and aggregations are therefore meaningless. The context of the survey prompted the respondents to think of a regular trip or the most frequent trip they made.

Figure 26 shows the summary results of the responses to the two questions. A quick comparison of the two graphs shows that cost probably played a stronger role in mobility decisions than time savings. Specifically, a monthly cost increase of $\$ 100$ would persuade $66 \%$ of the respondents to switch to ridesourcing services, on the other hand, a 25-minute time saving was needed to achieve 
the same magnitude of the effect, which would be unrealistic considering that the average trip length was about 24 minutes. More than 35\% of the respondents indicated that they needed at least 30 minutes of time savings for regular trips to switch to on-demand service as a mobility option.

The Analysis of Variance (ANOVA) showed that individuals below 18 years old had the lowest expectations of time and cost saving (16.38 minutes/day and \$94.4/month) while older respondents (60-69 years old) tended to expect higher savings (23 minutes/day and \$127/month). Interestingly, gender and household size had no significant impact. Those with a drivers' license had higher saving expectations (19.9 minutes per day and \$119.64 per month).

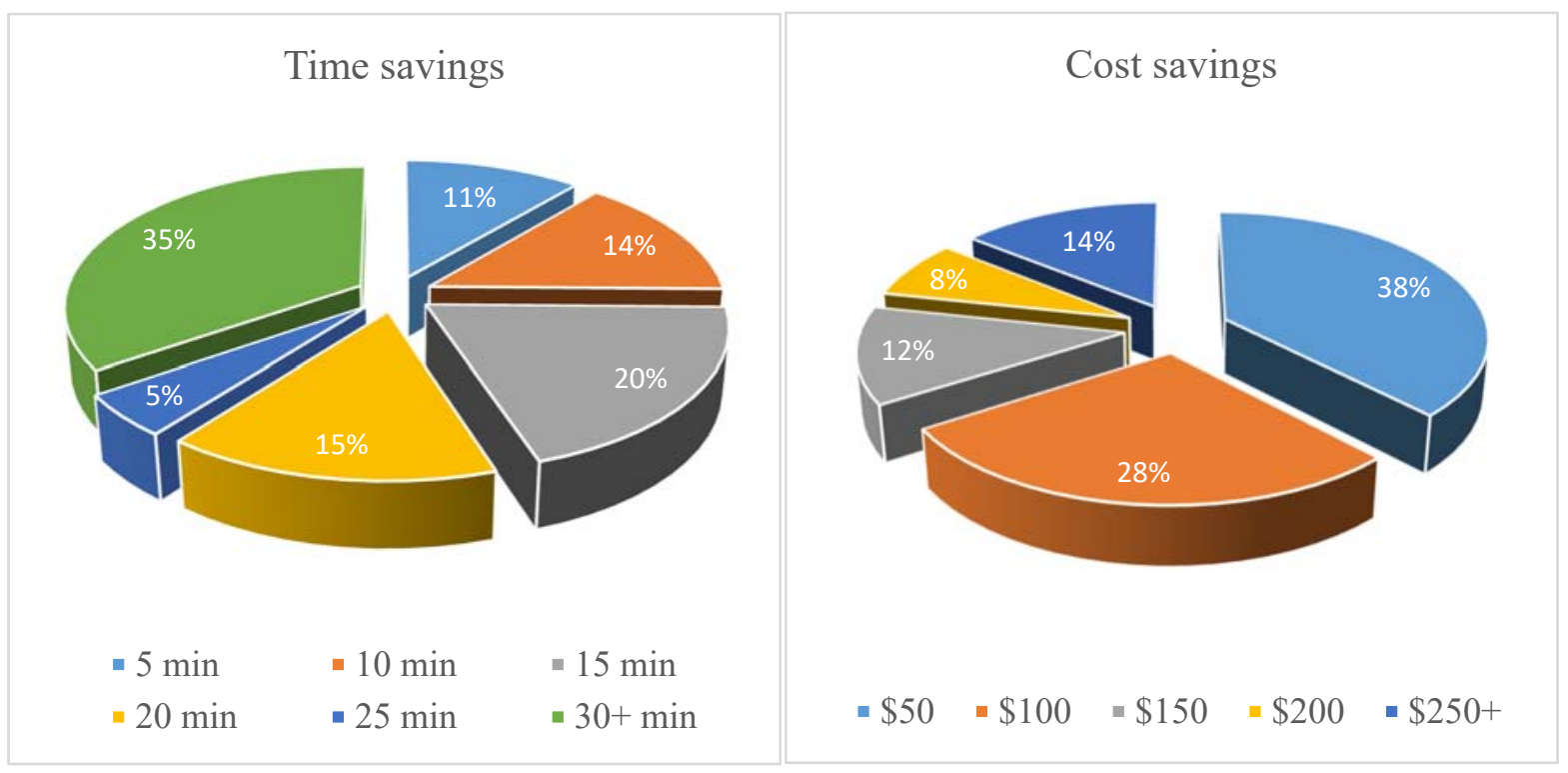

Figure 26 Minimum time and cost saving needed to switch to ridesourcing.

\subsubsection{Model Results}

An SEM approach was employed to estimate the expected time and cost saving to switch to ridesourcing. This section discusses the results of the measurement portion of the model, as presented in 15. It reveals seven major latent factors. Accordingly, Factor 1 is positively associated with the joy of driving and individuals' unwillingness to multitask. Factor 2 indicates how individuals count on the utility they obtain from their mobility choices, ranging from monetary and time costs to functionality and convenience. Hence, we label this factor as "mode choice reasoning". Factor 3 expressed individuals' trust issues when using shared mobility. Finally, Factor 4 represents a combination of multitasking and technology savviness. Factors 5 through 7 represent the perception of private ownership advantages and disadvantages. Particularly, disadvantages are separated into financial and non-financial categories. Interestingly, attitudes about benefit-concern perceptions did not show any significant contribution to the model. 
Table 15 Result of Measurement Equations

\begin{tabular}{|c|c|c|c|c|c|c|c|}
\hline & Factor 1 & Factor 2 & Factor 3 & Factor 4 & Factor 5 & Factor 6 & Factor 7 \\
\hline Attitudinal Questions & $\begin{array}{l}\text { Joy of } \\
\text { Driving }\end{array}$ & $\begin{array}{l}\text { Mobility } \\
\text { Choice } \\
\text { Reasoning }\end{array}$ & Trust & $\begin{array}{l}\text { Multitasking } \\
\text { and new } \\
\text { technologies }\end{array}$ & $\begin{array}{c}\text { Private } \\
\text { Ownership } \\
\text { Pros }\end{array}$ & $\begin{array}{l}\text { Private } \\
\text { Ownership } \\
\text { Cons: Non- } \\
\text { financial } \\
\end{array}$ & $\begin{array}{l}\text { Private } \\
\text { Ownership } \\
\text { Cons: } \\
\text { Financial } \\
\end{array}$ \\
\hline I enjoy driving & 1 (Fixed) & & & & & & \\
\hline $\begin{array}{l}\text { I prefer doing one thing at } \\
\text { a time. }\end{array}$ & $\begin{array}{r}1.013 \\
(6.701) \\
\end{array}$ & & & & & & \\
\hline $\begin{array}{l}\text { Driving in traffic } \\
\text { congestions is stressful. }\end{array}$ & & 1 (Fixed) & & & & & \\
\hline $\begin{array}{l}\text { When going somewhere, I } \\
\text { want to do so in the fastest } \\
\text { and easiest way and am } \\
\text { willing to use any } \\
\text { transportation option to } \\
\text { achieve this. }\end{array}$ & & $\begin{array}{c}1.964 \\
(10.677)\end{array}$ & & & & & \\
\hline $\begin{array}{l}\text { My transportation option } \\
\text { must have the functionality } \\
\text { to meet my traveling needs } \\
\text { and lifestyle }\end{array}$ & & $\begin{array}{l}1.175 \\
(9.198)\end{array}$ & & & & & \\
\hline $\begin{array}{l}\text { My total cost when going } \\
\text { somewhere needs to be } \\
\text { low, and I will choose a } \\
\text { transportation option that } \\
\text { is the cheapest. }\end{array}$ & & $\begin{array}{l}1.409 \\
(9.574)\end{array}$ & & & & & \\
\hline $\begin{array}{l}\text { I believe that shared } \\
\text { transportation services can } \\
\text { help me save on my } \\
\text { expenses. }\end{array}$ & & $\begin{array}{c}1.745 \\
(10.687)\end{array}$ & & & & & \\
\hline $\begin{array}{l}\text { On-demand services } \\
\text { increase the quality of life. }\end{array}$ & & $\begin{array}{c}1.724 \\
(10.802) \\
\end{array}$ & & & & & \\
\hline $\begin{array}{l}\text { I hardly trust to travel with } \\
\text { strangers. }\end{array}$ & & & 1 (Fixed) & & & & \\
\hline $\begin{array}{l}\text { Traveling by myself (or } \\
\text { with people I know) is } \\
\text { much more convenient } \\
\text { than with strangers. }\end{array}$ & & & $\begin{array}{c}1.065 \\
(9.803)\end{array}$ & & & & \\
\hline $\begin{array}{l}\text { I prefer multitasking on } \\
\text { my commute trip if } \\
\text { possible. }\end{array}$ & & & & 1 (Fixed) & & & \\
\hline $\begin{array}{l}\text { I consider myself highly } \\
\text { engaged in online activities } \\
\text { (e.g., social networking, } \\
\text { following the news, and } \\
\text { searching for information, } \\
\text { etc.). }\end{array}$ & & & & $\begin{array}{c}1.358 \\
(15.018)\end{array}$ & & & \\
\hline $\begin{array}{l}\text { I regularly use smartphone } \\
\text { apps to facilitate my daily } \\
\text { errands (online } \\
\text { transactions, navigation, } \\
\text { and checking emails, etc.). }\end{array}$ & & & & $\begin{array}{c}1.645 \\
(15.206)\end{array}$ & & & \\
\hline
\end{tabular}




\begin{tabular}{|c|c|c|c|c|c|c|c|}
\hline \multirow[b]{2}{*}{ Attitudinal Questions } & Factor 1 & Factor 2 & Factor 3 & Factor 4 & Factor 5 & Factor 6 & Factor 7 \\
\hline & $\begin{array}{l}\text { Joy of } \\
\text { Driving }\end{array}$ & $\begin{array}{l}\text { Mobility } \\
\text { Choice } \\
\text { Reasoning }\end{array}$ & Trust & $\begin{array}{l}\text { Multitasking } \\
\text { and new } \\
\text { technologies }\end{array}$ & $\begin{array}{c}\text { Private } \\
\text { Ownership } \\
\text { Pros }\end{array}$ & $\begin{array}{c}\text { Private } \\
\text { Ownership } \\
\text { Cons: Non- } \\
\text { financial }\end{array}$ & $\begin{array}{c}\text { Private } \\
\text { Ownership } \\
\text { Cons: } \\
\text { Financial }\end{array}$ \\
\hline $\begin{array}{l}\text { I would like to learn about } \\
\text { and use new technologies } \\
\text { in my life. }\end{array}$ & & & & $\begin{array}{c}1.16 \\
(14.991)\end{array}$ & & & \\
\hline $\begin{array}{l}\text { Reason for private } \\
\text { ownership: Convenience }\end{array}$ & & & & & 1 (Fixed) & & \\
\hline $\begin{array}{l}\text { Reason for private } \\
\text { ownership: Enjoy Driving }\end{array}$ & & & & & $\begin{array}{c}1.247 \\
(10.818)\end{array}$ & & \\
\hline $\begin{array}{l}\text { Reason for private } \\
\text { ownership: Car Lover }\end{array}$ & & & & & $\begin{array}{l}0.993 \\
(9.718)\end{array}$ & & \\
\hline $\begin{array}{l}\text { Reason for private } \\
\text { ownership: Privacy }\end{array}$ & & & & & $\begin{array}{c}1.724 \\
(12.206)\end{array}$ & & \\
\hline $\begin{array}{l}\text { Reason for private } \\
\text { ownership: Reliability }\end{array}$ & & & & & $\begin{array}{c}1.726 \\
(12.184) \\
\end{array}$ & & \\
\hline $\begin{array}{l}\text { Reason against private } \\
\text { ownership: Prefer other } \\
\text { modes }\end{array}$ & & & & & & 1 (Fixed) & \\
\hline $\begin{array}{l}\text { Reason against private } \\
\text { ownership: Limited } \\
\text { number of daily trips }\end{array}$ & & & & & & $\begin{array}{c}0.739 \\
(3.306)\end{array}$ & \\
\hline $\begin{array}{l}\text { Reason against private } \\
\text { ownership: lack of parking } \\
\text { space }\end{array}$ & & & & & & $\begin{array}{c}0.826 \\
(3.751)\end{array}$ & \\
\hline $\begin{array}{l}\text { Reason against private } \\
\text { ownership: Ownership } \\
\text { cost }\end{array}$ & & & & & & & 1 (Fixed) \\
\hline $\begin{array}{l}\text { Reason against private } \\
\text { ownership: Maintenance } \\
\text { cost }\end{array}$ & & & & & & & $\begin{array}{l}1.106 \\
(4.768)\end{array}$ \\
\hline
\end{tabular}

Table 16 presents the structural portion of the model. The variables tested in the model include socio-economics and demographics, current mobility expenses, habitual indices for each mode, previous ride-sharing experience, as well as personal attitudes.

In the absence of any other information about the sample, our model predicts a time saving of approximately 18 minutes per trip and a cost saving of roughly \$106 in mobility expenses per month, that are required to motivate the respondents to switch to ridesourcing.

Before we proceed to the quantitative analysis of model results, it is worth mentioning that a positive coefficient indicates a higher amount of savings (either in terms of travel time or in view of mobility expenses) required by the market to shift to ridesourcing. In other words, parameters accompanied by positive coefficients are those that inhibit the potential switch to ridesourcing. On the other hand, attributes with negative coefficients could be interpreted as those who require lower savings and are therefore persuaded more easily compared to other groups. 
With this in mind, only three variables, income, auto-dependency, and self-employment, directly affected both decisions, and in all cases, a commonality effect (similar signs) was observed. Likewise, the positive correlation associated with the two endogenous variables of time-saving and cost saving reflects a commonality effect of unobserved variables on these two decisions. In other words, higher time-saving levels lead to higher cost saving and vice versa.

Table 16 Result of Structural Model

\begin{tabular}{|c|c|c|}
\hline Variables & Time Saving & Cost Saving \\
\hline Intercept & $18.258(24.752)$ & $105.688(22.281)$ \\
\hline Male & & $8.122(2.249)$ \\
\hline Age 18-24 & $-1.762(-2.476)$ & \\
\hline Age 25-29 & $-1.514(-2.206)$ & \\
\hline Age $30-34$ & & $20.612(3.636)$ \\
\hline Age35-39 & & $17.569(2.809)$ \\
\hline Age55-59 & & $-10.815(-1.694)$ \\
\hline White & $0.954(1.735)$ & \\
\hline Asian & & $-24.91(-1.788)$ \\
\hline Other ethnicities & $7.38(2.31)$ & \\
\hline Less than 9th grade & $-8.86(-3.191)$ & \\
\hline Associate degree & $1.787(2.037)$ & \\
\hline Self-employed & $2.825(2.571)$ & $14.446(1.645)$ \\
\hline Income less than $25 \mathrm{k}$ & $-1.824(-2.868)$ & $-22.837(-4.478)$ \\
\hline Income $25-50 \mathrm{k}$ & $-1.249(-2.326)$ & $-12.68(-2.93)$ \\
\hline Income 125-150k & & $25.565(2.318)$ \\
\hline Habit strength_private vehicle driver & $0.714(4.875)$ & $4.924(4.761)$ \\
\hline Habit Strength_Ridesourcing & $-1.389(-2.616)$ & \\
\hline Habit Strength_Public Transit & $0.695(1.844)$ & \\
\hline Parking fare per trip: $\$ 10 \_15$ & & $33.356(2.44)$ \\
\hline Time spent on finding a parking spot: $5 \_10$ mins & & $-15.989(-3.03)$ \\
\hline Factor 2: Mobility Choice Reasoning & & $-42.546(-6.292)$ \\
\hline Factor 3: Trust & & $13.004(3.353)$ \\
\hline Factor 5: Private Ownership Pros & & $60.6(4.787)$ \\
\hline Factor 7: Private Ownership Cons: Financial & $-32.919(-4.329)$ & \\
\hline Factor 4: Multitasking and new technologies & $3.134(3.117)$ & \\
\hline Factor 6: Private Ownership Cons: Non-financial & $-16.602(-2.012)$ & \\
\hline Covariance parameter & \multicolumn{2}{|c|}{$114.139(15.903)$} \\
\hline Correlation & \multicolumn{2}{|c|}{0.299} \\
\hline The goodness of fit measures & \multicolumn{2}{|c|}{$\chi^{2}=2575.746, \mathrm{df}=769, \frac{\chi^{2}}{d f}=3.34, \quad$ RMSEA $=$} \\
\hline
\end{tabular}

As far as socio-economic and demographics are concerned, one can refer that individuals younger than 25 years old, between 55 to 59, those with less than 9th-grade education, low-income people (below 50k), and Asians are easier to be persuaded toward ride-source usage. Interestingly, middle-aged individuals (30-40 years old) required the highest amount of cost saving compared 
to other age categories. This seems reasonable as this age group is most probably family heads and full-time workers, with higher daily trip rates, including daily commutes and other cardependent activities, and therefore are not willing to give up their personal vehicles unless a high incentive is on the way. The model predicts that males call for higher cost saving compared to females (by roughly $\$ 8$ per month).

In view of education, results show that the lowest educated group expected lower time savings with no significant impacts on cost saving. This might indicate that these individuals have lower values of time compared to other market segments and that probably travel time does not play an important role in their mobility choice decisions.

As expected, low-income people would welcome ridesourcing options at small amounts of time/cost saving. This might reflect that low-income groups are more cautious toward their mobility expenses and even small amounts of savings will highly motivate them.

We also incorporated mobility habits into our decision-making structure. Consequently, highly car-dependent individuals are the hardest to persuade toward switching from their private ownership. On the contrary, people who had already experienced on-demand services tended to require lower expectations, mainly in terms of time savings. In other words, they are easier to be motivated for ridesourcing services. In order to persuade transit-dependent individuals, policies should target travel time savings because transit-dependent users looked insensitive toward cost saving (probably because they are already using the cheapest mobility alternative).

In view of personal preferences, latent constructs derived from the measurement model are incorporated into the structural equations. Based on the model results, individuals who highly benefited from private ownership advantages (e.g., convenience, reliability, the joy of driving, etc.), along with those who experienced a lack of trust in traveling with strangers, were the hardest to motivate to switch to ridesourcing services. The positive coefficients associated with these individuals show that higher levels of cost saving are required to persuade them to shift from private vehicle ownership to ridesourcing option. In particular, the former group calls for an additional cost saving of approximately $\$ 60$ per month, which reflects an increase of $57 \%$ compared to the base expected cost saving. On the other hand, those with high levels of the "mobility choice reasoning" factor, are predicted to have lower expectations of cost saving. This might indicate that the decision to choose between conventional modes and emerging options is not restricted to the minimization of travel cost and may well be influenced by a variety of other parameters such as functionality, accessibility, adaptability to specific conditions, etc.

In view of travel time, results show that lower savings were needed by people who believe in private mobility disadvantages, and this included both financial and non-financial drawbacks of owning a private vehicle. On the other hand, higher amounts of travel time savings were expected by those who favored multitasking and new technologies. This is an interesting point to notice because multitasking has always been referred to as a benefit of ridesourcing and emerging 
mobility alternatives, our model showed that it is not yet perceived as strong enough to trade for travel time.

The SEM model also estimates the covariance (correlation) between the error terms associated with the two dependent variables. Accordingly, the model reveals a significant and positive correlation (0.299). The positive correlation implies that the unobserved parameters have commonality effects on the two decisions, i.e., higher expectations of time savings will be accompanied by higher expectations of cost saving and vice versa. In other words, and when it comes to the level of service, people expect savings in both time and cost. They might trade time or cost to gain other benefits such as safety, multitasking, etc. but they are unlikely to mutually trade any of these two for one another. Details of the modeling can be found in a previous effort by the authors (Jin and Asgari, 2020).

\subsubsection{Discussions}

The results of this study showed that people younger than 29 years old, low-income individuals, and people with previous ridesourcing experience tend to expect less in view of both travel time and travel cost saving and therefore, will be persuaded more easily compared to other groups. On the contrary, middle-aged people, highly car-dependent individuals, and the self-employed category were likely to demand higher savings from ridesourcing options.

In view of latent attitudinal factors, it is evident that trust issues and private ownership advantages (such as comfort, convenience, and reliability) act as barriers against regular ridesourcing utilization, therefore required higher cost saving to convince them to switch to ridesourcing. On the other hand, those concerned with both financial (including capital and maintenance costs) and non-financial (such as parking issues) issues of private ownership required less time-saving for them to choose ridesourcing.

As expected, those with higher levels of reasoning factor (as opposed to habitual actions) are more likely to switch to ridesourcing with less cost saving. Interestingly, while we expected to see an encouraging impact of multitasking on ridesourcing (i.e., a negative coefficient in our model), the model showed the opposite. Accordingly, even those who favor multitasking still expect to see some amount of time-saving compared to their conventional modes. This probably indicates that the market is not yet ready to trade travel time for multitasking. Finally, the significant and positive correlation between time and cost saving reveals that respondents expected both savings simultaneously, i.e., an increase in cost saving expectation will result in an increase in time-saving and vice versa. They are not likely to tradeoff the two.

The results of this study are expected to provide helpful insights into the public perception of the level of service associated with on-demand mobility services. With the fast pace of enhancement in automotive technology, it challenges the planners to predict when the public will welcome shared mobility and give up on their private vehicle ownership, which is perceived as a normbreaking and revolutionary decision. In this regard, this study provides an approach to evaluate 
the propensity of ridesourcing options in view of the expected travel time and cost saving. A better understanding of the magnitude of time and cost saving needed to motivate the public to adopt ridesourcing would provide policymakers with valuable information in designing and guiding mobility services, such as fare structures or incentives that would help promote ridesourcing services. Moreover, the analysis based on market segmentation can provide further insights into prescribing effective and efficient strategies.

\subsection{Impacts of Mode Dependency on Ridesourcing Decisions}

This section provides an effort to analyze frequent ridesourcing decisions by identifying significant determinants and quantifying their impacts on individuals' ridesourcing behavior. In particular, we focus on latent mode-dependency patterns. For this study, the regularity of ridesourcing usage is derived from the following survey question:

Q: How often do you travel in ridesourcing mode?
a) daily or almost daily
b) 1-3 times a week
c)1-3 times a month
d) a few times a year
e) less than once a year or never

Accordingly, we consider " $\mathrm{a}$ " and " $\mathrm{b}$ " as a "frequent" ride-hailer while the rest are labeled as a "non-frequent" or occasional ride-hailer. As expected, 9\% of the sample used ridesourcing options regularly (at least once a week), while $91 \%$ are occasional consumers.

In addition, respondents were asked about their perceptions toward driving, service quality, shared transportation, multitasking, and new technologies. Given the preference variables, factor analysis was performed to identify the latent factors that represent respondents' attitudes. Based on the results of the factor analysis, four major attitude factors were identified:

- Factor 1- Joy of driving: reflects the positive association with the joy of driving and individuals' unwillingness to multitask;

- Factor 2- Mode choice reasoning: indicates how individuals count on the utility they obtain from their mobility choices, ranging from monetary and time costs to functionality and convenience;

- Factor 3- Trust issue: expresses individuals' trust issue toward shared mobility;

- Factor 4- Technology savviness: represents individuals' interest in technology-related services and multitasking.

These factors were included in the model to explore whether and to what extent attitudes may have affected users' mobility choices on ridesourcing usage.

\subsubsection{Mode Dependency}

The major hypothesis is that a long-term mobility decision (in this case, a permanent substitution of private vehicle modes with ridesourcing) could not be fully explained by comparing the perceived utilities associated with the two choices. There might be certain latent factors that attach 
the respondents to their private cars and govern their decisions as obstacles against shifting to alternative mobility choices. These latent schemes are referred to as "mode-dependency" patterns. The concept of mode-dependency is not new. In particular, few studies have documented auto-dependency and its significant impact on mode choice decisions (Chang and Wu 2008, Sohn and Yun 2009, Habib and Zaman 2012).

For the purpose of this study, mode-dependency patterns were derived through factor analysis based on several observed variables in the survey data, including:

- Personal attributes associated with driving: holding a driver's license

- Household structure variables: number of vehicles owned, number of drivers per household, etc.

- Mode usage parameters: mode frequency (daily, 1-3 times a week, 1-3 times a month, a few times a year, less than once a year or never) for each mode, most frequent one-way trip distance for each mode, the trip purpose for each mode used (commute and others).

- Employment status: worker, non-worker, unemployed, student, retired, others, etc.

Table 17 Results of Factor Analysis for Mode Dependency

\begin{tabular}{|c|c|c|c|c|c|c|}
\hline & \multicolumn{6}{|c|}{ Component } \\
\hline & $\begin{array}{c}\text { Factor } \\
1\end{array}$ & $\begin{array}{c}\text { Factor } \\
2\end{array}$ & $\begin{array}{c}\text { Factor } \\
3\end{array}$ & $\begin{array}{c}\text { Factor } \\
4\end{array}$ & $\begin{array}{l}\text { Factor } \\
5\end{array}$ & $\begin{array}{l}\text { Factor } \\
6\end{array}$ \\
\hline Has a driver license (yes) & 0.658 & -0.158 & 0.002 & 0.032 & 0.273 & -0.201 \\
\hline Number of $\mathrm{HH}$ drivers & 0.135 & 0.086 & -0.027 & -0.021 & 0.905 & 0.054 \\
\hline Number of HH vehicles & 0.159 & 0.13 & -0.113 & 0.08 & 0.856 & 0.061 \\
\hline Mode frequency of private vehicle-driver & 0.839 & 0.056 & -0.121 & 0.061 & 0.067 & -0.077 \\
\hline Mode frequency of private vehicle-passenger & 0.05 & 0.813 & 0.055 & 0.046 & 0.065 & -0.031 \\
\hline Mode frequency of transit & -0.149 & 0.089 & 0.798 & 0.14 & -0.099 & 0.039 \\
\hline Trip distance for private vehicle-driver (mile) & 0.775 & 0.113 & 0.061 & -0.065 & 0.062 & 0.043 \\
\hline $\begin{array}{l}\text { Trip distance for private vehicle-passenger } \\
\text { (mile) }\end{array}$ & 0.331 & 0.643 & 0.133 & -0.166 & 0.047 & -0.002 \\
\hline Trip distance associated with transit (mile) & 0.024 & 0.113 & 0.841 & 0.049 & -0.03 & 0.027 \\
\hline Use private vehicle driver mode for commute & 0.7 & -0.026 & -0.21 & 0.279 & 0.028 & 0.079 \\
\hline $\begin{array}{l}\text { Use private vehicle passenger mode for } \\
\text { commute }\end{array}$ & -0.175 & 0.631 & -0.038 & 0.172 & 0.063 & 0.107 \\
\hline $\begin{array}{l}\text { Use private vehicle driver mode for other } \\
\text { purposes }\end{array}$ & 0.768 & -0.045 & -0.308 & -0.011 & 0.073 & 0.007 \\
\hline $\begin{array}{l}\text { Use private vehicle passenger for other } \\
\text { purposes }\end{array}$ & -0.062 & 0.767 & -0.01 & 0.021 & 0.051 & -0.006 \\
\hline $\begin{array}{l}\text { Use alternate modes (other than private car) for } \\
\text { non-commute purposes }\end{array}$ & -0.37 & -0.156 & 0.698 & 0.074 & -0.018 & -0.008 \\
\hline Worker & 0.097 & 0.052 & 0.124 & 0.935 & 0.007 & -0.267 \\
\hline Non-worker & -0.073 & -0.072 & -0.155 & -0.944 & -0.056 & -0.178 \\
\hline Student & -0.057 & 0.039 & 0.058 & -0.046 & 0.105 & 0.972 \\
\hline
\end{tabular}

Results from the factor analysis are presented in Table 17. Accordingly, six latent factors were identified: 
- Factor 1: Highly car-dependent drivers: those who hold a driver's license and use their private vehicles for almost all purposes, regardless of employment status.

- Factor 2: Highly car-dependent passengers: those without a driver's license who get rides from family members or friends and tend to use the same passenger mode for all trips, regardless of employment status.

- Factor 3: Transit-dependent travelers: those who do not hold a driver's license and use transit for non-commute purposes, and unlikely to drive for any trip purposes.

- Factor 4: Daily commuters: Workers who use their cars for daily commutes and are less likely to use their private vehicles for other purposes.

- Factor 5: Abundant households: People with a driver's license from big families and high vehicle ownership. It seems that they use cars either as passengers or as drivers, but no alternate mode usage.

- Factor 6: Students with no driver's license: They either get rides from other family members or use alternate modes.

\subsubsection{Model Results}

An SVM approach was applied to investigate ridesourcing adoption behavior considering mode dependency and attitudinal factors. By considering balanced class-weights for a linear kernel SVM, a hyperparameter $\mathrm{C}=1$ was detected. The model performance results are illustrated in Table 18. The precision measure represents the ratio of true positives over the sum of true positives and false positives. The recall measure refers to the ratio of true positives over the sum of true positives and false negatives. Accuracy measures the ratio of all correctly predicted observations (true positives true negatives) over the whole sample. A summary of the model performance is demonstrated in Table 18.

\section{Table $18 \quad$ Linear SVM Model Performances}

\begin{tabular}{llllll}
\hline & \multicolumn{5}{l}{ Linear SVM } \\
\hline Hyperparameter & C & 1 & & 0.25 & \\
Class weights & W-non-frequent & balanced & 2.5 & \\
& W-frequent & balanced & 8 & \\
Train Data & Overall Accuracy & $86.40 \%$ & & $92.30 \%$ & \\
& & Precision & Recall & Precision & Recall \\
& Majority-Non-frequent & 0.99 & 0.86 & 0.98 & 0.94 \\
Test data & Minority-frequent & 0.4 & 0.92 & 0.56 & 0.78 \\
& Overall Accuracy & $85 \%$ & & $90.40 \%$ & \\
& & Precision & Recall & Precision & Recall \\
& Majority-Non-frequent & 0.97 & 0.86 & 0.97 & 0.93 \\
& Minority-frequent & 0.36 & 0.76 & 0.51 & 0.71 \\
\hline
\end{tabular}

The model showed an overall accuracy of $86.4 \%$ and $85 \%$ on training and test sets, respectively, with no signs of overfitting (recall value close to 1). However, a further look into the confusion 
matrix, reveals that the model's accuracy is mainly due to its performance on the majority class (non-regular riders). On the contrary, the precision of minority class predictions is quite low, 0.4 and 0.36 for training and test sets, respectively. This is a critical issue given the nature of the study. The main objective of the model is to capture frequent riders, which is less than $10 \%$ of the sample. In this regard, underestimating the number of frequent riders (i.e., false negatives, or type II error) might not be as crucial as overestimating (false positives or type I error). Hence, it sounds reasonable to slightly sacrifice the recall of minority class in exchange for an increase in precision. In this regard, we further manipulated the class-weights and re-ran the grid search algorithm in search for better models. Consequently, we were able to optimize the model by increasing the misclassification penalty on the minority group and decreasing it in the majority class.

In terms of contributing factors, Table 19 presents the model coefficients. It reveals that millennials showed the highest positive impact on frequent usage of ridesourcing. This sounds reasonable taking into account that millennials are highly involved in school, work, social activities, and of course they are the leading generation in adoption and use of technologies. On the contrary, mixed results are observed for generation $x$ and baby boomers. This complies with the literature, where boomers and generation $x$ tend to be more specific in their decisions when they are offered new technologies.

As expected, there was a positive association between education and frequent ridesourcing. In particular, those with graduate and undergrad degrees showed the highest positive impact on frequent ride-source adoption. The positive correlation between education and technology adoption has been well documented in the literature. In view of income, low (below \$ 75k) and very high (above \$200k) categories discouraged regular ridesourcing. This might somewhat comply with common sense, where mid-to-high income people tend to have the highest utilization of ride-source on a regular basis. According to statistics published by Uber in 2017, around $44 \%$ of the riders fall within the mid $50 \%$ of income (www.statista.com).

Ethnicity is another variable that we focused on. Accordingly, Hispanics were the most likely to use ride-source service regularly while Asians were the least likely. Among different employment types, the model reveals that unemployed people were the most likely to use ridesourcing regularly while self-employment discouraged frequent ridesourcing usage.

When it comes to mobility expenses, we look into parking time and parking costs for private car users as well as access/waiting time for transit users as additional expenses imposed on travelers that potentially could be saved by using ridesourcing. Our hypothesis is that higher costs associated with conventional modes may lead to high usage of ridesourcing to avoid such costs. The model results did show a general positive association between high costs and more frequent ridesourcing usage, except for very high parking time (30 minutes or above) and high transit access time (15 minutes or above). This might be an indication of areas with high congestion and discourages driving, as a result, transit might be the better option than ridesourcing. 
Table 19 Linear SVM Model Coefficients

\begin{tabular}{|c|c|c|}
\hline & Variables & Coefficients \\
\hline \multirow[t]{7}{*}{ Age } & $25-29$ & 0.819544 \\
\hline & $30-34$ & 0.501355 \\
\hline & $35-39$ & 0.629495 \\
\hline & $45-49$ & 0.168338 \\
\hline & $50-54$ & -0.466283 \\
\hline & $55-59$ & 0.2753 \\
\hline & $60-64$ & -0.475362 \\
\hline \multirow[t]{2}{*}{ Ethnicity } & Hispanic/Latino & 0.595465 \\
\hline & Asian & -1.188994 \\
\hline \multirow[t]{4}{*}{ Education } & 9-12 grade, no diploma & -0.639201 \\
\hline & Some college, no degree & -0.547403 \\
\hline & Bachelor's & 0.067266 \\
\hline & Graduate or professional degree & 0.660968 \\
\hline \multirow[t]{3}{*}{ Employment } & Part-time & -0.101923 \\
\hline & Unemployed & 2.016964 \\
\hline & Other/self-employed & -1.036305 \\
\hline \multirow[t]{5}{*}{ Income } & $0-25 k$ & -0.269743 \\
\hline & $25-50 \mathrm{k}$ & -0.541611 \\
\hline & $50-75 k$ & -0.311766 \\
\hline & $100-125 k$ & -0.277185 \\
\hline & $>200 \mathrm{k}$ & -0.008079 \\
\hline \multirow[t]{7}{*}{ Mobility Expenses } & Parking fare: \$ 10-15 & 0.712856 \\
\hline & Parking fare $>=\$ 20$ & 1.460178 \\
\hline & Parking time $0-5$ mins & -0.490483 \\
\hline & Parking time $10-15$ mins & -0.774337 \\
\hline & Parking time $20-30$ mins & 1.493997 \\
\hline & Parking time $>=30$ mins & -0.240898 \\
\hline & Transit Access time $15-30$ mins & -0.786305 \\
\hline \multirow[t]{4}{*}{ Attitudinal Factors } & Technology savviness & 0.135294 \\
\hline & Mode choice reasoning & 0.111572 \\
\hline & Trust issues & -0.216203 \\
\hline & Joy of driving & 0.324693 \\
\hline Dependency & Highly car-dependent & -0.083075 \\
\hline \multirow[t]{5}{*}{ Factors } & Car Passengers & 0.328291 \\
\hline & Transit users & 0.990097 \\
\hline & Daily commuters & 1.603314 \\
\hline & Drivers from big families & 0.0614 \\
\hline & students without license & 0.352222 \\
\hline
\end{tabular}

In view of attitudinal factors, technology savviness and mode choice reasoning tended to encourage ridesourcing frequency. This is quite reasonable. Ridesourcing, by definition, is a direct manifestation of technology adoption and is expected to increase as people become more technology-oriented. Likewise, as individuals learn more about the higher level of service associated with ridesourcing options, they tend to use it more frequently, which justifies the positive coefficient of reasoning factor. Trust is still a big issue for travelers, and hinders the use ridesourcing. Interestingly, those who enjoyed driving tended to use ridesourcing frequently. 
All six mode dependency factors showed significant impacts. It seemed that highly cardependent individuals were less likely to use ridesourcing frequently, followed by those coming from large families (with a high number of drivers and number of vehicles). In the former case, the person uses his/her car for almost every daily activity. There seems to be no desire for other alternatives as long as the person has access to a private vehicle. In the latter situation, there seems to be an abundance of private vehicle/driver availability in the household. Hence, using ridesourcing is not a priority. Transit-dependent individuals and those whose car usage is limited to daily commutes were the most likely to be a frequent ride-hailer, which implies that they view ridesourcing as a suitable mobility option. As expected, students without driver's licenses were likely to use ridesourcing frequently. Details of the modeling can be found in Azimi et al. (2020a).

\subsubsection{Discussions}

The finding of this study indicated that highly car-dependent drivers were the least likely to shift to regular ride-hail usage, followed by individuals from large families with abundant drivers and vehicles. On the other hand, transit-dependent travelers and daily auto commuters showed the highest propensity toward regular ridesourcing usage. In between, comes the non-driving students and car-dependent passengers with a medium affinity toward frequent-ride hailing.

This study used a support vector machine as a strong machine learning classifier to predict the regularity of ridesourcing usage. The final model still suffers from high type II error (low recall values) on the test sample, which means it underestimates frequent-ride-hailers in the validation process. This might stem from the small sample size, limited range of grid search in hyperparameter tuning step, and of course lack of certain variables such as environmental and built-in parameters, lack of level of service associated with different modes, as well as detailed information on work schedules and commute distance.

Market segmentation is an important factor in policy planning. Taking into account that the market will not react homogeneously toward new technology and that their behavior in view of adoption, willingness to pay, and frequency of usage will differ from one segment to another is a key concept that leads to more efficient policies. While recent research has documented the impact of certain socio-demographic attributes and personal preferences in defining market segments, this study steps further and investigates the role of mode-dependency in explaining individuals' behavior. In particular, mode-dependency patterns showed a stronger correlation (compared to the other attitudinal factors), which reflects their importance in defining ride-hail usage as a potential substitute for conventional modes.

Furthermore, identifying mode-dependency patterns seem to be somewhat easier compared to other attitudinal assessments. Travel behavior surveys (including NHTS) usually gather different information on different modes used by individuals (including purpose, frequency, annual mileage, etc.), which can help planners come up with an estimate of mode-dependency distribution in different areas. Such dependency patterns along with other socio-demographic attributes can equip policy plans with a higher level of accuracy in their market analysis. 


\section{MODE CHOICE}

In this section, two distinct approaches have been considered to investigate travelers' mode choice between conventional modes (driving private vehicle or transit) and emerging mobility options (exclusive ride or shared ride). The first approach explored the choice behavior with a special focus on incorporating habitual behavior and mobility expenses into the modeling framework. The second approach studied the mode choice behavior of two different markets: transit users and auto users.

\subsection{Incorporating Habitual Behavior}

This section intends to evaluate the influence of habits on individuals' mode choice considering emerging mobility options.

The survey aimed to understand how travelers view the trade-offs between emerging modes (e.g., AVs and shared mobility services) and conventional modes (e.g., private vehicles and public transit). Driving private vehicles has the advantages of convenience, reliability (always available), trip flexibility, etc., while ridesourcing and AVs may offer the opportunities of multitasking with lower driving stress, and free others from escorting duties. Travelers' choice behavior and preferences may be different depending on the circumstances. To better reflect the trade-offs among the travel modes and capture the preferences under different conditions, this survey considered four distinct scenario types:

1. S1 (Drivers) - focuses on the choice between driving and ridesourcing. This reflects the situation where the traveler has access to a car and usually drives for daily activities.

2. S2 (Passengers) - captures the choice behavior between passenger ride and ridesourcing. The difference is that a passenger ride depends on the availability and schedule of other household members or friends. A most common example would be escorting trips.

3. S3 (Transit users) - considered the choice between transit and ridesourcing in regular conditions.

4. S4 (Visitors) - considered the choice between transit and ridesourcing when private vehicles are not available for occasional situations, e.g., when visiting a place or traveling to/from an airport.

The survey first asked the respondents to think of a trip that they made on a regular basis, then to record detailed trip information. Based on the mode reported for the regular trip that was recently made, the respondents were assigned to one of the first three scenario types. Those assigned to S1 and S2 were then asked to consider an occasional situation when a private vehicle was not available, before they were presented the $S 4$ (visitors) scenarios. The main purpose for these scenario types was to see how travelers' behavior may differ between those who have access to private vehicles and those who don't have access on a regular or daily basis and how their behavior may change in occasional situations. 
The details of each scenario type are illustrated in Figure 27. Each scenario has three alternatives defined by attributes in terms of travel time, travel cost, level of multitasking, or driver availability (for passengers). Each attribute has three levels of attribute values. The "private vehicle" alternative in scenario type 2 has three levels of availability, which takes into account the fact that a ride with a family member or friend is constrained by the availability and schedule of the driver. An example of a choice scenario presented in the SP section is shown in Figure 28.

\section{S1 (e.g. for regular/frequent daily activities such as work)}

- Alternatives: Private Vehicle, Single Ride, Shared Ride

- Attributes: Travel Time (3), Travel Cost (3), Level of Multitasking (None, High, Medium)

\section{S2 (e.g. pick-up/drop-off trips, escorting trips)}

- Alternatives: Private Vehicle, Single Ride, Shared Ride

- Attributes: Travel Time (3), Travel Cost (3), Driver Availability (High, Medium, Low)

\section{S3 (e.g. transit captive) and S4 (e.g. visitor trips, airport trips)}

- Alternatives: Transit, Single Ride, Shared Ride

- Attributes: Travel Time (3), Travel Cost (3), Level of Multitasking (Low, High, Medium)

\section{Figure 27 Choice alternatives and attributes for different scenarios.}

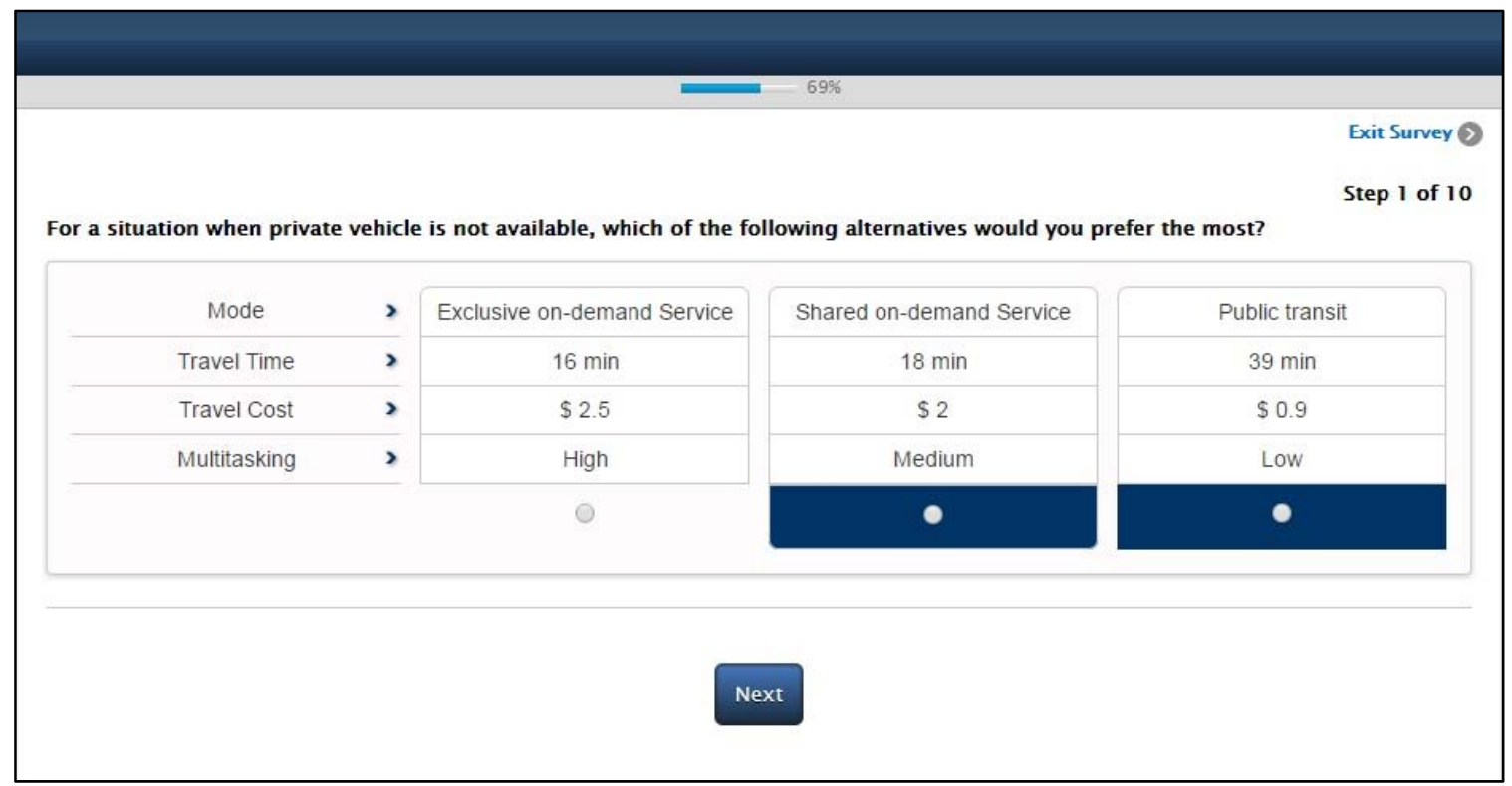

\section{Figure 28 A sample screenshot for the SP scenario.}

\subsubsection{Habitual Strength Index}

According to the habituation perspective, the more frequently a behavior has been performed in the past, the more it has come under stimulus control, that is, the stronger the habit. This tendency is referred to as Past Behavior Frequency (PBF). According to this model, the probability that an act will be performed is a function of intentions and habits (moderated by facilitating conditions), 
and habit strength "is measured by the number of times the act has already been performed by the person (Ajzen 2002).

The Response Frequency Measure (RFM), measures the relative frequency of certain behavior under different circumstances (with time pressure to answer the question as quickly as possible and limited information provided regarding the circumstance).

In order to account for habitual behavior, a heuristic combined index is formulated based on the $\mathrm{PBF}$ and RFM. PBF is measured as an ordinal variable indicating the frequency of using a specific mode on a regular basis in the past, RFM reflects the relative frequency of choosing one specific mode in different situations. The CHSI for mode $\mathrm{i}$ for each individual can be derived as:

$$
\text { Combined Habitual Strength Index }(C H S I)_{i}=P B F_{i} \times R F M_{i}(12)
$$

$P B F_{i}=$ Past Behavior Frequency of Mode $i$

$R F M_{i}=$ Response Frequency Measure for Mode $i$

In the survey, each respondent was asked how often they traveled in each mode, i.e., private vehicle driver, private vehicle passenger, public transit, taxi, ridesourcing, and car sharing. The choices ranged from "Less than once a year or never" to "Daily or almost daily". Correspondingly, the PBF values for each individual range from 1 to 5.

In regard to RFM, each respondent was asked how they would typically travel under ten different conditions, including:

- When the weather is bad,

- When they were running late,

- When they were under time pressure,

- When they were concerned about safety,

- When traffic is bad,

- When they needed to carry a lot of stuff,

- When money is tight,

- When they did not have access to a reliable vehicle,

- When they were new or unfamiliar with the area, and

- When parking costs were high or when it was difficult to find parking.

These varying situations were given to gauge how strong the habit was to stick with a particular mode, even when the contexts did not favor that mode. Based on the answers to this question, an RFM measure is derived for each person by mode. The RFM values range from 0 to 1 . If a person has consistently chosen the same model in all ten situations, the RFM for that mode would be 1, and 0 for all other modes. The sum of RFM values for all modes for the same person would always be 1 . Therefore, it can be used to measure the relative strength of habitual behavior with one mode against the other modes. 
Figure 29 shows the frequency distribution diagrams of PBF and RFM for the sample. It shows that around $59 \%$ of the sample used private vehicle as a driver daily $\left(P B F_{P V D}=5\right)$, while $17 \%$ of the sample stated that they would use private vehicle drivers under any circumstances (RFM=1). On the other hand, $15 \%$ of the sample never or drove less than once a year (note that the sample included people aged from 16 to 75 and above, and it oversampled people below 34). Only 3.3\% of the sample used ridesourcing daily $\left(P B F_{R S}=5\right)$. About $35 \%$ of the respondents relied on another family member (s) or friend(s) to drive them one to three times a week. About $63 \%$ of the sample never used public transit or used it less than once a year, that share climbs to $70 \%$ when it comes to ridesourcing.

Interestingly, $20 \%$ of the respondents preferred non-driving modes under all circumstances. $45 \%$, $70 \%$, and $76 \%$ of the respondents would never consider private vehicle passenger, public transit and ridesourcing, respectively, regardless of the situation. Private vehicle drivers had the highest average value of RFM (0.52), which indicates that more than half of the sample preferred driving at least half of the time.

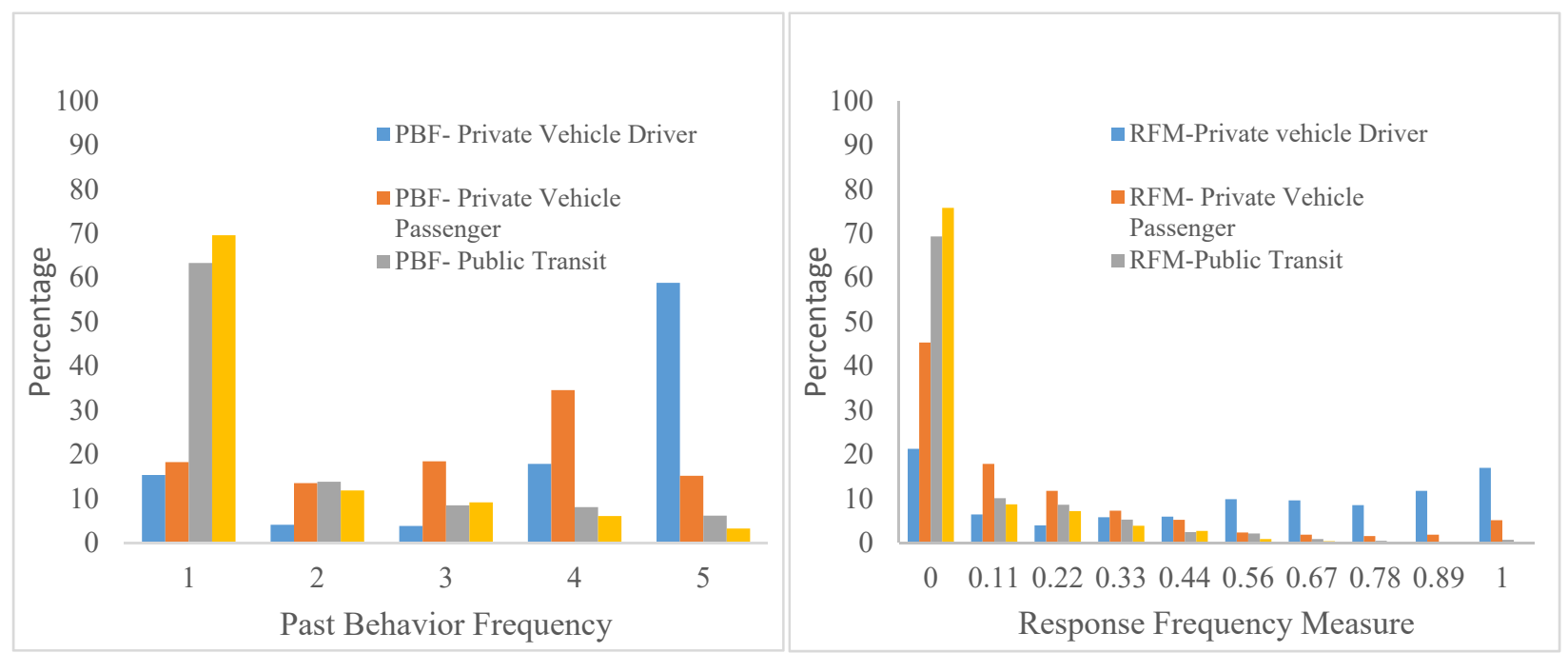

\section{Figure 29 Frequency distribution of PBF and RFM indices.}

Figure 30 shows the frequency distribution diagram of CHSI for different modes. The values range from 0 to 5. A CHSI value of zero means the individual seldom used the mode and wouldn't use it regardless of the situation, indicating minimum habit associated with this model. On the other hand, a value of 5 indicates that the individual showed the highest habitual strength with this mode. Figure 30 shows that about $20 \%$ of the respondents had a minimum attachment to driving private vehicles, while another $20 \%$ highly attached to this mode. The average CHSI value for private vehicle drivers was 2.39, which is also the highest among the different modes. About $70 \%$ and $80 \%$ of the respondents showed a minimum habitual strength associated with public transit and ridesourcing, respectively. 


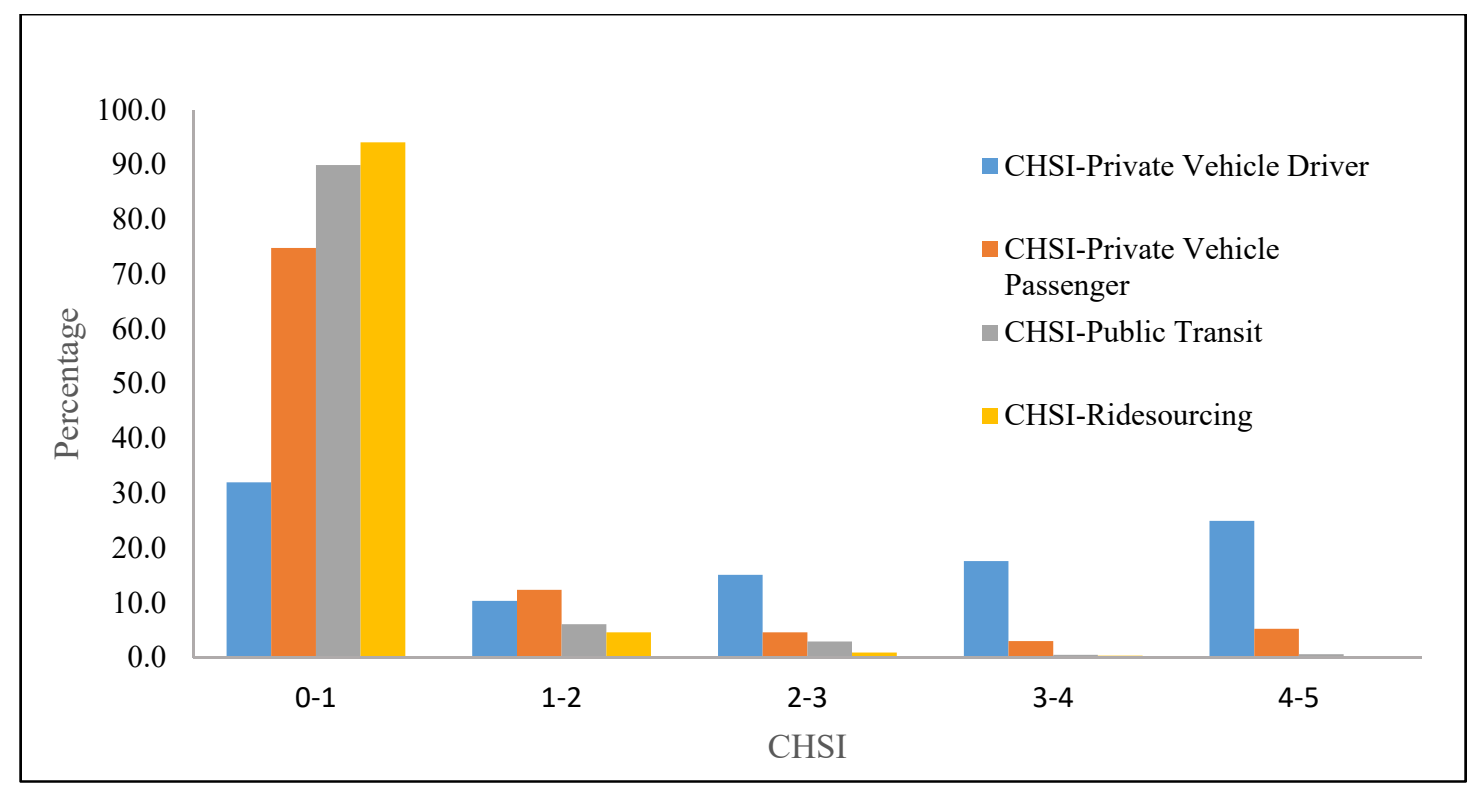

\section{Figure 30 Distribution of CHSI for different modes.}

In view of habitual indices, we also looked into socio-economic and demographic segments in order to assess the presence of heterogeneity in the market. Among the age groups, older adults (aged 50 or above) were attached to driving $\left(C_{P S I_{P V D}} \sim 2.9-3.1\right)$, minors (below 18) showed the highest habit strength for the private vehicle as passenger $\left(C H S I_{P V P, 16-27} \sim 1.69\right)$ or public transit $\left(C_{P S I_{P V, 16-17}}\right.$ 0.49), while young adults (aged between 18 and 24) were more likely to use ridesourcing $\left(\mathrm{CHSI}_{\mathrm{RS}, 18-24} \sim 0.3\right)$.

Males had higher habitual usage of public transit and ridesourcing while females show higher habitual strength toward the private vehicle as a passenger than males. Gender did not show any significant difference in terms of habits for driving. Interestingly, having a driver's license did not show any influence on ridesourcing habits.

In view of ethnicity, whites had the highest driving habits $\left(C H S I_{P V D, \text { white }} \sim 2.62\right)$, while Native

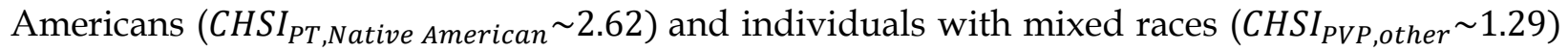
had the highest habits toward transit and private vehicle passenger, respectively. Interestingly, Hispanics had the highest habit strength index for ridesourcing $\left(C_{H S I_{\text {,Hispanic }}} \sim 0.268\right)$. Speaking of education, respondents with a bachelor's or graduate degree also had higher ridesourcing habits.

Large families (consisting of 6-7 people) showed more likelihood toward alternate modes, including ridesourcing. As expected, among different employment types, students showed higher habit strengths for public transit and ridesourcing while retirees had slightly higher CHSI values of private vehicle driving. 


\subsubsection{Mobility Auxiliary Expenses}

In order to account for the impacts of long-term incentives (i.e., no parking cost) of sharedmobility options, add-on mobility expenses associated with private vehicle usage are incorporated into the model. The major motivation for incorporating the auxiliary expenses is to highlight their roles in mobility choices and in acting as habit-breakers potentially. The hypothesis is that travelers who experience higher levels of auxiliary costs associated with private car usage, such as parking costs and the time spent to find parking, are more likely to switch to shared mobility alternatives.

It is reasonable to assume that the higher level of service associated with emerging mobility options (including lower fares or lower travel times) has not been practically experienced to the fullest potential, and therefore the public lacks the required psychological background in view of the level of service comparisons. On the contrary, costs associated with private car use such as parking costs or time spent on parking have been well experienced. Targeting such long-term drawbacks of private ownership are more likely to provide the required psychological intentions that contribute to a behavioral shift from private ownership to shared mobility options.

Figure 31 illustrates the distribution of parking costs and the time spent to find parking for those who drove regularly. Accordingly, more than $90 \%$ of the respondents used free parking for their regular trips. The average parking fare per trip was $\$ 14.9$ after excluding the free parking individuals. In terms of time spent on finding a parking lot, around $74 \%$ of the respondents stated that they spent less than 5 minutes for parking.

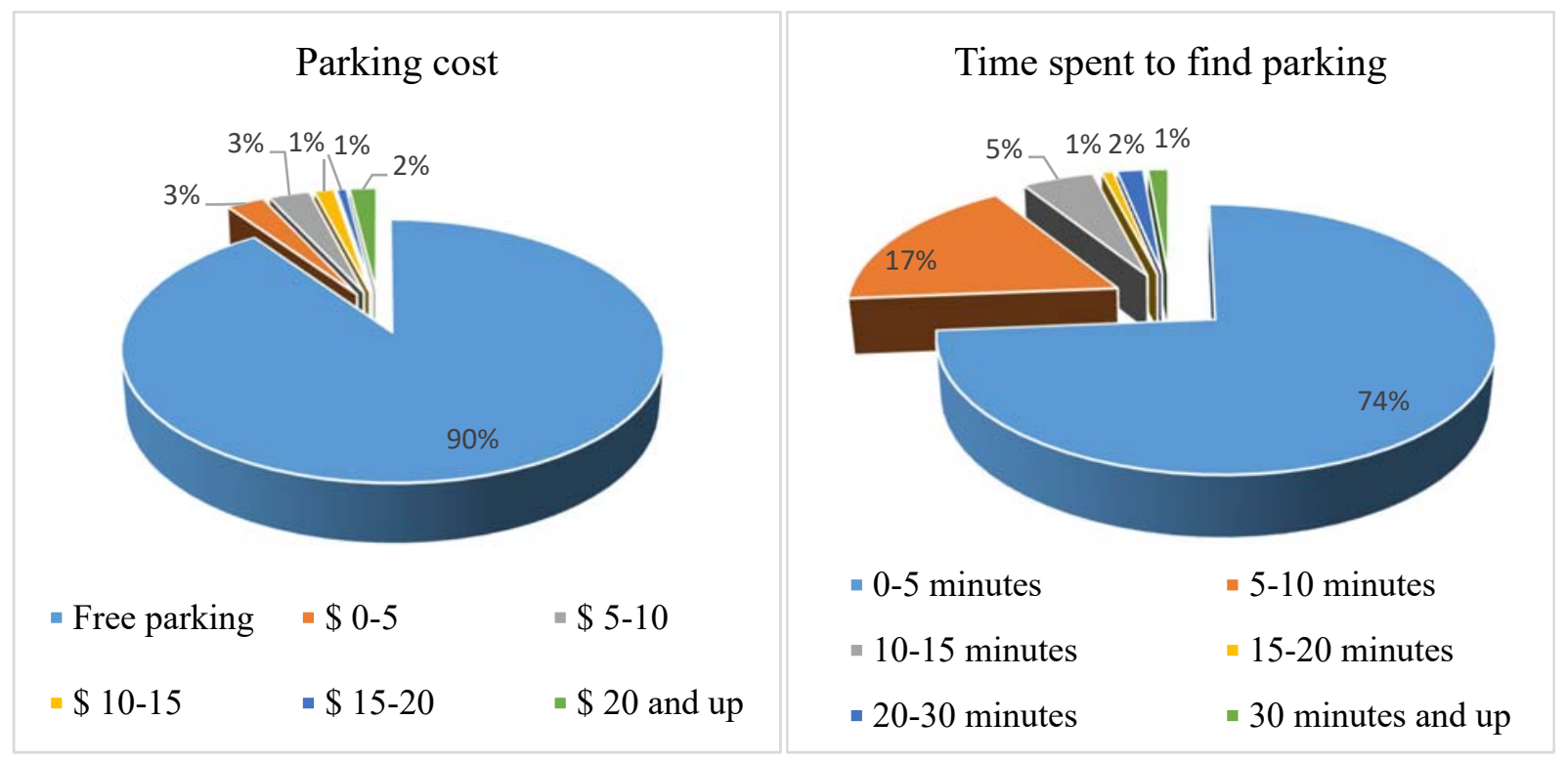

Figure $31 \quad$ Private mobility add-on expenses. 


\subsubsection{Mode Choice Results}

An error component model with a nested structure was used to estimate travelers' mode choice while incorporating habitual behavior. As indicated, respondents were faced with three alternatives in each scenario: conventional modes, exclusive on-demand services, and shared ondemand services. One nest was considered for the emerging modes, including exclusive and shared on-demand services.

The model results are summarized in Table 20 and Table 21, for regular (frequent) and occasional trips, respectively. Travel time and travel cost are considered as random parameters, the mean and standard deviation values are presented in the tables. Vehicle availability is an alternative specific variable which only applies to private vehicle passenger alternative. Conventional modes (i.e., private vehicle driver, private vehicle passenger, and public transit) are considered as the base category for all other parameters. The tables only present variables that showed significant impacts at a $95 \%$ confidence interval.

Both models showed a reasonable overall model fit based on $\rho^{2}$ values, and the likelihood ratio test were found to be significant at a level greater than 99 percent. Both models showed significant standard deviation values for travel time and travel cost suggesting taste variations among the individuals.

In terms of correlations between the two on-demand service alternatives, both models presented significant variance between the nest, $\sigma_{n}=0.613(\mathrm{t}=12.51)$ for regular trips, and $\sigma_{n}=0.189(\mathrm{t}=15.07)$ for occasional trips, indicating the presence of common unobserved factors in choosing emerging modes. This might indicate that the decision on whether to use ridesourcing services could be viewed as a binary decision at a higher level, with substitution patterns between the two ridesourcing alternatives at the lower level. In particular, this effect was stronger for regular trips, which exhibited a higher covariance value than occasional trips. This is reasonable considering that for regular or long-term mobility arrangements, the decision is more likely to involve a higher-level choice on whether to adopt on-demand services or not.

Since the purpose of this study is to gauge the impacts of habitual behavior, we focus on habitual related variables. A quick review of the model results for regular trips (Table 20) reveals that the other variables, including alternative specific attributes and socio-economic demographic variables showed reasonable coefficient values in terms of both the sign and the magnitude.

In general, the models showed positive influences of high income and full employment toward exclusive rides, mid-income toward shared rides, and a negative association between lower education and retirees and ridesourcing options. It also showed that social and school trips had a higher propensity of using exclusive ride services than other trips. In terms of age, seems that college students or young graduates (age between 18-24) or those aged between 50 and 54 were more likely to take shared rides, people between 30-34 were more likely to use on-demand services (both exclusive and shared) compared to other age groups. 
Table 20 Mode Choice Model Results for Regular Trips (t-ratios in brackets)

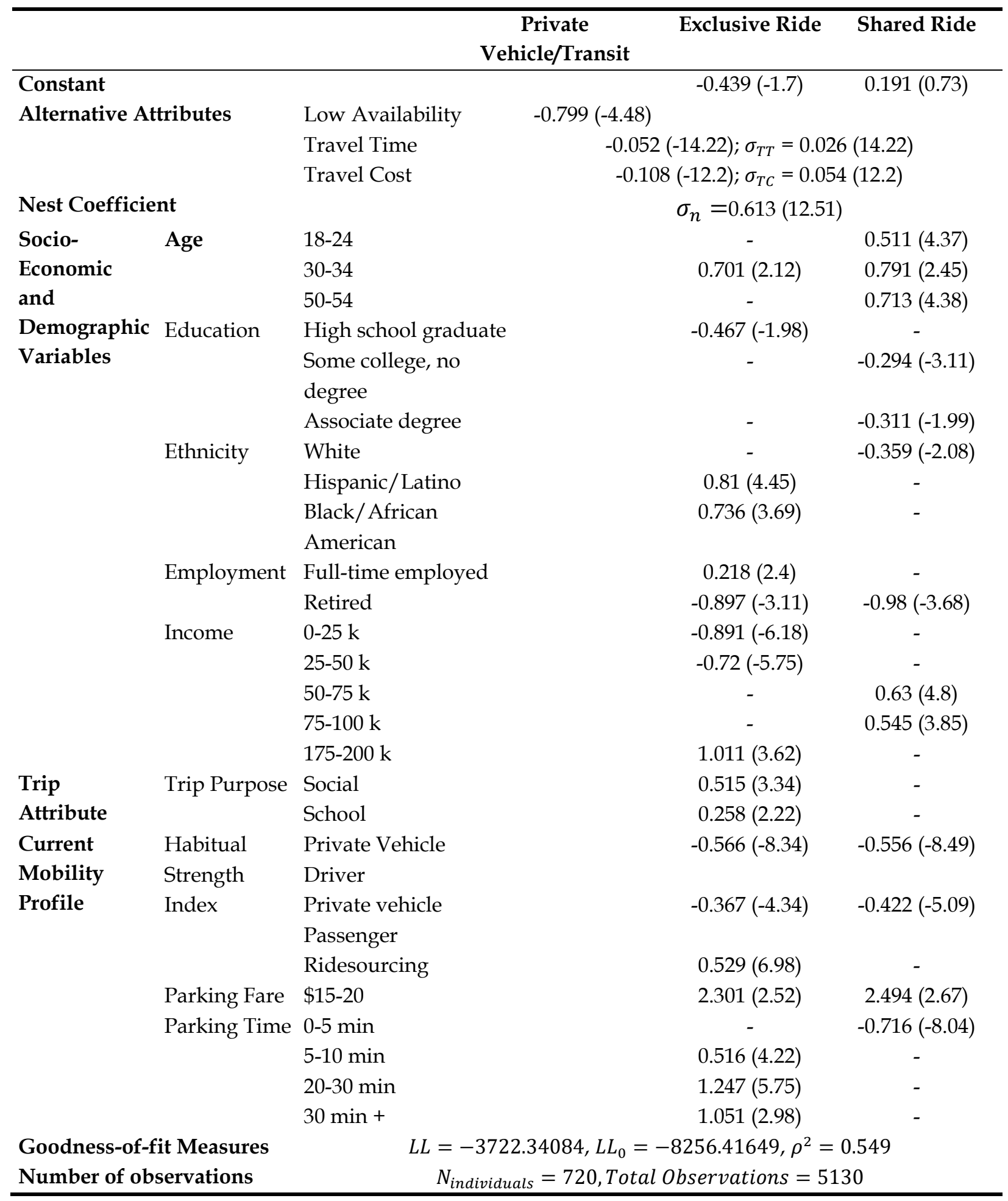

For regular circumstances, Table 20 shows that both habits and existing mobility expenses showed significant impacts on the choice of mode. Specifically, habit associated with private vehicles, either as a driver or passenger, had strong negative impacts on the utility of ridesourcing 
modes, either as exclusive ride or shared ride. It indicates that if a person frequently drives his private vehicle for regular trips, the probability of shifting to alternative options significantly decreases, despite the desirable level of service of the alternative modes.

The magnitude of impacts of the habitual variables was comparable between exclusive ride and shared-ride options. Among the three conventional modes, the habitual behavior associated with private vehicles as a driver showed the largest impacts, while the habitual linkage with public transit was not significant. This indicates that transit habits are probably the easiest to break when it comes to emerging mobility options. On the other hand, the habitual strength index for ridesourcing mode showed strong positive impacts on the probability of choosing ridesourcing for regular trips. Interestingly, this effect only affects the choice for an exclusive ride. It does not present significant impacts on the choice of a shared ride. This may imply the barrier in arranging shared rides for regular daily purposes.

In view of the auxiliary expenses, Table 20 indicates that high parking fares (\$15-20/trip) had a positive impact on ridesourcing alternatives. It shows that the potential to avoid parking costs could be a remarkable motivation to shift from private vehicle ownership to ridesourcing options. However, the impact was not significant until the parking fares reach a high level. Similar results could be inferred in view of the time spent to find a parking space. Higher values of parking time (above 20 minutes) showed a significant positive influence on exclusive rides.

Interestingly, parking time was not a positive factor in motivating people toward shared rides. Perhaps time was of the essence to these users, and shared rides do not necessarily provide the time advantage in this aspect. The variables for high parking cost and parking time showed the highest coefficients values among the variables in the model. This confirms the initial hypothesis that such auxiliary expenses could act as disutility for conventional mobility options, and that higher levels of expenses would increase the probability of switching to emerging mobility options.

Table 21 shows the model results for occasional situations when a private vehicle is not an option. In comparison to the regular conditions, a lower value of time (VOT) is derived, about $\$ 11.8$ per hour (based on the coefficients of time and cost), compared to $\$ 28.8$ per hour derived from Table 20. This confirms the necessity to have separate scenario types to capture the changes in travelers' choice behavior and preferences under different circumstances. In this scenario type, those who regularly had access to private vehicles were asked to think of a situation when private vehicles were not available, such as when they were visiting a place or a trip from/to the airport.

As expected, mobility auxiliary expenses did not show a significant impact on occasional trips. In view of the habitual parameters, habits associated with public transit usage would decrease the utility of shared mobility options, especially for exclusive on-demand services, while habits for ridesourcing showed strong positive impacts on both shared mobility options. This probably indicates the high potential of shared on-demand services for visitors, and first/last mile connecting services, etc. 
Table 21 Mode Choice Model Results for Occasional Trips (t-ratios in brackets)

\begin{tabular}{|c|c|c|c|c|c|}
\hline \multicolumn{3}{|l|}{ Variables } & Public Transit & Exclusive Ride & Shared Ride \\
\hline \multicolumn{3}{|l|}{ Constant } & & $3.11(10.76)$ & $1.56(5.42)$ \\
\hline \multirow{2}{*}{\multicolumn{2}{|c|}{ Alternative Attributes }} & Travel Time & \multicolumn{3}{|c|}{$-0.095(-27.56) ; \sigma_{T T}=0.047(27.56)$} \\
\hline & & Travel Cost & \multicolumn{3}{|c|}{$-0.482(-32.96) ; \sigma_{T C}=0.241(32.96)$} \\
\hline \multicolumn{3}{|c|}{ Nest Coefficient } & \multicolumn{3}{|c|}{$\sigma_{n}=0.189(15.07)$} \\
\hline Socio- & \multirow[t]{3}{*}{ Age } & $25-29$ & & $0.809(1.85)$ & $0.928(2.12)$ \\
\hline Economic & & $30-34$ & & $1.12(2.17)$ & $1.24(2.34)$ \\
\hline Demographic & & $35-39$ & & - & $0.316(3.02)$ \\
\hline \multirow[t]{7}{*}{ Variables } & & $45-49$ & & - & $0.281(2.67)$ \\
\hline & \multirow[t]{2}{*}{ Employment } & Full-time employed & & - & $0.431(6.06)$ \\
\hline & & Unemployed & & $-0.579(-6.15)$ & - \\
\hline & \multirow[t]{4}{*}{ Income } & $0-25 \mathrm{k}$ & & $-0.335(-3.76)$ & - \\
\hline & & $25-50 \mathrm{k}$ & & $-0.285(-4.08)$ & - \\
\hline & & $125-150 \mathrm{k}$ & & - & $0.446(2.59)$ \\
\hline & & $200 \mathrm{k}$ and higher & & $1.38(3.87)$ & - \\
\hline \multirow[t]{7}{*}{ Trip Attribute } & \multirow[t]{3}{*}{ Trip Purpose } & Social & & $0.289(3.76)$ & - \\
\hline & & Recreation & & - & $-0.164(-2.32)$ \\
\hline & & last $\backslash$ first mile & & $2.28(2.63)$ & - \\
\hline & \multirow[t]{4}{*}{ Trip distance } & 5 miles & & $-1.55(-3.88)$ & $-0.893(-2.19)$ \\
\hline & & 10 miles & & $-1.69(-4.5)$ & $-1.12(-2.97)$ \\
\hline & & 15 miles & & $-0.3839(-3.51)$ & - \\
\hline & & 25 miles & & - & $0.525(3.19)$ \\
\hline Current & Habitual & Public Transit & & $-1.361(-3.77)$ & $-1.088(-2.98)$ \\
\hline \multirow[t]{2}{*}{ Mobility } & Strength & Ridesourcing & & $2.269(7.04)$ & $2.298(6.93)$ \\
\hline & \multicolumn{5}{|l|}{ Index } \\
\hline \multicolumn{2}{|c|}{ Goodness-of-fit Measures } & \multicolumn{4}{|c|}{$L L=-3705.81314, L L_{0}=-5203.02780, \rho^{2}=0.288$} \\
\hline \multicolumn{2}{|c|}{ Number of observations } & \multicolumn{4}{|c|}{$N_{\text {individuals }}=592$, Total Observations $=4736$} \\
\hline
\end{tabular}

Overall, both model results show that habitual strength indices as well as private vehicle expenses are significant determinants of choice behavior toward emerging mobility options. In particular, the discouraging role of conventional mobility habits is quite remarkable compared to other variables in the model. On the other hand, a high level of private mobility expenses would strongly motivate travelers to shift to emerging mobility options.

\subsubsection{Discussions}

Results showed that habits played a significant role in acting as a barrier to behavioral changes. On the other hand, the long-term disutility factors associated with private mobility has the potential to break such habits. Both parameters showed higher effects compared to most of the socio-economic and demographic variables. Model results confirm the hypothesis that incorporating these factors improves the model performance and probably leads to a more reliable assessment of the market toward future mobility options. 
Habitual parameters can have significant impacts on travel behavior and potentially enhance the existing planning framework. In view of policy implications, they can provide inputs for market analysis in evaluating public reactions toward emerging mobility options. For instance, they can help explain why some travelers are highly prone to certain modes. In addition, understanding the habitual behavior serves as the first step to the development of efficient policies and strategies to break the habit or attachment to private vehicles.

These results provide additional insights into how current mobility patterns can affect future travel behavior in light of emerging mobility options. Although habitual behavior seems to favor conventional modes, additional costs associated with private mobility can motivate travelers to alternative options. Hence, market segmentation based on habitual patterns and private mobility expense profiles can provide a foundation for better assessment of future travel behavior trends. This may also provide important inputs for the development of strategies in promoting alternative mobility options. Details of the modeling can be found in previous work by the authors (Asgari and Jin, 2020).

\subsection{Transit and Auto Users' Mode Choice of Ridesourcing: The Role of Attitudes}

With a focus on understanding the potential market of ridesourcing, this section puts an effort in examining the factors that influence travelers' mode choice between transit and ridesourcing. We are particularly interested in exploring how transit users (those who use transit regularly) and auto users (in occasional situations when a private vehicle is not available) might have different attitudes and preferences toward mobility options, and how their attitudes may affect their mode choice toward ridesourcing options.

As stated before, the survey collected information on respondents' current travel patterns, preferences, and attitudes, as well as their mode choices in SP scenarios. Each mode was associated with three attributes: travel time, travel cost, and level of multitasking. The respondents were presented with the definitions for each mode and each attribute associated with the modes before they were taking to the SP scenarios. Travel time refers to how long it takes to reach the destination from door to door, which includes walking times from/to the transit stops or waiting time for ridesourcing services, travel cost indicates the fares.

Existing fares for transit were utilized in the scenarios, while the fares for ridesourcing were reduced to one-third of existing amounts considering the potential reduction in the operation cost with driverless technologies. As we are hoping to look into the barriers to the adoption of ridesourcing beyond cost considerations, the scenario design reduced the cost-gap between transit and ridesourcing on purpose so that cost would be more comparable and other determinant factors may be revealed in respondents' choice decisions. The level of multitasking was a fixed attribute (low for transit, medium for shared service, and high for exclusive service), and was included as an additional feature that differentiates transit service from ridesourcing. 
Two different markets are considered: transit users, and auto users. Transit users were identified as those who reported using transit for a regular or most frequent trip in the revealed preference (RP) section. They were asked to think of this RP trip as a reference for the SP scenarios (Scenario 3). Auto users were those who use their private vehicles for a regular trip. They were then given the instructions to think of a situation when their private vehicles were not available, such as a trip from/to the airport, or when visiting a place, then fill out the information for the RP trip. Then auto users would continue to the SP scenarios with this non-regular or occasional RP trip in mind (Scenario 4). As can be seen, the two scenario types represent two user groups, as well as regular vs. occasional situations. We are interested in identifying the behavioral differences in both aspects.

Also, the survey included four sets of questions that focused on different aspects of attitudes:

- General preferences toward mobility options (preferences),

- Perceptions of the benefits and concerns of ridesourcing (perceptions),

- The reasons they own or don't own private vehicles (vehicle ownership), and

- Motivations to use automated vehicles (AV) and desired features (AV features).

\subsubsection{Latent Attitudinal Factors}

The major focus of this section is to investigate the impacts of attitudes on mode choice. As stated previously, the survey included four sets of questions that potentially measure different aspects of individuals' mobility attitudes. This large number of attitude-related variables makes it challenging to incorporate them into behavior models, especially when the variables are correlated. To address these issues, factor analysis, which converts a set of observed correlated variables into a group of linearly uncorrelated variables called factors or factor analysis was conducted to extract latent attitude factors based on individuals' responses to the survey questions. Table 22 shows the factor analysis results. In total, 18 latent factors were identified that represent individuals' mobility attitudes.

Table 22 Identified Latent Attitude Factors

\begin{tabular}{ll}
\hline Factors & Description \\
\hline F1- Technology & $\begin{array}{l}\text { represents an individual's engagement with online activities, the use of } \\
\text { smartphone apps, and eagerness to learn about and use new technologies. } \\
\text { refers to the consideration of service quality (ranging from travel time, } \\
\text { cost, functionality, to convenience) in mobility decisions. } \\
\text { indicates an individual's concerns on traveling with strangers. } \\
\text { positively associated with the joy of driving and individuals' } \\
\text { F3- Travel with Strangers } \\
\text { F4- Joy of Driving }\end{array}$ \\
F5- Trust and Data Privacy & $\begin{array}{l}\text { positively associated with an individual's concern on data privacy and } \\
\text { trust with technologies, and negatively associated with concerns on cost } \\
\text { and service request procedure. } \\
\text { reflects people's positive beliefs in on-demand services, and negative } \\
\text { interest in multitasking during the trips. }\end{array}$ \\
\hline
\end{tabular}


Table 22 continued

\begin{tabular}{|c|c|}
\hline Factors & Description \\
\hline F7- Cost Effectiveness & refers to the beliefs in the cost-effectiveness of ridesourcing \\
\hline F8- System Reliability & $\begin{array}{l}\text { represents an individual's concerns on system reliability of ridesourcing, } \\
\text { and negatively associated with concerns on data privacy. }\end{array}$ \\
\hline F9- Stress Relief & refers to the beliefs in reducing driving stress using ridesourcing \\
\hline F10- Travel Time & $\begin{array}{l}\text { indicates an individual's positive concerns on travel time due to multiple } \\
\text { pickups and waiting time, and negative concerns on technology (trust and } \\
\text { procedure) }\end{array}$ \\
\hline $\begin{array}{l}\text { F11- Utility of Private } \\
\text { Vehicle }\end{array}$ & $\begin{array}{l}\text { refers to the positive preference for a private vehicle due to privacy, } \\
\text { reliability, the joy of driving, flexibility, and attachment to cars. }\end{array}$ \\
\hline F12- Alternative Modes & $\begin{array}{l}\text { indicates the preference for transit, walking, or biking. Interestingly, the } \\
\text { lack of parking space significantly contributed to this factor. }\end{array}$ \\
\hline F13- Travel Cost & $\begin{array}{l}\text { indicates the consideration of cost as a dominant factor for ownership } \\
\text { decisions }\end{array}$ \\
\hline F14- Ownership Cost & $\begin{array}{l}\text { represents the concern on ownership and maintenance costs, which may } \\
\text { act as a barrier toward ownership. }\end{array}$ \\
\hline $\begin{array}{l}\text { F15- Driving Assistance \& } \\
\text { Safety }\end{array}$ & $\begin{array}{l}\text { indicates the desire for driving assistance features, such as lane-keeping, } \\
\text { self-parking, adaptive cruise control, as well as safety features of, like } \\
\text { collision avoidance. }\end{array}$ \\
\hline F16- Automation & represents the preferences for better technology and full connectivity. \\
\hline $\begin{array}{l}\text { F17- Mobility for Non- } \\
\text { Drivers }\end{array}$ & $\begin{array}{l}\text { refers to the desire for auto-driving feature, especially for those how } \\
\text { cannot drive. }\end{array}$ \\
\hline $\begin{array}{l}\text { F18- Efficiency and } \\
\text { Technology }\end{array}$ & $\begin{array}{l}\text { positively associated with the desire for higher efficiency and better } \\
\text { technology }\end{array}$ \\
\hline
\end{tabular}

\subsubsection{Mode Choice Results}

Separate error component models were applied for transit users and auto users to estimate travelers' mode choice while incorporating latent attitudinal factors. Respondents were faced with three alternatives in each scenario: public transit, exclusive on-demand services, and shared on-demand services.

Table 23 and Table 24 presents the results of the error component models, for transit users and auto users, respectively. Travel time and travel costs were treated as random parameters, and transit was considered as the base category. The final model embraces several socio-economic and demographic characteristics as well as attitudinal factors that offer a deeper vision on the role of attitudes in the propensity to use ridesourcing services. The tables present the variables that are significant at a $90 \%$ confidence level.

\section{Transit Users}

Travel time showed significant mean and standard deviation confirming the presence of taste variations among individuals. Interestingly, no heterogeneity in travel cost was detected among 
transit users. Female users showed a positive tendency to use ridesourcing services and were more inclined to use exclusive rides than shared rides. Full-time employees had a positive impact on exclusive rides. This positive correlation may indicate the impact of work-schedule restrictions associated with full-time employees and that they may prefer exclusive services for lower travel times and probably higher reliability. Such a positive correlation between full-time employees and ridesourcing is also supported in the literature (Sikder 2019, Dias et al., 2017).

Table 23 Model Results for Transit Users

\begin{tabular}{|c|c|c|c|c|c|}
\hline & & & $\begin{array}{l}\text { Public } \\
\text { Transit }\end{array}$ & Exclusive Ride & Shared Ride \\
\hline \multicolumn{2}{|l|}{ Constant } & & & $-1.06(-3.59)$ & $-0.872(-2.96)$ \\
\hline \multirow{2}{*}{\multicolumn{2}{|c|}{ Alternative Attributes }} & Travel Time & $-0.97(-5.38)$ & \multicolumn{2}{|c|}{$\sigma_{T T}=1.01(5.5)$} \\
\hline & & Travel Cost & $-1.29(-1.93)$ & \multicolumn{2}{|c|}{$\sigma_{T C}=1.1(076)$} \\
\hline \multirow{10}{*}{$\begin{array}{l}\text { Socio-economic } \\
\text { Demographic } \\
\text { Variables }\end{array}$} & Gender & Female & & $0.657(2.17)$ & $0.611(1.96)$ \\
\hline & Employment & Full Time & & $0.544(3.03)$ & - \\
\hline & Education & Less than $9^{\text {th }}$ grade & & $-2.15(-4.27)$ & $10.2(9.18)$ \\
\hline & & High School Graduate & & - & $0.59(2.35)$ \\
\hline & & Bachelor & & $1.1(2.43)$ & $1.56(3.93)$ \\
\hline & Income & $\$ 25 \mathrm{~K}-\$ 50 \mathrm{~K}$ & & $-1.00(-2.60)$ & $-0.689(-1.95)$ \\
\hline & & \$75K-\$100K & & $1.52(3.16)$ & $1.94(5.01)$ \\
\hline & & $\$ 100 \mathrm{~K}-\$ 125 \mathrm{~K}$ & & $1.72(2.35)$ & - \\
\hline & & $\$ 125 \mathrm{~K}-\$ 150 \mathrm{~K}$ & & $3.22(3.85)$ & - \\
\hline & & More than $\$ 200 \mathrm{~K}$ & & - & $-1.96(-1.80)$ \\
\hline \multirow{9}{*}{$\begin{array}{l}\text { Attitudinal } \\
\text { Factors }\end{array}$} & Preferences & Technology Savvy & & 0.735 (3.92) & $0.307(1.88)$ \\
\hline & Perceptions & On-Demand Service & & $0.55(2.79)$ & $0.409(2.50)$ \\
\hline & & Travel time & & $0.468(2.75)$ & $0.366(2.32)$ \\
\hline & $\begin{array}{l}\text { PV } \\
\text { Ownership }\end{array}$ & $\begin{array}{l}\text { The utility of Private } \\
\text { Vehicle }\end{array}$ & & $-0.477(-2.22)$ & $-0.332(-1.68)$ \\
\hline & & $\begin{array}{l}\text { Prefer alternative } \\
\text { modes }\end{array}$ & & $-0.379(-3.37)$ & - \\
\hline & & Ownership Cost & & - & $0.359(3.33)$ \\
\hline & AV Features & Full Automation & & - & $0.257(1.71)$ \\
\hline & & $\begin{array}{l}\text { Mobility for Non- } \\
\text { Drivers }\end{array}$ & & $0.275(2.07)$ & - \\
\hline & & $\begin{array}{l}\text { Efficiency and } \\
\text { Technology }\end{array}$ & & - & $0.343(3.06)$ \\
\hline \multicolumn{2}{|c|}{ Log-Likelihood } & \multicolumn{4}{|c|}{$\mathrm{LL}=-939.709 \quad \mathrm{LL}_{0}=-1077.302$} \\
\hline \multicolumn{2}{|c|}{ Number of Observations } & \multicolumn{4}{|c|}{ No. of individuals $=136$ No. of Observations $=1,088$} \\
\hline
\end{tabular}

Interestingly, users with a lower level of education (less than 9th grade) had a negative tendency to use exclusive rides compared with transit, but a very high positive tendency to use shared rides, probably due to considerations of cost. Similar results were observed for users with high school degrees for using shared rides. Those holding a bachelor's degree showed a positive 
tendency toward both exclusive and shared rides. It seems that people with higher education are more aware of such services, and they can leverage such services through the use of technology. Similar findings have been documented by the literature (Rayle et al., 2016; Clewlow and Mishra, 2017; Dias et al., 2017).

The pattern associated with income also sounds sensible. Very low-income individuals ( $\$ 50 \mathrm{~K}$ or less) were less likely to use ridesourcing, particularly exclusive rides. Very high-income groups ( $\$ 200 \mathrm{~K}$ or above) were less likely to use shared services. Those in between, generally showed a higher tendency to use exclusive rides compared with transit as income levels increased.

In view of attitudes, technology-savvy users showed a positive impact on using ridesourcing options, especially exclusive rides. This positive association was expected since those with a technology-driven lifestyle are more likely to adopt these technology-related services (Dias et al., 2017). Regarding perceptions of ridesourcing, people who believed in the on-demand aspect of the service or those concerned on travel time chose ridesourcing services over transit, which seems reasonable.

In terms of private vehicle ownership, results showed that even those who enjoyed the utility of private vehicles preferred to use transit than ridesourcing services. One of the reasons could be that their regular use of transit was associated with congestion, delay, or other factors, in which case ridesourcing could not provide better services than transit. Similarly, those who preferred alternative modes or with short travel distances also showed a higher likelihood of choosing transit over ridesourcing.

When it comes to views toward AVs, positive associations were observed between the tendency to use shared rides and the interest in full automation and technology and efficiency. Individuals who seek efficiency and technology were interested in using shared ride services, presumably because shared travel modes are cost-efficient. Moreover, those who cared about mobility for non-drivers were inclined to use exclusive services. This may indicate the preference for those who are not able to drive themselves, but prefer a private and exclusive travel experience.

\section{Auto Users}

As shown in Table 24, travel time and travel cost had significant standard deviations, indicating the presence of heterogeneity. Students showed a positive tendency to use on-demand services, both exclusive and shared ride service. This might be related to the fact that students are usually more open and eager to experience new technologies. Income showed mixed results. In general, low-income individuals were less likely to use exclusive rides, and high-income individuals are less likely to use shared rides.

Similar to transit results, technology-savvy individuals had positive impacts on using both ridesourcing services compared to transit. Choice reasoning also showed a positive impact on using ridesourcing services, especially for shared ride services. It might indicate that individuals 
would use ridesourcing services when they believe that the service provides better utility, in terms of travel time, cost, convenience, etc.

Table 24 Model Results for Car Users

\begin{tabular}{|c|c|c|c|c|c|}
\hline & & & $\begin{array}{l}\text { Public } \\
\text { Transit }\end{array}$ & $\begin{array}{l}\text { Exclusive } \\
\text { Ride }\end{array}$ & Shared Ride \\
\hline \multicolumn{3}{|l|}{ Constant } & & $1.83(13.96)$ & $1.23(9.98)$ \\
\hline \multirow{2}{*}{\multicolumn{2}{|c|}{ Alternative Attributes }} & Travel Time & $-1.02(-4.39)$ & \multicolumn{2}{|c|}{$\sigma_{\mathrm{TT}}=1.06(8.98)$} \\
\hline & & Travel Cost & $-0.77(-1.66)$ & \multicolumn{2}{|c|}{$\sigma_{\mathrm{TC}}=2.02(2.16)$} \\
\hline \multirow{7}{*}{$\begin{array}{l}\text { Socio- } \\
\text { economic } \\
\text { Demographic } \\
\text { Variables }\end{array}$} & Ethnicity & Native American & & $1.04(2.16)$ & $0.925(2.54)$ \\
\hline & Employment & Student & & $1.45(4.28)$ & $1.05(3.69)$ \\
\hline & Income & $\$ 0-\$ 25 K$ & & $-0.462(-2.85)$ & - \\
\hline & & $\$ 25 \mathrm{~K}-\$ 50 \mathrm{~K}$ & & - & $0.373(2.87)$ \\
\hline & & $\$ 75 \mathrm{~K}-\$ 100 \mathrm{~K}$ & & $-0.318(-2.15)$ & - \\
\hline & & $\$ 125 \mathrm{~K}-\$ 150 \mathrm{~K}$ & & - & $0.562(2.21)$ \\
\hline & & More than $\$ 200 \mathrm{~K}$ & & - & $-0.625(-1.77)$ \\
\hline \multirow{10}{*}{$\begin{array}{l}\text { Attitudinal } \\
\text { Factors }\end{array}$} & Preferences & Technology- Savvy & & $0.437(5.25)$ & $0.369(4.77)$ \\
\hline & & Choice Reasoning & & $0.227(2.17)$ & $0.463(4.64)$ \\
\hline & & Travel with Strangers & & $-0.384(-3.17)$ & $-0.565(-4.89)$ \\
\hline & & Joy of Driving & & $-0.316(-3.42)$ & $-0.278(-3.04)$ \\
\hline & Perceptions & On-Demand & & $0.195(3.43)$ & $0.409(2.50)$ \\
\hline & & Cost-effectiveness & & $-0.104(-1.98)$ & \\
\hline & & Stress Relief & & $0.088(1.65)$ & - \\
\hline & $\begin{array}{l}\text { PV } \\
\text { Ownership }\end{array}$ & $\begin{array}{l}\text { The utility of Private } \\
\text { Vehicle }\end{array}$ & & $0.147(2.44)$ & - \\
\hline & & Alternative Modes & & $-0.087(-1.65)$ & - \\
\hline & AV Features & $\begin{array}{l}\text { Driving Assistance \& } \\
\text { Safety }\end{array}$ & & $0.229(2.18)$ & $0.244(2.38)$ \\
\hline \multicolumn{2}{|c|}{ Log-Likelihood } & \multicolumn{4}{|c|}{$L L=-6420.355 \quad L_{0}=-7394.985$} \\
\hline \multicolumn{2}{|c|}{ Number of Observations } & \multicolumn{4}{|c|}{ No. of individuals $=951$ No. of Observations $=7,608$} \\
\hline
\end{tabular}

As expected, those who had concerns with traveling with strangers were less likely to choose ridesourcing, especially shared services. This issue may be considered as a major predicament that discourages the use of ridesourcing services, indicated by the large negative coefficient values. Interestingly, people who enjoyed driving also showed a negative tendency toward ridesourcing. This may be associated with less willingness to use new modes.

In terms of perceptions, users who are a fan of on-demand services showed a positive tendency to choose both exclusive-ride and shared-ride services over transit. On the other hand, those who were concerned about the cost-effectiveness of their trips were less likely to use exclusive ride services, probably due to cost considerations. Individuals who cared about driving stress had a trivial positive propensity toward exclusive ride services. 
Views toward private vehicle ownership showed similar results for auto users and transit users. There was a positive impact on the use of exclusive rides for those who value the utility of private vehicles and, and a negative association between the preference of alternative modes and the tendency for ridesourcing. Considering AV features, those who desire driving assistance and safety were more likely to use ridesourcing than transit services.

\subsubsection{Discussions}

Model results indicate that some similarities were observed between transit and auto users in terms of mode choice between transit and ridesourcing options. For instance, in both groups, technology savviness encouraged the use of ridesourcing, and very high-income groups in both segments were unlikely to use shared rides. Also, people who preferred alternative modes (transit, walking/biking) were less likely to use exclusive rides. In general, however, the model results confirmed our initial hypothesis that there are significant disparities between the two market segments., especially in terms of attitudes. For transit users, the decision to shift to ridesourcing was highly affected by the perceptions of time and cost as well as motivations for technology, while the concerns on traveling with strangers and joy of driving were major barriers for auto users to use ridesourcing. Auto users would use ridesourcing when they believe that they would receive higher utilities, in terms of time, cost, reliability, convenience, comfort, and stress relief, etc.

This study provides further insights into the contributing factors to the choice between transit and ridesourcing services. The results present a better understanding of the potential market for ridesourcing and highlight underlying attitudes that have significant influences on choice behavior. The findings could be helpful for planners and service providers to better plan for and address the needs and concerns of travelers. In terms of further research, the model structure can be enhanced by nesting the two ridesourcing options taking into account the potential existing correlation between the two modes, or by allowing correlations between any of the two modes using a cross-nested structure. Further research is also needed to examine the associations

between attitudinal factors and demographic characteristics. Details of the modeling can be found in previous research by the authors (Azimi et al., 2020b). 


\section{SUMMARY OF FINDINGS}

In summary, we developed econometric models and analyzed travelers' mobility choice behavior in different aspects: long-term AV adoption, mid-term mobility option, and short-term mode choice at trip level. Models' results and discussions were provided for each aspect in the previous sections. Here we highlight the major findings.

\section{AV Adoption and WTP}

The survey results revealed that the majority of the respondents were either willing to maintain basic vehicle utilization (36\%) or at most add some advanced features (37\%) such as adaptive cruise control. Only $12 \%$ of the respondents expected themselves to be riding in a fully autonomous vehicle in the next ten years. The average WTP increased along with the level of adoption, ranging from $\$ 652$ for basic vehicles to $\$ 1,192$ for advanced features, $\$ 1,542$ for partial automation, and $\$ 1,769$ for fully automated alternatives.

In terms of the role of attitudes, those who enjoy driving would be the hardest to persuade toward $\mathrm{AV}$ adoption or to pay for automated features. Technology-savvy people showed a higher tendency toward AV adoption. People showed a higher willingness to pay for automated features if they believe that these features provide them better utility, in terms of time and cost saving, convenience, etc. Individuals with trust issues also showed higher WTP, which might indicate that strategies or services that address privacy issues may be worthwhile even at a higher cost for some group of users.

In terms of demographic variables, individuals 55-59 years old, high school graduates, lowincome groups $(<\$ 50 \mathrm{k})$, and those with driver's license were less likely to adopt partial or fully AVs, compared to their counterparts. Full-time students, self-employed individuals, Black Americans, frequent online shoppers and those who already experienced ride-sharing options were willing to pay more for AV technologies.

\section{Ridesourcing vs. Private Vehicle - Mobility Option}

This analysis focuses on what it takes or what will convince travelers to adopt ridesourcing instead of private mobility.

Survey results indicated that a monthly cost increase of $\$ 100$ would persuade $60 \%$ of the drivers to switch to ridesourcing services. The average cost of driving was about $\$ 9,300$ annually, or about $\$ 773$ per month according to AAA ${ }^{1}$. This shows promising potential for ridesourcing options. On the other hand, a 25-minute time saving was needed to achieve the same magnitude of effect, which would be unrealistic considering that the average trip length was about 24 minutes. About $39 \%$ of the drivers indicated that they needed at least 30 minutes of time savings for regular trips

\footnotetext{
${ }^{1}$ AAA 2019 Your Driving Costs Study. https:// exchange.aaa.com/automotive/driving-

costs/\#.XsQZIGhKiHs. Average cost per mile calculated based on annual mileage of 15,000.
} 
to switch to on-demand service as a mobility option. To some degree, this might indicate that cost plays a stronger role in mobility decisions than time savings, or people mostly view cost saving as the main advantage of ridesourcing compared to driving private vehicles.

For transit users, the time and cost saving required to switch to ridesourcing were much lower compared to drivers, at about $\$ 50$ per month and 15 minutes per trip to persuade $60 \%$ of the users. According to APTA 2017 data $^{2}$, the average passenger fare per unlinked trip was \$1.52, with average trip length of 5.6 miles, among all modes. This leads to the calculation of an average fare of $\$ 0.27$ per passenger mile.

Model results showed that young people (25 years old or younger), low-income individuals, and people with previous ridesourcing experience tend to expect less in view of both travel time and travel cost saving and, therefore, will be persuaded more easily to use ridesourcing compared to other groups. On the contrary, middle-aged people, highly car-dependent individuals, and selfemployed were likely to demand higher savings from ridesourcing options.

In view of latent attitudinal factors, it is evident that trust issues and private ownership advantages (such as comfort, convenience, and reliability) act as barriers against regular ridesourcing usage, therefore required higher cost saving to convince them to switch to ridesourcing. On the other hand, those concerned with both financial (including capital and maintenance costs) and non-financial (such as parking issues) issues of private ownership required less time-saving for them to choose ridesourcing. As expected, those with higher levels of reasoning factor (as opposed to habitual actions) are more likely to switch to ridesourcing with less cost saving. Interestingly, even those who favor multitasking still expect to see some amount of time-saving compared to the conventional modes.

\section{Ridesourcing vs. Private Vehicle - Mode choice}

This analysis focuses on daily mode choice between private vehicles and ridesourcing (including exclusive rides and shared rides) for a regular trip.

In general, the models showed positive influences of high income and full employment toward exclusive rides, mid-income toward shared rides, and a negative association between lower education and retirees and ridesourcing options. It also showed that social and school trips had a higher propensity of using exclusive ride services than other trips. In terms of age, seems that college students or young graduates (age between 18-24) or those aged between 50 and 54 were more likely to take shared rides, people between 30-34 were more likely to use on-demand services (both exclusive and shared) compared to other age groups.

Habit associated with private vehicles, either as a driver or passenger, had strong negative impacts on the probability of using ridesourcing services, either as an exclusive ride or shared

2 APTA 2018 Public Transportation Fact Book. https://www.apta.com/wpcontent/uploads/Resources/resources/statistics/Documents/FactBook/2018-APTA-Fact-Book.pdf 
ride. It indicates that if a person frequently drives for regular trips, the probability of shifting to alternative options significantly decreases, despite the desirable level of service of the alternative modes. The habitual linkage with public transit was not significant. This may indicate that transit users are more willing to use ridesourcing services. On the other hand, the habitual linkage with ridesourcing showed strong positive impacts on the probability of choosing ridesourcing. Interestingly, this effect only affects the choice for an exclusive ride. It does not present significant impacts on the choice of a shared ride. This may imply the barrier in arranging shared rides for regular daily purposes. High parking costs and time also showed a positive influence on the usage of ridesourcing alternatives.

\section{Ridesourcing vs. Transit - Mode choice}

This analysis focuses on daily mode choice between transit and ridesourcing (including exclusive rides and shared rides) in two different contexts: daily travel for regular transit users, and occasional trip (such as visiting a new place, to or from airports, etc.) for regular auto users. Regular auto users are those who use a private vehicle on a regular basis, transit users are those who use transit for a regular or most frequent trip.

For regular transit users, females showed a positive tendency to use ridesourcing services and were more inclined to use exclusive rides, compared with transit. Full-time employees were more likely to use exclusive rides. This positive correlation may indicate the impact of work-schedule restrictions associated with full-time employees and that they may prefer exclusive services for lower travel times and probably higher reliability. Students and lower education groups (high school of less) showed a strong inclination to use shared rides compared to transit. As expected, low-income groups (less than $\$ 50 \mathrm{k}$ annually) were more likely to use transit than ridesourcing. Very high-income groups ( $\$ 200 \mathrm{~K}$ or above) were less likely to use shared services. Those in between, generally showed a higher tendency to use exclusive rides compared with transit as income levels increased.

In view of attitudes, technology savviness, on-demand service and travel time advantage are positive factors toward the choice of ridesourcing (both exclusive and shared forms) instead of transit. Interestingly, those who desire the utility of private vehicles or prefer alternative modes are more likely to stay with transit. Positive associations were observed between the tendency to use shared rides and the interest in full automation and technology and efficiency. Individuals who seek efficiency and technology were interested in using shared ride services, presumably because shared travel modes are cost-efficient. Moreover, those who cared about mobility for non-drivers were inclined to use exclusive services. This may indicate the preference for those who are not able to drive themselves but prefer a private and exclusive travel experience.

For auto users, students showed a positive tendency to use on-demand services, both exclusive and shared ride service. Probably because students are usually more open and eager to experience new technologies. Income showed mixed results. In general, low-income individuals were less likely to use exclusive rides, and high-income individuals are less likely to use shared rides. 
In view of attitudes, tech-savvy individuals, choice reasoning users, and those desire on-demand services would choose ridesourcing over transit services. Interestingly, those who enjoy driving or have issues with traveling with strangers preferred transit over ridesourcing options. On the other hand, those who desire stress relief or enjoy the utility of private vehicles would be more likely to use exclusive rides than transit.

Table 25 and 26 presents the influential factors to individual's choice behavior in light of emerging mobility options. "+" represents positive influence, and “_" represents negative association.

Table 25 Summary of Influential Attitudes to Emerging Mobility Options

\begin{tabular}{|c|c|c|c|c|c|}
\hline \multirow[t]{2}{*}{ Attitude Factors } & \multirow{2}{*}{$\begin{array}{c}\text { AV } \\
\text { Adoption \& } \\
\text { WTP }\end{array}$} & \multirow{2}{*}{$\begin{array}{l}\text { Shared } \\
\text { Mobility }\end{array}$} & \multicolumn{3}{|c|}{ Mode Choice } \\
\hline & & & $\begin{array}{l}\text { Drive/ } \\
\text { Transit }\end{array}$ & $\begin{array}{l}\text { Exclusive } \\
\text { Ride }\end{array}$ & $\begin{array}{l}\text { Shared } \\
\text { Ride }\end{array}$ \\
\hline Tech -savvy & + & + & & + & + \\
\hline Utility reasoning & + & + & & + & + \\
\hline Time sensitive & & & & + & \\
\hline On-demand service & + & & & + & + \\
\hline Mobility for non-drivers & + & & & + & \\
\hline $\begin{array}{l}\text { Driving assistance, safety, } \\
\text { automation }\end{array}$ & + & & & + & + \\
\hline Trust with strangers & $-/+$ & - & & - & - \\
\hline Data privacy & - & & & & \\
\hline $\begin{array}{l}\text { Private vehicle utility (joy of driving, } \\
\text { convenience, etc.) }\end{array}$ & - & - & + & + & - \\
\hline $\begin{array}{l}\text { Ownership concerns (cost, parking, } \\
\text { etc.) }\end{array}$ & & + & & & + \\
\hline Better technology & & & & & + \\
\hline
\end{tabular}

Table 26 Summary of Influential Variables to Emerging Mobility Options

\begin{tabular}{|c|c|c|c|c|c|}
\hline \multirow[t]{2}{*}{ Personal Variables } & \multirow{2}{*}{$\begin{array}{c}\text { AV } \\
\text { Adoption \& } \\
\text { WTP }\end{array}$} & \multirow{2}{*}{$\begin{array}{l}\text { Shared } \\
\text { mobility }\end{array}$} & \multicolumn{3}{|c|}{ Mode Choice } \\
\hline & & & $\begin{array}{c}\text { Drive/ } \\
\text { Transit }\end{array}$ & $\begin{array}{c}\text { Exclusive } \\
\text { Ride }\end{array}$ & $\begin{array}{c}\text { Shared } \\
\text { Ride }\end{array}$ \\
\hline Higher education (BS or above) & + & + & - & + & + \\
\hline Unemployed, or retired & - & + & + & - & - \\
\hline Lower income $(<50 \mathrm{~K})$ & - & + & + & - & $+/-$ \\
\hline Mid-income & - & & & + & + \\
\hline High income & & - & & & - \\
\hline White & - & - & + & & \\
\hline Age: $<30$ & + & + & & & + \\
\hline Age:30-54 & & + & & + & + \\
\hline Age:55+ & - & - & & & \\
\hline Male & & - & + & & \\
\hline Short trip (<5 mile) & - & & & & \\
\hline Medium trip (15-30 miles) & + & & & & \\
\hline High parking cost or time & + & + & - & + & + \\
\hline Social and school trip & & & & + & \\
\hline
\end{tabular}




\section{RECOMMENDATION}

In this chapter, we present our recommendations on how to incorporate ACES considerations in the modeling framework. Previous effort has focused on ACES analysis in the four-step modeling framework (FDOT, 2018), six different scenarios were tested, and the results on VMT and VHT were discussed. This study mainly focusses on considerations that can be implemented in an activity-based modeling framework.

\section{The Framework}

As discussed previously in the literature, the potential impacts of ACES technologies may be viewed from three main levels: (1) long-term impacts on location choices, urban development and land use; (2) mid-term lifestyle choices, such as mobility, auto ownership, etc.; and (3) shortterm daily travel choices, such as activity participation and trip generation. Therefore, ACES considerations should be incorporated into the analysis framework at all three levels. Figure 32 below illustrates the aspects of the modeling and analysis framework that need to be addressed for ACES considerations.

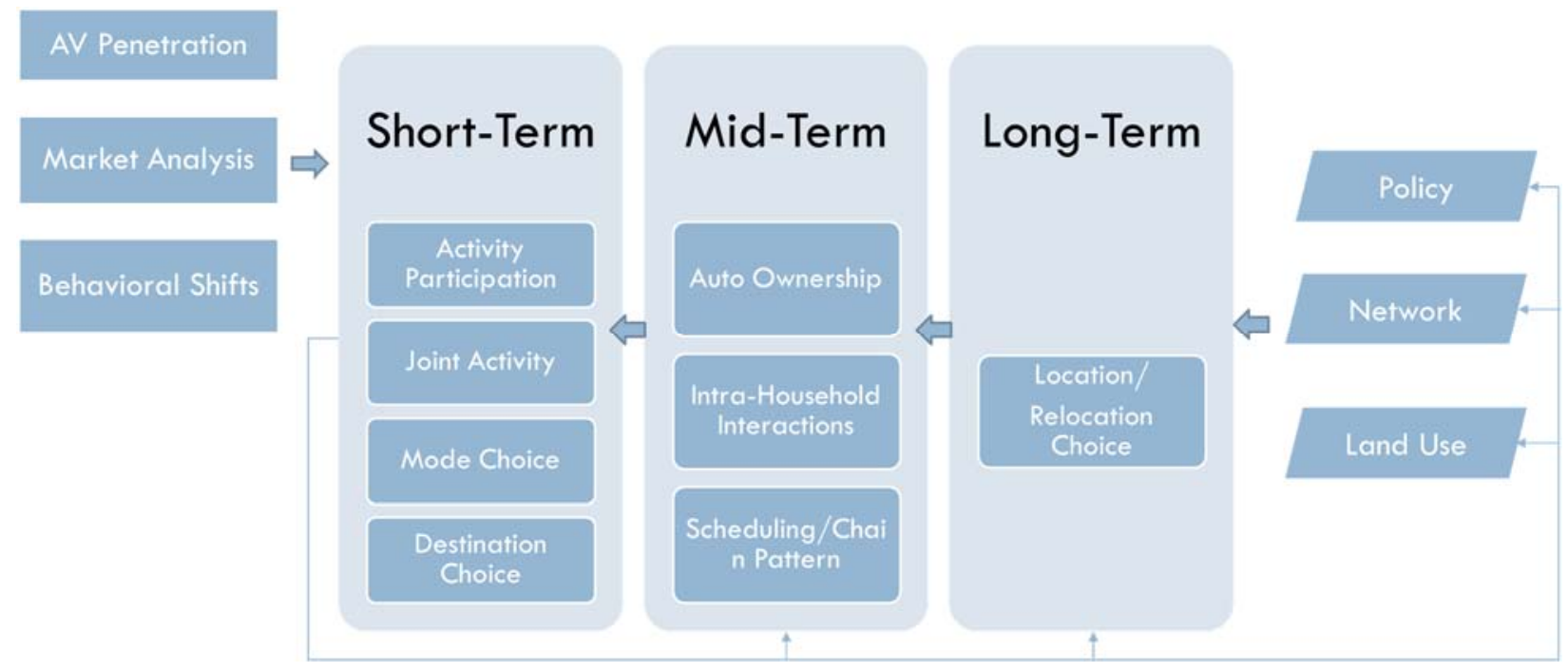

\section{Figure 32 Potential impacts of ACES technologies.}

Figure 32 illustrates the interconnections between the model components and highlights the iterative and continuous efforts in the modeling and planning process. The insights derived from the earlier analysis in this study will support market analysis for ACES technologies, which helps estimate the most immediate short-term changes in mode choice and activity arrangement, etc. The consequent impacts on the network (such as travel time, speed, delay, etc.) may lead to changes in the mid-term and long term, which in turn influence the short-term travel patterns. The network outcomes will also inform decisions and actions in policy development, transportation network investment, and land development, which again serve as the inputs for the long-, mid-, and short-term modeling analysis. 
Given the unknowns and uncertainties associated with technology development, user adoption, and policy formation, scenario analysis becomes a popular tool to help understand and assess the potential impacts of ACES. It allows one to explore a wide range of possibilities and evaluate the outcomes of different scenarios or combinations of different scenarios. To incorporate ACES into scenario analysis, there are a few major considerations:

- Identify the model components and choice elements that are directly affected by ACES technologies, such as auto ownership, mode choice, trip generation, etc., or indirectly affected due to changes in upstream models, such as destination model, accessibility, etc.

- Determine the market segments that are likely to behave differently in response to ACES. Age and household income are common segmentation variables. Others may include education, gender, and urban type, etc., depending on the specifications of the models.

- Develop assumptions and identify parameter ranges to be tested. It can reflect different levels of penetration, or various degrees of behavioral changes. Model test runs may be necessary to find the appropriate parameter changes through trial-and-error.

- Consider individual scenarios focusing on certain policies with different assumptions, such as transit enhancements, parking policies, and land development scenarios, etc.

Figure 33 presents a detailed flowchart that illustrates the model components that needs to be reconsidered and their connections with other components in the overall modeling framework.

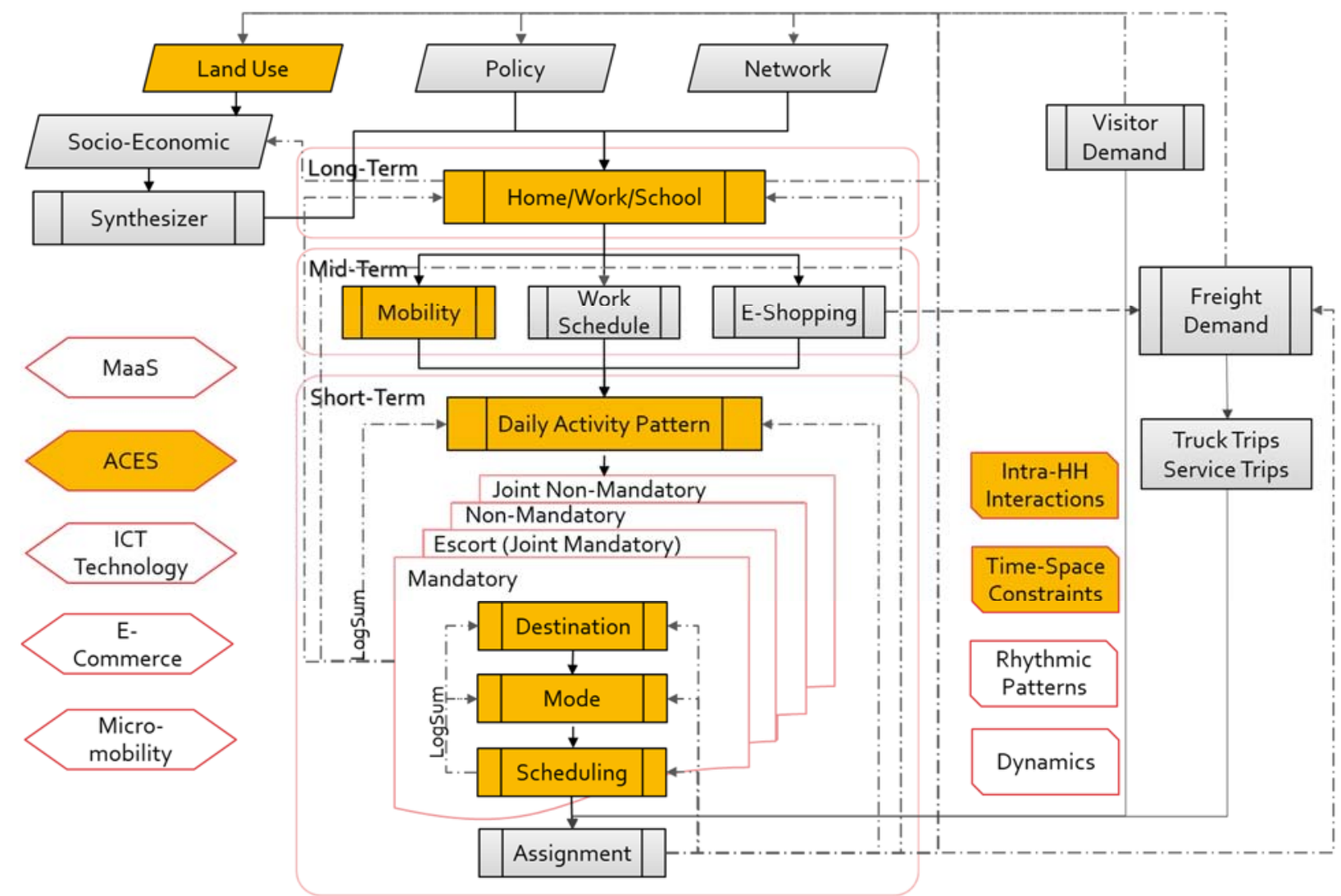

Figure 33 Modeling analysis focus areas. 


\section{Behavioral Changes in Scenario Development}

In order to develop plausible assumptions on behavioral changes to address ACES considerations, we first provide a brief overview of how ACES may change travel behavior with respect to the three main levels. Regarding the potential long-term impacts on land use and urban development patterns, the main expectation is that while AVs contribute to relaxed or more productive driving, less congested network, and shorter travel times, they reduce the disutility of travel time and distance, and the overall travel costs. Consequently, the urban/regional development patterns are likely to change. On the one hand, a reduction in transportation costs would increase the willingness of households, and possibly some firms, to locate farther away from the urban core, which would lead to a much more dispersed and scattered urban growth pattern (Anderson et al., 2014; Kim et al., 2015). On the other hand, AV technologies could lead to greater density in core urban areas due to significant reductions in demand for parking spaces (Anderson et al., 2014).

The mid-term impacts of ACES mainly focus on vehicle ownership and mobility options. As we expect more efficient use of cars and vehicle sharing, vehicle ownership is expected to drop. Regarding the future of mass transit in light of the emergence of AVs, some argued that transit ridership would decrease since ACES would take the edge off public transportation with respect to the stress of driving, multitasking, and service for disabled and other transit-captive population. On the other hand, ACES might bring new opportunities for transit, such as autonomous feeder bus services, demand-responsive and flexible routes, or even Uber-like shared ride services (Malokin et al., 2015).

Besides reducing overall transportation costs, ACES would enhance mobility and lead to an increase in travel demand, especially for those currently unable or not permitted to use conventional vehicles, such as the disabled, older citizens, and adolescents under the driving age. In addition to increased or induced travel demand, ACES have the potential to free people from escorting trips, and certain types of maintenance trips such as grocery shopping (Anderson et al., 2014; Pendyala and Bhat, 2014). This may also reduce the interactions among household members, which has been considered an important factor influencing an individual's travel choices. From this perspective, the modeling community may need to revisit the theory of daily activity-travel pattern and scheduling, which is largely built on the temporal and spatial constraints of mandatory trips, and the interactions among household members.

In addition to the above impacts brought by ACES technologies, there are also behavioral shifts that influence travel choices. It was observed that Millennials have the tendencies of owning fewer cars, driving less, and using non-motorized modes more often than the older generations (Blumenberg et al., 2012; Kuhnimhof et al., 2012). These unique travel behavioral traits may be attributed to this generation's lifestyle preferences in delayed marriage and childbearing age, urban residences, and adoption of new technologies (McDonald, 2015). The younger generations

were also more environmentally conscious and prefer living in an urban setting with extensive 
transit options (NCHRP, 2014). Census data showed that Millennials represent a significant share of new city residents (NCHRP, 2014). Overall these traits can lead to increased use of shared mobility and non-motorize modes. Although it is still unclear how much of these behaviors will remain once most of the millennials get married and have children (Circella et al., 2016), it is expected that the younger generations (Millennials and Generation Z) will have different preferences and attitudes toward new technologies and mobility options.

Given the above discussions, Table 27 presents potential changes that can be considered to address ACES considerations and behavioral shifts in modeling analysis.

Table 27 Potential Model Changes for ACES Considerations

\begin{tabular}{|c|c|c|c|}
\hline $\begin{array}{l}\text { Impact } \\
\text { Level }\end{array}$ & $\begin{array}{l}\text { Model } \\
\text { Component }\end{array}$ & $\begin{array}{l}\text { Choice } \\
\text { Element }\end{array}$ & Parameter Change \\
\hline Land Use & $\begin{array}{l}\text { Population } \\
\text { Synthesizer }\end{array}$ & Relocation & $\begin{array}{l}\text { - Shift millennial and younger generations to urban areas } \\
\text { - Older generations away from urban centers }\end{array}$ \\
\hline Mobility & $\begin{array}{l}\text { Auto } \\
\text { Ownership }\end{array}$ & $\begin{array}{l}\text { Vehicle } \\
\text { Adoption }\end{array}$ & $\begin{array}{l}\text { - Reduce autos for younger households } \\
\text { - Replace portions of fleets with AVs at different market } \\
\text { penetration levels } \\
\text { - Shared AV program or on-demand service subscription }\end{array}$ \\
\hline \multirow[t]{3}{*}{ Daily } & $\begin{array}{l}\text { Daily Activity } \\
\text { Pattern }\end{array}$ & $\begin{array}{l}\text { Tour } \\
\text { generation }\end{array}$ & $\begin{array}{l}\text { - Enable travel for children ( } 11+\text { years old) } \\
\text { - Remove constraints on household vehicle sufficiency and } \\
\text { driver status } \\
\text { - Relax constraints for adults with chauffeuring duties }\end{array}$ \\
\hline & Tour/Trip & Mode choice & $\begin{array}{l}\text { - Increase younger generations preference for non-auto } \\
\text { modes } \\
\text { - TNC - create new mode if not already there, with higher } \\
\text { operation cost (than driving), zero parking cost, and wait } \\
\text { time in nonurban areas } \\
\text { - Transit - add auto egress linkages, with higher operation } \\
\text { cost, zero parking cost, and wait time in nonurban areas } \\
\text { - AV - reduce parking cost, reduce in-vehicle-time coefficient }\end{array}$ \\
\hline & Assignment & Route & $\begin{array}{l}\text { - New classes for assignment (maybe) } \\
\text { - Dedicated facilities/routes (maybe) }\end{array}$ \\
\hline \multirow[t]{2}{*}{ Supply } & Network & & $\begin{array}{l}\text { - Capacity increase by facility type } \\
\text { - Transit auto egress links }\end{array}$ \\
\hline & Parking & & $\begin{array}{l}\text { - Reduce parking cost } \\
\text { - Reduce terminal times }\end{array}$ \\
\hline
\end{tabular}




\section{CONCLUSION}

This study investigated potential travel behavior changes in light of automated, connected, electric, and shared-use vehicle (ACES) technologies. Particularly, this study focuses on exploring the roles of attitudes in individuals' travel choice behavior. Data collected through a stated preference (SP) survey were used for this study. The survey targeted 10 metropolitan areas in the nation and the state of Florida. The survey included a series of attitude-related questions that cover various aspects of user attitudes, which include general mobility preferences, perceived benefits and concerns of shared mobility, reasons against or for private ownership, and motivations for and desired features of AVs.

Three main aspects of choice behavior were investigated: AV adoption and willingness to pay (WTP), shared mobility adoption, and mode choice. Various modeling techniques were employed to identify influential factors and examine the impacts of attitudes, including error component models, structural equations model, and support vector machine method. The models identified various attitudes that played significant roles in individuals' choice behavior. These include joy of driving, technology-savviness, choice reasoning, trust issues, data privacy concerns, favor for private-vehicle utility, on-demand services, green travel preferences, and desire for efficiency and technology, etc. Model results showed that attitudes played important roles in shaping travelers' choice behavior. Incorporating these factors improved the model performance and prediction accuracy of travel behavior models, which will lead to a more reliable assessment of the likelihood and magnitude of behavioral shifts toward future mobility options.

This study provides useful and meaningful insights into users' attitudes and perceptions toward ACES technologies, and how these attitudes and other contributing factors may influence travelers' choice behavior. Recognizing that the market will not react homogeneously toward new technologies, the study results contribute to a better understanding of user acceptance and adoption of emerging mobility options and better assessment of their potential impacts. The findings could be helpful for planners and service providers to better plan for and address the needs and concerns of travelers. This may also provide important inputs for the development of strategies in promoting alternative mobility options.

Future research can adopt the behavioral insights derived from this study and develop assumptions on model parameter changes to reflect potential behavioral shifts under different scenarios. This scenario analysis will help explore a wide range of possibilities and evaluate the combined effects or outcomes of new technologies and trends. 


\section{REFERENCES}

1 Ajzen, I. (2002). Residual effects of past on later behavior: Habituation and reasoned action perspectives. Personality and social psychology review, 6(2), 107-122.

2 Alemi, F., Circella, G., Mokhtarian, P., \& Handy, S. (2018). On-demand ride services in California: Investigating the factors affecting the frequency of use of Uber/Lyft. Presented at Annual Meeting of the Transportation Research Board, Washington, D.C., 18-05563.

3 Anderson, J. M., Kalra, N., Stanley, K. D., Sorensen, P., Samaras, C., \& Oluwatola, O. (2014). Autonomous vehicle technology: a guide for policymakers. Santa Monica, CA: RAND Corporation. Transportation, Space, and Technology Program.

4 Asgari, H., \& Jin, X. (2019). Incorporating attitudinal factors to examine adoption of and willingness to pay for autonomous vehicles. Transportation Research Record, 2673(8), 418429.

5 Asgari, H., \& Jin, X. (2020). Incorporating habitual behavior into Mode Choice Modeling in light of emerging mobility services. Sustainable Cities and Society, 52, 101735.

6 Azad, M., Hoseinzadeh, N., Brakewood, C., Cherry, C. R., \& Han, L. D. (2019). Fully Autonomous Buses: A Literature Review and Future Research Directions. Journal of Advanced Transportation, 2019, 1-16.

7 Azimi, G., Rahimi, A., Asgari, H., \& Jin, X. (2020a). Investigating the Impacts of ModeDependency on Ride-Hailing Decisions. Presented at 20th COTA International Conference of Transportation Professionals, Xi'an, China.

8 Azimi, G., Rahimi, A., Asgari, H., \& Jin, X. (2020b). The Role of Attitudes in Transit and Auto Users' Mode Choice of Ridesourcing. Transportation Research Record. In Press

9 Bansal, P., \& Kockelman, K. M. (2017). Forecasting Americans' long-term adoption of connected and autonomous vehicle technologies. Transportation Research Part A: Policy and Practice, 95, 49-63.

10 Bansal, P., Kockelman, K. M., \& Singh, A. (2016). Assessing public opinions of and interest in new vehicle technologies: An Austin perspective. Transportation Research Part C: Emerging Technologies, 67, 1-14.

11 Blumenberg, E., Taylor, B. D, Smart, M., Ralph, K., Wander, M., \& Brumbagh, S. (2012). What's Youth Got to Do with It? Exploring the Travel Behavior of Teens and Young Adults. UC Berkeley: University of California Transportation Center.

12 Bollen, K. A. (1989). Structural equations with latent variables. New York: Wiley.

13 Chang, H. L., \& Wu, S. C. (2008). Exploring the vehicle dependence behind mode choice: Evidence of motorcycle dependence in Taipei. Transportation research part A: policy and practice, 42(2), 307-320.

14 Charness, N., Yoon, J. S., Souders, D., Stothart, C., \& Yehnert, C. (2018). Predictors of attitudes toward autonomous vehicles: the roles of age, gender, prior knowledge, and personality. Frontiers in psychology, 9, 2589. 
15 Childress, S., Nichols, B., Charlton, B., \& Coe, S. (2015). Using an activity-based model to explore the potential impacts of automated vehicles. Transportation Research Record, 2493(1), 99-106.

16 Circella, G., Tiedeman, K., Handy, S., Alemi, F., \& Mokhtarian, P. (2016). What Affects U.S. Passenger Travel? Current Trends and Future Perspectives. UC Davis: National Center for Sustainable Transportation.

17 Clewlow, R., \& Mishra, G. S. (2017). Shared mobility: Current adoption, use, and potential impacts on travel behavior. Presented at Annual Meeting of the Transportation Research Board, Washington, D.C., 17-05729

18 Cohn, J., Ezike, R., Martin, J., Donkor, K., Ridgway, M., \& Balding, M. (2019). Examining the equity impacts of autonomous vehicles: a travel demand model approach. Transportation research record, 2673(5), 23-35.

19 Daziano, R. A., Sarrias, M., \& Leard, B. (2017). Are consumers willing to pay to let cars drive for them? Analyzing response to autonomous vehicles. Transportation Research Part C: Emerging Technologies, 78, 150-164.

20 Dias, F. F., Lavieri, P. S., Garikapati, V. M., Astroza, S., Pendyala, R. M., \& Bhat, C. R. (2017). A behavioral choice model of the use of car-sharing and ridesourcing services. Transportation, 44(6), 1307-1323.

21 Finney, S. J., \& DiStefano, C. (2006). Non-normal and categorical data in structural equation modeling. Structural equation modeling: A second course. Charlotte: Information Age Publishing, 10(6), 269-314.

22 Florida Department of Transportation (FDOT), Office of Policy Planning. (2018). Guidance for Assessing Planning Impacts and Opportunities of Automated, Connected, Electric and Shared-Use Vehicles. Florida Department of Transportation.

23 Fujii S, Gärling T \& Kitamura R (2001) Breaking habitual defecting by a temporary structural change. Paper presented at the Ninth International Conference on Social Dilemmas, June 29July 3, Chicago, IL, USA.

24 Fujii, S., \& Gärling, T. (2005). Temporary structural change: A strategy to break car-use habit and promote public transport. In International Conference of Traffic and Transport Psychology, 585-592.

25 Fujii, S., \& Kitamura, R. (2003). What does a one-month free bus ticket do to habitual drivers? An experimental analysis of habit and attitude change. Transportation, 30(1), 81-95.

26 Habib, K. M. N., \& Zaman, M. H. (2012). Effects of incorporating latent and attitudinal information in mode choice models. Transportation Planning and Technology, 35(5), 561576.

27 Haboucha, C. J., Ishaq, R., \& Shiftan, Y. (2017). User preferences regarding autonomous vehicles. Transportation Research Part C: Emerging Technologies, 78, 37-49.

28 Hagenauer, J., \& Helbich, M. (2017). A comparative study of machine learning classifiers for modeling travel mode choice. Expert Systems with Applications, 78, 273-282.

29 Hensher, D. A., Rose, J. M., \& Greene, W. H. (2005). Applied choice analysis: a primer. London: Cambridge University Press. 
30 Howard, D., \& Dai, D. (2014). Public Perceptions of Self-Driving Cars: The Case of Berkeley, California. Presented at Annual Meeting of the Transportation Research Board, Washington, D.C., 14-4502.

31 Jin, X. \& Asgari, H. (2020). Propensity Toward Ridesourcing: Expected Travel Time and Cost saving to Switch from Private Mobility. Transportation Research Part C. In Press.

32 John Lu, Z. Q. (2010). The Elements of Statistical Learning: Data Mining, Inference, and Prediction. Journal of the Royal Statistical Society: Series A (Statistics in Society), 173(3), 693694.

33 Johnstone, I. M., \& Lu, A. Y. (2009). On consistency and sparsity for principal components analysis in high dimensions. Journal of the American Statistical Association, 104(486), 682693.

34 Kim, K. H., Yook, D. H., Ko, Y. S., \& Kim, D. H. (2015). An analysis of expected effects of the autonomous vehicles on transport and land use in Korea. New York: Marron Institute of Urban Management.

35 Kong, X., Hu, C., \& Duan, Z. (2017). Generalized Principal Component Analysis. In Principal Component Analysis Networks and Algorithms. Singapore: Springer, 185-233.

36 Kuhnimhof, T., Armoogum, J., Buehler, R., Dargay, J., Denstadli, J.M., \& Yamamoto, T. (2012). Men shape a downward trend in car use among young adults-evidence from six industrialized countries. Transport Reviews 32 (6), 761-79.

37 Kuppam, A. R., Pendyala, R. M., \& Rahman, S. (1999). Analysis of the Role of Traveler Attitudes and Perceptions in Explaining Mode-Choice Behavior. Transportation Research Record: Journal of the Transportation Research Board, 1676(1), 68-76.

38 Mahdinia, I., \& Habibian, M. (2017). Evaluating the transportation system performance based on efficiency, effectiveness and efficacy: a case study of the U.S. states. Presented at Annual Meeting of the Transportation Research Board, Washington, D.C., 17-06578.

39 Malokin, A., Circella, G., \& Mokhtarian, P. L. (2015). How do activities conducted while commuting influence mode choice? Testing public transportation advantage and autonomous vehicle scenarios. Presented at Annual Meeting of the Transportation Research Board, Washington, D.C., 15-1179.

40 Malokin, A., Circella, G., \& Mokhtarian, P. L. (2019). How do activities conducted while commuting influence mode choice? Using revealed preference models to inform public transportation advantage and autonomous vehicle scenarios. Transportation Research Part A: Policy and Practice, 124, 82-114.

41 McDonald, N. C. (2015). Are millennials really the "go-nowhere" generation?. Journal of the American Planning Association, 81(2), 90-103.

42 McFadden, D., \& Zarembka, P. (1974). Frontiers in econometrics. Conditional logit analysis of qualitative choice behavior. New York: Academic Press, 105-142.

43 Nadafianshahamabadi, R., Corning Padilla, A., Tayarani, M., \& Rowangould, G. (2019). Integrated Travel Demand and Land Use Modeling for Evaluating the Congestion and Land Use Effects of Autonomous Vehicles (AVs). Presented at Annual Meeting of the Transportation Research Board, Washington, D.C., 19-02103. 
44 National Cooperative Highway Research Program (NCHRP) (2014). Strategic issues facing transportation, volume 6: The effects of socio-demographics on future travel demand. Transportation Research Board, Washington, DC.

45 Nazari, F., Noruzoliaee, M., \& Mohammadian, A. (2018). Shared Mobility Versus Private Car Ownership: a Multivariate Analysis of Public Interest in Autonomous Vehicles. Presented at Annual Meeting of the Transportation Research Board, Washington, D.C. 18-04289.

46 Nazari, F., Noruzoliaee, M., \& Mohammadian, A. K. (2019a). Adoption of Autonomous Vehicles with Endogenous Safety Concerns: A Recursive Bivariate Ordered Probit Model. Presented at Annual Meeting of the Transportation Research Board, Washington, D.C., 1902998.

47 Nazari, F., Rahimi, E., \& Mohammadian, A. K. (2019b). Simultaneous estimation of battery electric vehicle adoption with endogenous willingness to pay. eTransportation, 1, 100008.

48 Omrani, H. (2015). Predicting travel mode of individuals by machine learning. Transportation Research Procedia, 10, 840-849.

49 Payre, W., Cestac, J., \& Delhomme, P. (2014). Intention to use a fully automated car: Attitudes and a priori acceptability. Transportation Research Part F: Traffic Psychology and Behaviour, 27, 252-263.

50 Pendyala, R. M., \& Bhat, C. R. (2014). Activity-travel behavior impacts of driverless cars. Presented at Annual Meeting of the Transportation Research Board, Washington, D.C., 130552.

51 Perrine, K. A., Kockelman, K. M., \& Huang, Y. (2020). Anticipating long-distance travel shifts due to self-driving vehicles. Journal of Transport Geography, 82, 102547.

52 Rahimi, A., Azimi, G., \& Jin, X. (2020a). Examining human attitudes toward shared mobility options and autonomous vehicles. Transportation Research Part F: Traffic Psychology and Behaviour, 72, 133-154.

53 Rahimi, A., Azimi, G., Asgari, H., Jin, X. (2020b). Potential implications of automated vehicle technologies on travel behavior-A literature review. Journal of Transportation Engineering. In Press.

54 Rahimi, E., Shamshiripour, A., Shabanpour, R., Mohammadian, A., \& Auld, J. (2020c). Analysis of Transit Users' Response Behavior in Case of Unplanned Service Disruptions. Transportation Research Record, 2674(3), 258-271.

55 Rahman, M. S., Abdel-Aty, M., Lee, J., \& Rahman, M. H. (2019). Safety benefits of arterials' crash risk under connected and automated vehicles. Transportation Research Part C: Emerging Technologies, 100, 354-371.

56 Rahmati, Y., \& Talebpour, A. (2017). Toward a collaborative connected, automated driving environment: A game theory based decision framework for unprotected left turn maneuvers. In 2017 IEEE Intelligent Vehicles Symposium (IV), Redondo Beach, CA, 1316-1321.

57 Rayle, L., Dai, D., Chan, N., Cervero, R., \& Shaheen, S. (2016). Just a better taxi? A surveybased comparison of taxis, transit, and ride-hailing services in San Francisco. Transport Policy, 45, 168-178. 
58 Sanbonmatsu, D. M., Strayer, D. L., Yu, Z., Biondi, F., \& Cooper, J. M. (2018). Cognitive underpinnings of beliefs and confidence in beliefs about fully automated vehicles. Transportation research part F: traffic psychology and behaviour, 55, 114-122.

59 Schoettle, B., \& Sivak, M. (2014). A survey of public opinion about autonomous and selfdriving vehicles in the US, the UK, and Australia. University of Michigan, Ann Arbor: Transportation Research Institute.

60 Sekhar, C. R., \& Madhu, E. (2016). Mode choice analysis using random forest decision trees. Transportation Research Procedia, 17, 644-652.

61 Shabanpour, R., Golshani, N., Shamshiripour, A., \& Mohammadian, A. K. (2018a). Eliciting preferences for adoption of fully automated vehicles using best-worst analysis. Transportation research part C: emerging technologies, 93, 463-478.

62 Shabanpour, R., Mousavi, S. N. D., Golshani, N., Auld, J., \& Mohammadian, A. (2017). Consumer preferences of electric and automated vehicles. In 2017 5th IEEE International Conference on Models and Technologies for Intelligent Transportation Systems (MT-ITS), Napoli, Italy, 716-720.

63 Shabanpour, R., Shamshiripour, A., \& Mohammadian, A. (2018b). Modeling adoption timing of autonomous vehicles: innovation diffusion approach. Transportation, 45(6), 1607-1621.

64 Shamshiripour, A., Golshani, N., Shabanpour, R., \& Mohammadian, A. (2019). Week-long mode choice behavior: dynamic random effects logit model. Transportation research record, 2673(10), 736-744.

65 Sharda, S., Astroza, S., Khoeini, S., Batur, I., Pendyala, R. M., \& Bhat, C. R. (2019). Do Attitudes Affect Behavioral Choices or Vice-Versa: Uncovering Latent Segments Within a Population. Presented at Annual Meeting of the Transportation Research Board, Washington, D.C., 19-03183.

66 Sikder, S. (2019). Who Uses Ride-Hailing Services in the United States?. Transportation Research Record, 2673(12), 40-54.

67 Skrondal, A., \& Rabe-Hesketh, S. (2014). Structural equation modeling: categorical variables. Hoboken: Wiley Statistics Reference Online.

68 Sohn, K., \& Yun, J. (2009). Separation of car-dependent commuters from normal-choice riders in mode-choice analysis. Transportation, 36(4), 423-436.

69 Spurlock, C. A., Sears, J., Wong-Parodi, G., Walker, V., Jin, L., Taylor, M., Duvall A., Gopal, A., \& Todd, A. (2019). Describing the users: Understanding adoption of and interest in shared, electrified, and automated transportation in the San Francisco Bay Area. Transportation Research Part D: Transport and Environment, 71, 283-301.

70 Talebian, A., \& Mishra, S. (2018). Predicting the adoption of connected autonomous vehicles: A new approach based on the theory of diffusion of innovations. Transportation Research Part C: Emerging Technologies, 95, 363-380.

71 Tang, L., Xiong, C., \& Zhang, L. (2015). Decision tree method for modeling travel mode switching in a dynamic behavioral process. Transportation Planning and Technology, 38(8), 833-850. 
72 Thøgersen, J., \& Møller, B. (2008). Breaking car use habits: The effectiveness of a free onemonth travelcard. Transportation, 35(3), 329-345.

73 von Behren, S., Minster, C., Magdolen, M., Chlond, B., Hunecke, M., \& Vortisch, P. (2018). Bringing travel behavior and attitudes together: An integrated survey approach for clustering urban mobility types. Presented at Annual Meeting of the Transportation Research Board, Washington, D.C., 18-04546.

74 Xu, X., Mahmassani, H. S., \& Chen, Y. (2019). Impact of Autonomous Vehicles on Household Activity and Travel Scheduling: An Integrated Dynamic Network Modeling Approach. Presented at Annual Meeting of the Transportation Research Board, Washington, D.C., 1905653.

75 Yap, M. D., Correia, G., \& van Arem, B. (2016). Preferences of travellers for using automated vehicles as last mile public transport of multimodal train trips. Transportation Research Part A: Policy and Practice, 94, 1-16.

76 Ye, R., \& Titheridge, H. (2017). Satisfaction with the commute: The role of travel mode choice, built environment and attitudes. Transportation Research Part D: Transport and Environment, 52, 535-547.

77 Yen, J. R., Mahmassani, H. S., \& Herman, R. (1994). Employer attitudes and stated preferences toward telecommuting: An exploratory analysis. Transportation Research Record, 1463, 15.

78 Zmud, J., Sener, I. N., \& Wagner, J. (2016). Consumer acceptance and travel behavior: impacts of automated vehicles. College Station, TX: Texas A\&M Transportation Institute. 